\title{
Investigation of Corrosion Behavior of Wrought Stellite Alloys
}

\author{
by \\ Xiaozhou Zhang
}

A thesis submitted to the Faculty of Graduate and Postdoctoral Affairs in partial fulfillment of the requirements for the degree of

Master of Applied Science

in

Mechanical Engineering

Carleton University

Ottawa, Ontario

C2012, Xiaozhou Zhang 
Library and Archives

Canada

Published Heritage

Branch

395 Wellington Street

Ottawa ON K1A ON4

Canada
Bibliothèque et

Archives Canada

Direction du

Patrimoine de l'édition

395 , rue Wellington

Ottawa ON K1A ON4

Canada
Your file Votre référence

ISBN: 978-0-494-94284-0

Our file Notre référence

ISBN: $978-0-494-94284-0$
NOTICE:

The author has granted a nonexclusive license allowing Library and Archives Canada to reproduce, publish, archive, preserve, conserve, communicate to the public by telecommunication or on the Internet, loan, distrbute and sell theses worldwide, for commercial or noncommercial purposes, in microform, paper, electronic and/or any other formats.

The author retains copyright ownership and moral rights in this thesis. Neither the thesis nor substantial extracts from it may be printed or otherwise reproduced without the author's permission.
AVIS:

L'auteur a accordé une licence non exclusive permettant à la Bibliothèque et Archives Canada de reproduire, publier, archiver, sauvegarder, conserver, transmettre au public par télécommunication ou par l'Internet, prêter, distribuer et vendre des thèses partout dans le monde, à des fins commerciales ou autres, sur support microforme, papier, électronique et/ou autres formats.

L'auteur conserve la propriété du droit d'auteur et des droits moraux qui protege cette thèse. $\mathrm{Ni}$ la thèse ni des extraits substantiels de celle-ci ne doivent être imprimés ou autrement reproduits sans son autorisation.
In compliance with the Canadian Privacy Act some supporting forms may have been removed from this thesis.

While these forms may be included in the document page count, their removal does not represent any loss of content from the thesis.
Conformément à la loi canadienne sur la protection de la vie privée, quelques formulaires secondaires ont été enlevés de cette thèse.

Bien que ces formulaires aient inclus dans la pagination, il n'y aura aucun contenu manquant. 


\section{Abstract}

The corrosion behavior of two wrought Stellite alloys, Stellite 6B and Stellite 6K, is studied under polarization test and immersion test. Two types of corrosive media, $3.5 \mathrm{wt} \%$ sodium chloride $(\mathrm{NaCl})$ aqueous solution and Green Death solution, are used in the polarization test. Both potentiodynamic polarization and cyclic polarization testes are performed to investigate general and localized corrosion resistance of these alloys. Immersion tests of the two alloys are conducted in Green Death solution to determine Critical Pitting Temperature (CPT), mass loss, thickness change and the Extreme Value (minimum thickness) of the Extreme Value Analysis (EVA) model which derived from the Gumbel Distribution. The minimum thickness for Stellite $6 \mathrm{~B}$ and Stellite $6 \mathrm{~K}$ that is required for an assumed service time is predicted. Maximum pit depths, which are the input of the EVA model, are measured using a surface texture and contour measuring instrument. A Scanning Electron Microscope (SEM) with Energy Dispersive X-ray (EDX) spectrum is utilized to analyze the chemical composition of the corrosion products (pits). The CPTs of Stellite 6B and Stellite $6 \mathrm{~K}$ in Green Death solution are determined to be all $60^{\circ} \mathrm{C}$. The experimental results demonstrate that Stellite $6 \mathrm{~B}$ and Stellite $6 \mathrm{~K}$ have good general and localized corrosion resistance by forming the protective Cr-oxide film. However, the presence of carbides generates potential in the electrochemical reaction, causing corrosion of the alloys in the solution. The larger the carbide volume fraction is, the more the pits are forming in the alloy. Carbide size affects maximum pit depths; the larger the carbide size is, the bigger and deeper the pits are. The EDX analysis results of pits show large amount of oxygen in the carbide phase and small amount of oxygen in the 
solid solution phase. The $\mathrm{Cr}$-rich carbides react with oxygen forming $\mathrm{Cr}$-rich carbonates which are easily brittle, loose and broken, while $\mathrm{Cr}$ in the solid solution reacts with oxygen forming hard protective Cr-oxide films. 


\section{Acknowledgements}

It is with great pleasure to take this opportunity to thank many people who made this thesis possible.

First, I would like to thank my advisor, Professor Rong Liu, for her guidance during my research and study at Carleton University. Her great guidance and patience have inspired me on the independent work.

I would also like to thank my co-supervisor at NRC, Dr. Kuiying Chen, his knowledge have given me critical thinking for the research. In addition, he was always accessible and willing to provide input.

As well, I would like to thank many people at NRC specifically Dr. Qi Yang. I appreciate his assistance and suggestions in providing me the instruments and technical experience during my time at NRC.

In addition, I would like to thank Kennametal Stellite Inc. in Belleville. Mathew Yao and Rachael Collier were in assisting me in figuring out the sample preparation and providing deep knowledge about Stellite alloys.

Moreover, I would like to thank my parents for their supports. They are always the strongest backing of mine.

Lastly, I would like to thank my girlfriend, Minyi Zhang, for her patience and great support during my thesis writing. 


\section{Table of Contents}

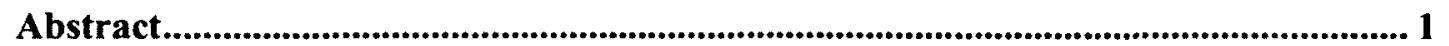

Acknowledgements ...................................................................................................................... 3

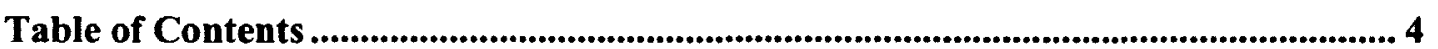

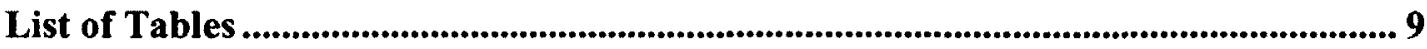

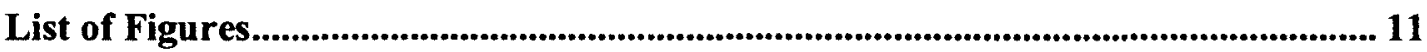

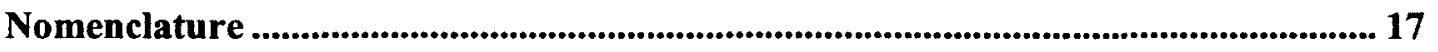

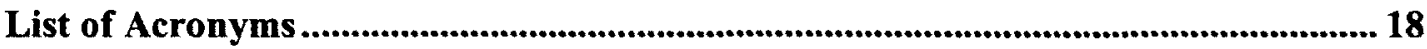

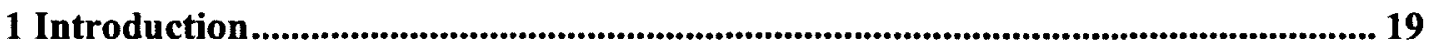

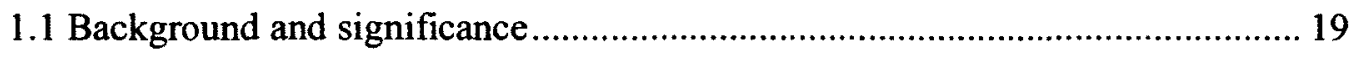

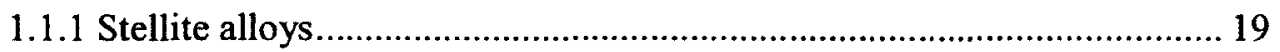

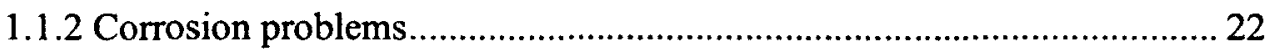

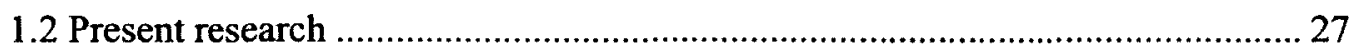

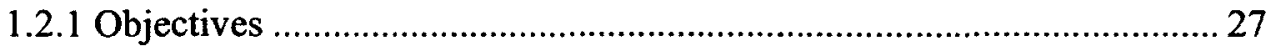

1.2.2 Tasks and methodologies........................................................ 28 
1.3 Organization of the thesis

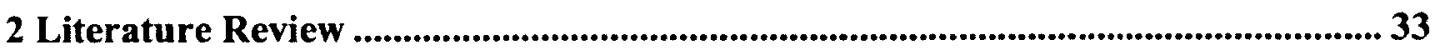

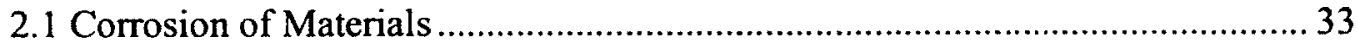

2.1.1 Mechanical components in corrosion environments............................ 34

2.1.2 Materials developed for corrosion resistance ................................... 35

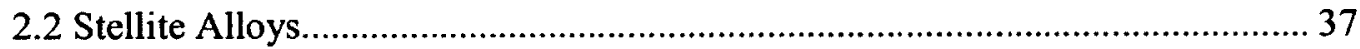

2.2.1 Chemical compositions and microstructures ....................................... 37

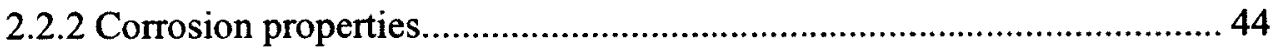

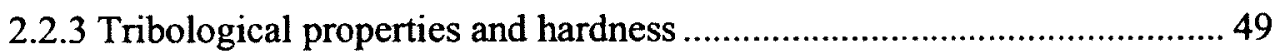

2.2.4 Mechanical properties ..................................................................... 50

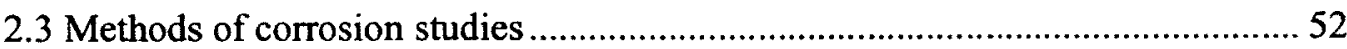

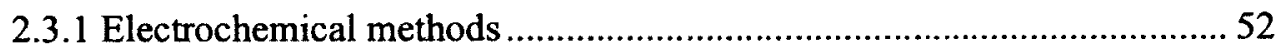

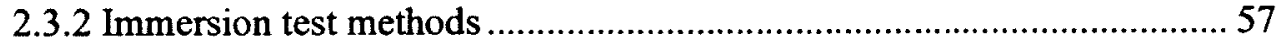

2.4 Extreme Value Analysis (EVA) models .................................................. 57

2.4.1 Extreme value theory and models................................................5 57

2.4.2 Application of EVA to corrosion tests................................................ 59 


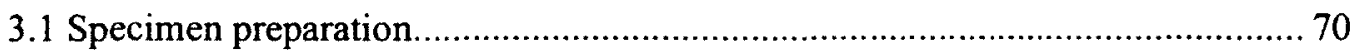

3.1.1 Chemical composition and microstructure .................................. 70

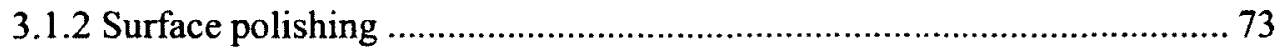

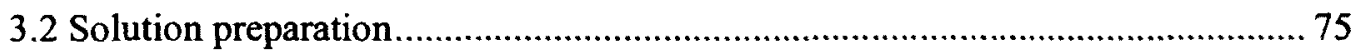

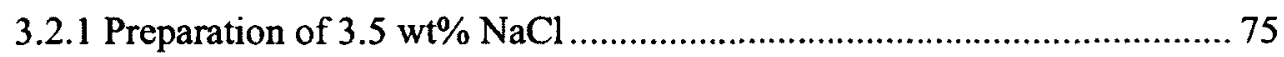

3.2.2 Preparation of Green Death solution............................................... 76

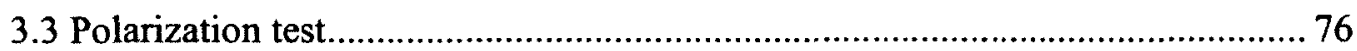

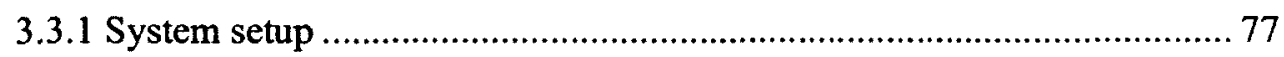

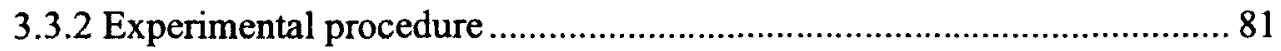

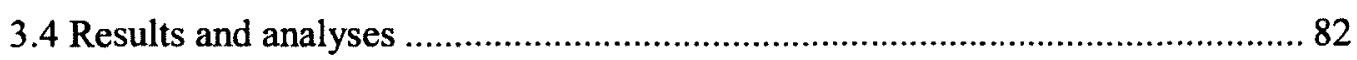

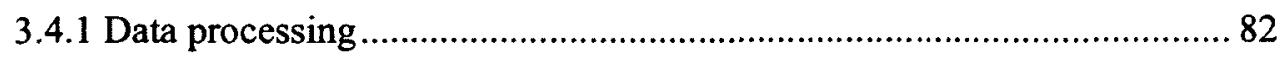

3.4.2 Polarization curves for the tests in $3.5 \mathrm{wt} \% \mathrm{NaCl}$ solution ................... 89

3.4.3 Polarization curves for the tests in Green Death solution..................... 91

3.4.4 Cyclic polarization curves......................................................... 94

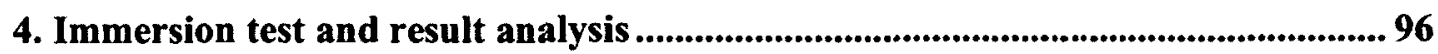

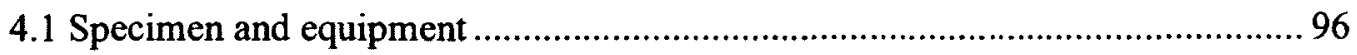




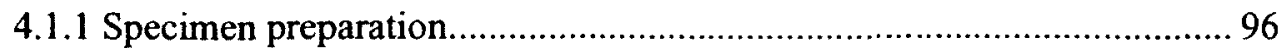

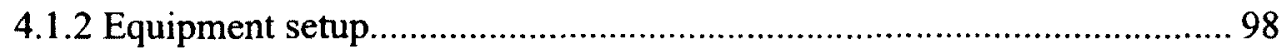

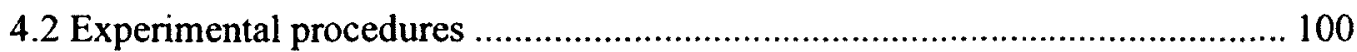

4.2.1 Critical Pitting Temperature (CPT) test ...................................... 100

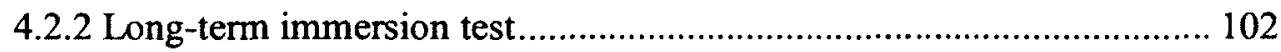

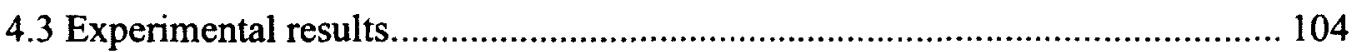

4.3.1 Critical Pitting Temperature (CPT) ….......................................... 104

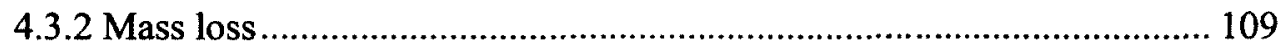

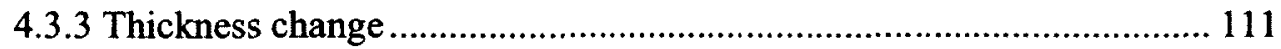

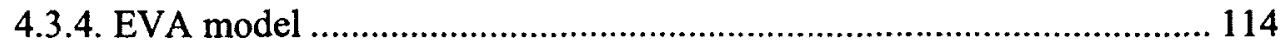

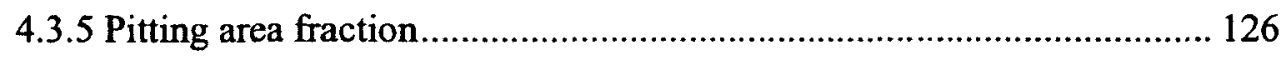

4.3.6 Chemical composition analysis of pits .............................................. 130

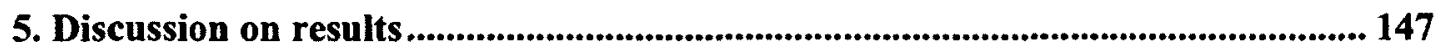

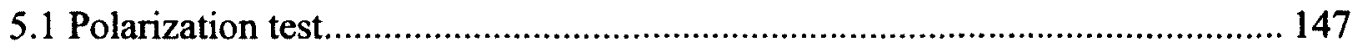

5.1.1 Electrochemical corrosion behavior in $\mathrm{NaCl}$ electrolyte ..................... 147

5.1.2 Electrochemical corrosion behavior in Green Death electrolyte ........... 149

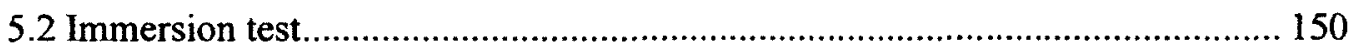


5.2.1 Carbide volume fraction effects

5.2.2 Carbide size effects

5.2.3 Oxidization effects

6. Conclusions and future work....................................................................................... 157

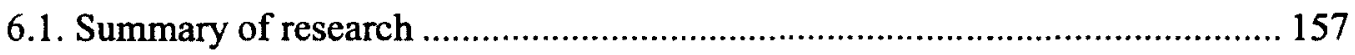

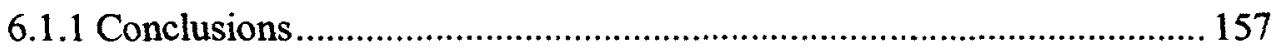

6.1.2 Significant contributions ............................................................. 160

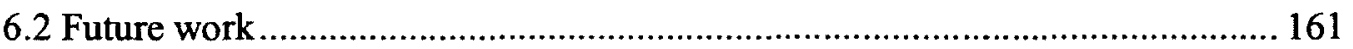

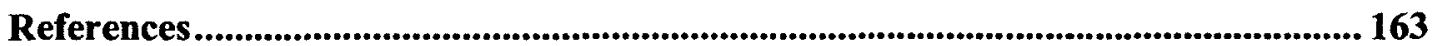




\section{List of Tables}

Table 2-1: Compositions (wt $\%$, Co in balance) of various Stellite alloys

Table 2-2: Chemical compositions (wt\%, Co in balance) of Stellite alloys for corrosion tests

Table 2-3: Polarization relevant parameters

Table 3-1 Chemical Compositions (wt $\%$, Co in balance) of Stellite alloys 70

Table 3-2: Summary of polarization test results of Stellite 6B and Stellite $6 \mathrm{~K}$ in 3.5 $\mathrm{wt} \% \mathrm{NaCl}$ solution. 90

Table 3-3: Summary of polarization test results of Stellite $6 \mathrm{~B}$ and Stellite $6 \mathrm{~K}$ in Green Death solution3.5 wt $\% \mathrm{NaCl}$ solution. 93

Table 4-1: CPT test results of Stellite 6B and Stellite 6K in Green Death solution 106

Table 4-2: Weight data (gram) of Stellite 6B 109

Table 4-3: Weight data (gram) of Stellite 6K 110

Table 4-4: Measured thickness data (mm) of Stellite 6B 112

Table 4-5: Measured thickness data (mm) of Stellite $6 \mathrm{~K}$ 113

Table 4-6: Modified maximum pit depths (mm) of Stellite 6B 119

Table 4-7: Modified maximum pit depths (mm) of Stellite $6 \mathrm{~K}$ 120 
Table 4-8: Cumulative probability distribution parameters for EVA model

Table 4-9: EVA model results for Stellite 6B and Stellite 6K

Table 4-10: Pitting area fraction (\%) of Stellite 6B

Table 4-11: Pitting area fraction (\%) of Stellite 6K

Table 5-1: Carbide volume fractions (\%) of Stellite $6 \mathrm{~B}$ and Stellite $6 \mathrm{~K}$ specimens

Table 5-2: Oxygen percentages (wt $\%$ ) in pitted Stellite $6 \mathrm{~B}$ specimens. 156

Table 5-3: Oxygen percentages (wt $\%$ ) in pitted Stellite $6 \mathrm{~K}$ specimens 156 


\section{List of Figures}

Figure 1-1: SEM microstructure of cast Stellite 6.

Figure 1-2: Stellite 6K knives from different batches of manufacturing: (a) pitting found during service; (b) no pits found during service and (c) after 120 h immersion test. 26

Figure 2-1: Typical microstructures of cast Stellite alloys: (a) Stellite 3, (b) Stellite 6, (c) Stellite 21 42

Figure 2-2: Corrosion resistance of W-containing Stellite 6 and Stellite 12 and Mo-containing Stellite 706 and Stellite 712 [2] 46

Figure 2-3: Corrosion resistance of Stellite alloys with varying $\mathrm{Ni}, \mathrm{Cu}$ and $\mathrm{Mo}$ contents: (a) at room temperature (b) at $60^{\circ} \mathrm{C}$ in $28 \% \mathrm{P}_{2} \mathrm{O}_{4}+13 \%$ $\mathrm{H}_{2} \mathrm{SO}_{4}+2 \% \mathrm{HF}[27]$ 48

Figure 2-4: Tensile properties of Stellite 21: (a) tensile strength and (b) elongation [24]. 51

Figure 2-5: Schematic diagram of three-electrode electrochemical cell [7]. 54

Figure 2-6: A typical hypothetical polarization curve defining the parameters [7].. 55

Figure 2-7: EIS curves for Ti-and $\mathrm{Cr}$-based nitride coatings in $3.5 \mathrm{wt} \% \mathrm{NaCl}$ solution [30]. 56 
Figure 2-8: Variations in the Cross-Sectional profile of Pits [33].

Figure 2-9: Corrosion pit profile [31] 65

Figure 2-10: Results of three extreme value analyses, obtained by dividing the whole area into 5,10 , and 20 segments [32] 67

Figure 2-11: Variation of the extreme value function $-\ln [-\ln F(z)]$ with extreme depth $z[31]$ 68

Figure 2-12: Variation of extreme value frequency distribution parameters with time of corrosion $\cdot \mu, \square \sigma[31]$ 68

Figure 3-1: Hitachi Model S-570 Scanning Electron Microscope. 71

Figure 3-2: SEM microstructure of Stellite 6B: (a) at low magnification and (b) at high magnification. 72

Figure 3-3: SEM microstructure of Stellite 6K: (a) at low magnification and (b) at high magnification 73

Figure 3-4: Buehler Ecomet-4 semiautomatic grinding machine. 75

Figure 3-5: electrochemical experimental setup. 78

Figure 3-6: Electrochemical cell setup (IAR-NRC Canada). 79 
Figure 3-7: A typical potentiodynamic polarization curve obtained from a potentiodynamic polarization test (Stellite 6B in Green Death solution). 83

Figure 3-8: Hypothetical cathodic and anodic polarization plots for a passive anode $[43]$ 84

Figure 3-9: Hypothetical cathodic and anodic polarization diagram [43]. 86

Figure 3-10: Linear regions of polarization curves: (a) cathodic curve and (b) anodic curve. 88

Figure 3-11: Polarization curves of Stellite $6 \mathrm{~B}$ and Stellite $6 \mathrm{~K}$ in $3.5 \mathrm{wt} \% \mathrm{NaCl}$ solution 90

Figure 3-12: Polarization curves of Stellite 6B in Green Death solution. 91

Figure 3-13: Polarization curves of Stellite $6 \mathrm{~K}$ in Green Death solution. 92

Figure 3-14: Comparison of polarization curves of Stellite $6 \mathrm{~B}$ and Stellite $6 \mathrm{~K}$ in Green Death solution. 93

Figure 3-15: Cyclic polarization curves of Stellite 6B in Green Death solution..... 94

Figure 3-16: Cyclic polarization curves of Stellite 6K in Green Death solution..... 95

Figure 4-1: Immersion test specimen. 97

Figure 4-2: Jeio Tech Model BW-10G water heating bath. 98 
Figure 4-3: Customer-designed flask set.

Figure 4-4: Customer-designed specimen holder. 100

Figure 4-5: Specimen with pits after immersion test: (a) bubble-like pits and (b) bubbles broken. 103

Figure 4-6: Specimens tested at $60^{\circ} \mathrm{C}$ showing pits (100X magnification): (a) Stellite $6 \mathrm{~B}$ and (b) Stellite $6 \mathrm{~K}$ 105

Figure 4-7: Struers Secotom-10 Cutting Device. 107

Figure 4-8: SEM images of a big pit in the Stellite $6 \mathrm{~K}$ specimen surface tested in Grteen Death solution at $60^{\circ} \mathrm{C}$ for $24 \mathrm{~h}$ : (a) surface view and (b) section view. 108

Figure 4-9: Comparison of mass loss between Stellite 6B and Stellite 6K in Green Death solution at $50^{\circ} \mathrm{C}$. 111

Figure 4-10: Comparison of thickness reduction between Stellite 6B and Stellite 6K in Green Death solution at $50^{\circ} \mathrm{C}$. 114

Figure 4-11: CONTOURECORD 1700SD surface texture and contour measuring instrument. 115

Figure 4-12: DT45505 stylus. .116

Figure 4-13: 2D profiles of cross section of pits in Stellite 6B specimen. 117 
Figure 4-14: 2D profiles of cross section of pits in Stellite 6K specimen.

Figure 4-15: Extreme value fitting of Stellite 6B according to the Gumbel extreme value distribution.

Figure 4-16: Extreme value fitting of Stellite 6K according to the Gumbel extreme value distribution.

Figure 4-17: Time-dependence of the Gumbel Distribution parameters for Stellite 6B. 124

Figure 4-18: Time-dependence of the Gumbel Distribution parameters for Stellite $6 \mathrm{~K}$ 125

Figure 4-19: Tescan Vega II XUM VPSEM imaging system. 127

Figure 4-20: A pitting specimen surface: (a) BSE-SEM image, (b) SE-SEM image and (c) pits identified. 128

Figure 4-21: Comparison of pitting area fraction between Stellite 6B and Stellite 6K.

Figure 4-22: Philips XL30S FEG Scanning Electron microscope (SEM) with an EDAX energy dispersive X-ray (EDX) spectroscopy system. 130

Figure 4-23: EDX results of reference specimen of Stellite 6B: (a) Co-rich solid solution and (b) Cr-rich carbides. 131 
Figure 4-24: EDX results of reference specimen of Stellite $6 \mathrm{~K}$ : (a) Co-rich solid solution and (b) Cr-rich carbides.

Figure 4-25: Pit region containing light and dark areas: (a) Stellite 6B; (b) Stellite $6 \mathrm{~K}$

Figure 4-26: EDX results of pits in the Stellite $6 \mathrm{~B}$ specimen immersion-tested for 2 days: (a) light area and (b) dark area. 135

Figure 4-27: EDX results of pits in the Stellite 6B specimen immersion-tested for 4 days: (a) light area and (b) dark area.

Figure 4-28: EDX results of pits in the Stellite 6B specimen immersion-tested for 12 days: (a) light area and (b) dark area.

Figure 4-29: EDX results of pits in the Stellite 6K specimen immersion-tested for 2 days: (a) light area and (b) dark area. 141

Figure 4-30: EDX results of pits in the Stellite 6K specimen immersion-tested for 4 days: (a) light area and (b) dark area. 143

Figure 4-31: EDX results of pits in the Stellite 6K specimen immersion-tested for 12 days: (a) light area and (b) dark area. 145

Figure 5-1: SEM images for carbide fraction calculation of Stellite 6B: (a) microstructure and (b) identified carbide region.

Figure 5-2: SEM images for carbide fraction calculation of Stellite 6K: (a) microstructure and (b) identified carbide region. 153 


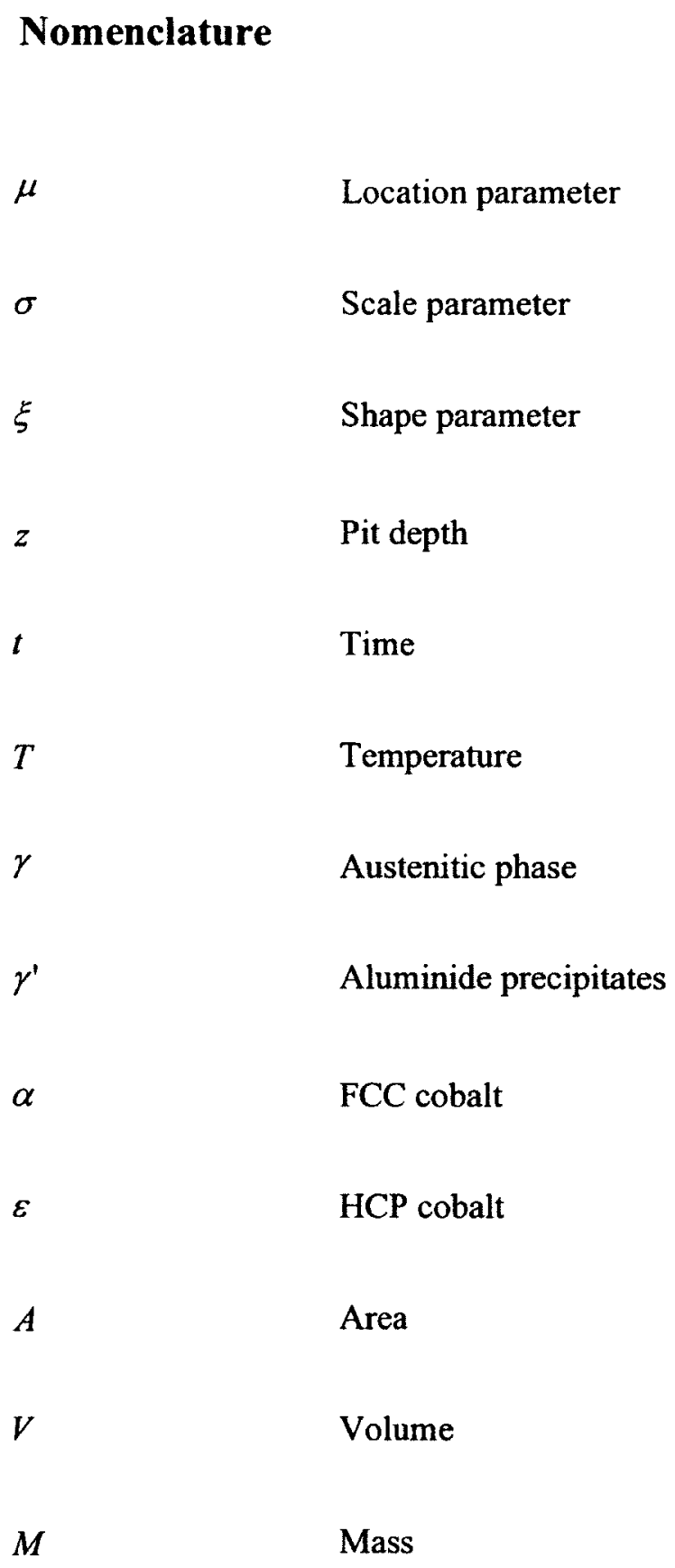




\section{List of Acronyms}

FCC

$\mathrm{HCP}$

BCT

$\mathrm{P} / \mathrm{M}$

HIP

SEM

EDX

BSE

SE

$\mathrm{XRD}$

XPS

SFE

EVA

ASTM

ASM
Face centered cubic

Hexagonal close packed

Body centered tetragonal

Powder metallurgy

Hot isostatic pressing

Scanning electron microscopy

Energy dispersive X-ray

Backscattered electron

Secondary electron

X-ray powder diffraction

X-ray photoelectron spectroscopy

Stacking fault energy

Extreme value analysis

American society for testing and material

American society for metals 


\section{Introduction}

\subsection{Background and significance}

\subsubsection{Stellite alloys}

Stellite alloys are cobalt-based superalloys designed for use in various industries, primarily for wear resistance applications. Many industrial processes such as gas turbine engine operation, oil production and refining, chemical processing industry, and mechanical manufacturing pose high stress, high temperature, and severe wear and corrosion environments. Stellite alloys display a unique combination of mechanical and tribological properties such as high hardness and strength, superior adhesive and abrasive wear resistance and excellent cavitation-erosion resistance in these industrial situations.

The main chemical composition of Stellite alloys consists of cobalt (Co), chromium (Cr), tungsten (W) or/and molybdenum (Mo) and a small ( $<3 \mathrm{wt} \%)$ amount of carbon (C). Depending on the carbon content, Stellite alloys can be categorized into three groups: high-carbon alloys $(1.2 \mathrm{wt} \% \sim 3 \mathrm{wt} \%)$ designed for wear service, medium $(0.5 \mathrm{wt} \% \sim$ $1.2 \mathrm{wt} \%$ ) to combat corrosion or simultaneous corrosion and wear, and low-carbon alloys $(<0.5 \mathrm{wt} \%)$ for high temperature service [1]. The different amount of carbon content, thus, different carbide volume fraction in the material, imparts individual Stellite alloy various performances, such as wear resistance, corrosion resistance, tensile strength, 
fracture toughness, and so on. Chromium has a dual function in Stellite alloys. It is both the predominant carbide former, i.e., most of the carbides are chromium-rich, and the most important alloying element in the matrix, where it provides added strength, as a solute, and resistance to corrosion and oxidation. Tungsten and molybdenum in Stellite alloys serve to provide not only additional strength to the matrix, but also improve general corrosion resistance of alloys, especially in reducing non-oxidizing conditions $[2]$.

Fabrication process affects the microstructure and thereby the various properties of Stellite alloys significantly. For example, the cast and weld-deposited forms of Stellite 6 $(30 \% \mathrm{Cr}, 4.5 \% \mathrm{~W}, 1.5 \% \mathrm{Mo}, 1.2 \% \mathrm{C}, \mathrm{Co}$ balance, in weight) have the typical hypo-eutectic structure consisting of wear-resistant carbides dispersed in a tougher, more ductile $\mathrm{CoCr}$ alloy matrix, as shown in Figure 1-1. This structure provides exceptional wear resistance, with the hard carbides providing sliding wear and abrasion resistance, and the $\mathrm{CoCr}$ matrix providing resistance to galling, cavitation and corrosion. The main disadvantage of the cast structure is the appearance of these brittle carbides in the form of a semi-continuous network. 


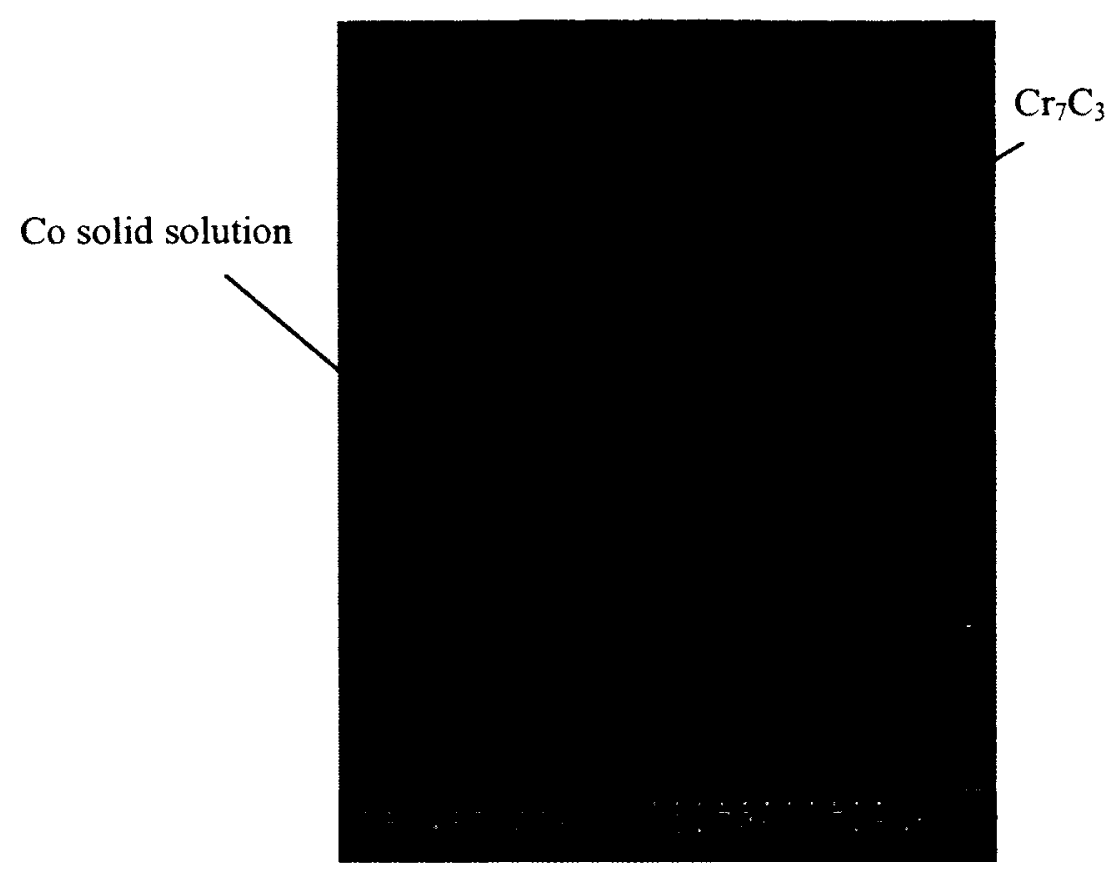

Figure 1-1: SEM microstructure of cast Stellite 6.

On the contrary, the wrought form of Stellite $6 \mathrm{~B}$ and Stellite $6 \mathrm{~K}$ has an entirely different structure. The carbides have been broken up and dispersed evenly in the microstructure during the mechanical deformation experienced by the material during manufacturing. This structure allows the carbides to continue to perform their function as the primary wear resistant component in the alloys, but inhibits their ability to act as a brittle crack-propagating network. Hence the wrought form exhibits dramatic improvements in mechanical properties and toughness. In addition, due to the more uniform carbide structure, the aqueous corrosion resistance of wrought alloys is also superior to the cast version. These dramatic improvements shown by the wrought Stellite $6 \mathrm{~B}$ and Stellite $6 \mathrm{~K}$ along with their machinability have made these materials an excellent choice for critical 
wear components where heat or corrosion is also involved. The hot isostatic press (HIP) consolidated form of Stellite 6 has a structure similar to that of the wrought form, but with an even finer carbide dispersion. The carbides are dispersed evenly in the microstructure because they have precipitated out of the gas-atomized powder during the HIP process. Compared to the wrought structure, the HIPed form exhibits even more dramatic improvements in the mechanical properties and toughness while wear resistance is unaffected, with the exception of severe low-angle abrasive-particle wear resistance a little reduced.

\subsubsection{Corrosion problems}

Corrosion, defined as the deterioration of a metal or its properties, attacks every component at every stage in the life of many fields, for example, oil and gas industries. From casting strings to production platforms, from drilling through to abandonment, corrosion is an adversary worthy of all the high technology. Because it is almost impossible to prevent corrosion, it is becoming more apparent that controlling the corrosion rate may be the most economical solution. Therefore, the material engineers are increasingly involved in developing highly corrosion-resistant materials.

Stellite alloys are generally corrosion-resistant owing to their high $\mathrm{Cr}$ content, but single-phase alloys are more resistant to corrosion than multi-phase alloys due to the lack of interfaces between phases. Therefore from a corrosion standpoint, Stellite alloys can 
be broadly classified into two categories. The alloys containing low levels of carbon $(0.025 \sim 0.15 \mathrm{wt} \%)$ are intended for use in severely corrosive environments, at high temperatures, or where ductility is an important consideration, due to less interfaces in their microstructures. The alloys having high carbon contents ( 1 to $>3 \%)$ exhibit high hardness, and provide resistance to low-stress abrasion, in addition to other forms of wear, but they exhibit low ductility [3]. Although the high-carbon content Stellite alloys possess some resistance to aqueous corrosion, they are limited by grain boundary carbide precipitation, the lack of vital alloying elements in the matrix materials, by chemical segregation in the microstructure. Examples of these alloys are Stellite 1, Stellite 6, Stellite 12 and Stellite 21 . Regarding the role of various alloying elements, $\mathrm{Cr}, \mathrm{Mo}$, and $\mathrm{W}$, are highly soluble in both the face-centered cubic (fcc) and hexagonal close-packed (hcp) atomic forms of cobalt. Chromium is added to Stellite alloys to provide passivity over a wide range of potentials and resistance to oxidation. Molybdenum and tungsten enhance resistance to corrosion within the active regime [4].

For the main application - wear resistance, the tribological properties of Stellite alloys have been extensively studies. However, in many industrial applications, the synergetic attack combining wear and corrosion often occurs; thus Stellite alloys are required to combat severe corrosion and reducing or oxidizing acid attack at high temperatures, in addition to resistance to wear, such as in oil production, refining, transportation, and gas turbine engines. Corrosion of metals and alloys by pitting constitutes one of the main failure mechanisms of the components and structures servicing in corrosive environments, 
for example, containers and pipes. Pits cause failure of materials through perforation. Pitting can occur in various applications. In oil and gas industries, pitting corrosion is a major problem, especially for pipelines [4]. Stellite $6 \mathrm{~K}$ has been employed as blades in rubber cutting production line. This working environment involves several key factors that degrade the material functions, including high stress, elevated temperature, oxidizing acid corrosion, kinetic friction and wear. Therefore, not only wear resistance but also corrosion resistance and tensile strength at high temperatures for Stellite $6 \mathrm{~K}$ should be considered. In fact, pitting corrosion of Stellite $6 \mathrm{~K}$ has been found in this servicing environment. The report from the customers of Kennametal Stellite Inc. indicates that different batches of Stellite $6 \mathrm{~K}$ have different performance in the same working condition. As shown in Figure 1-2, seven Stellite 6K knives that were manufactured in different batches were provided by Kennametal Stellite Inc., the four in Figure 1-2(a) were reported to find pitting, considered "Bad Knives", during service and the three in Figure 1-2(b) were found no pitting, called "Good Knives" by the customers. Figure 1-2(c) shows the seven knives after $120 \mathrm{~h}$ immersion test; the knives numbered 84-3967 and 87-4163 from "Bad Knives" were found oxidized, the others were still shiny. 


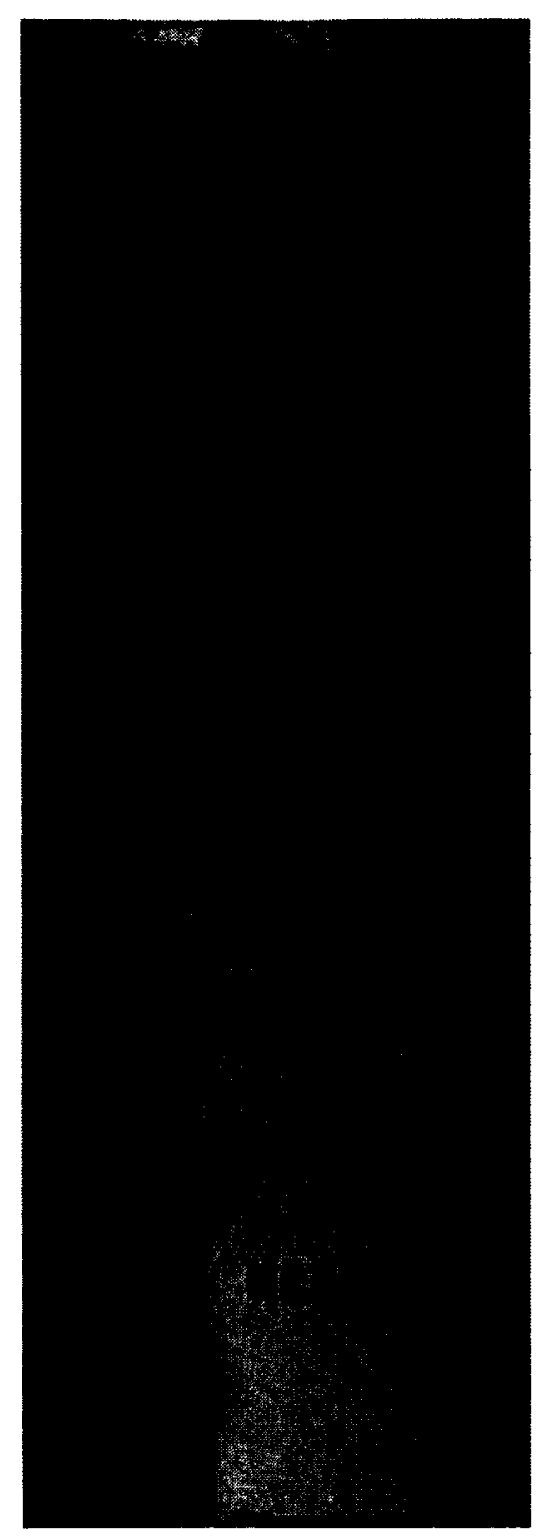

(a)

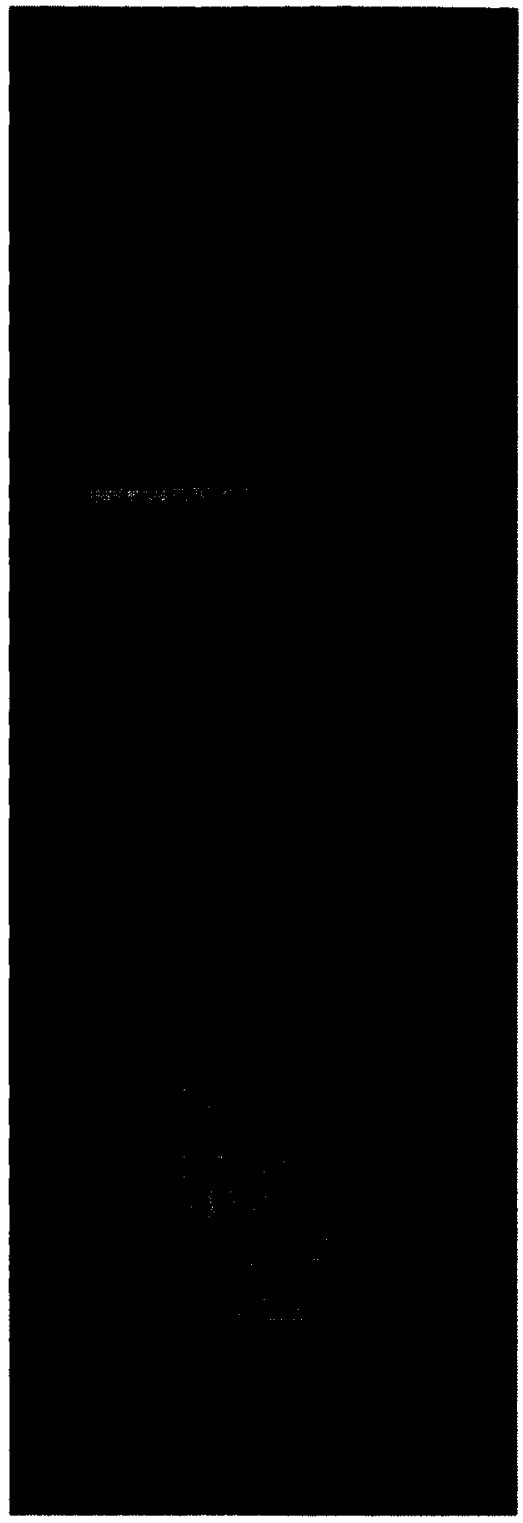

(b) 


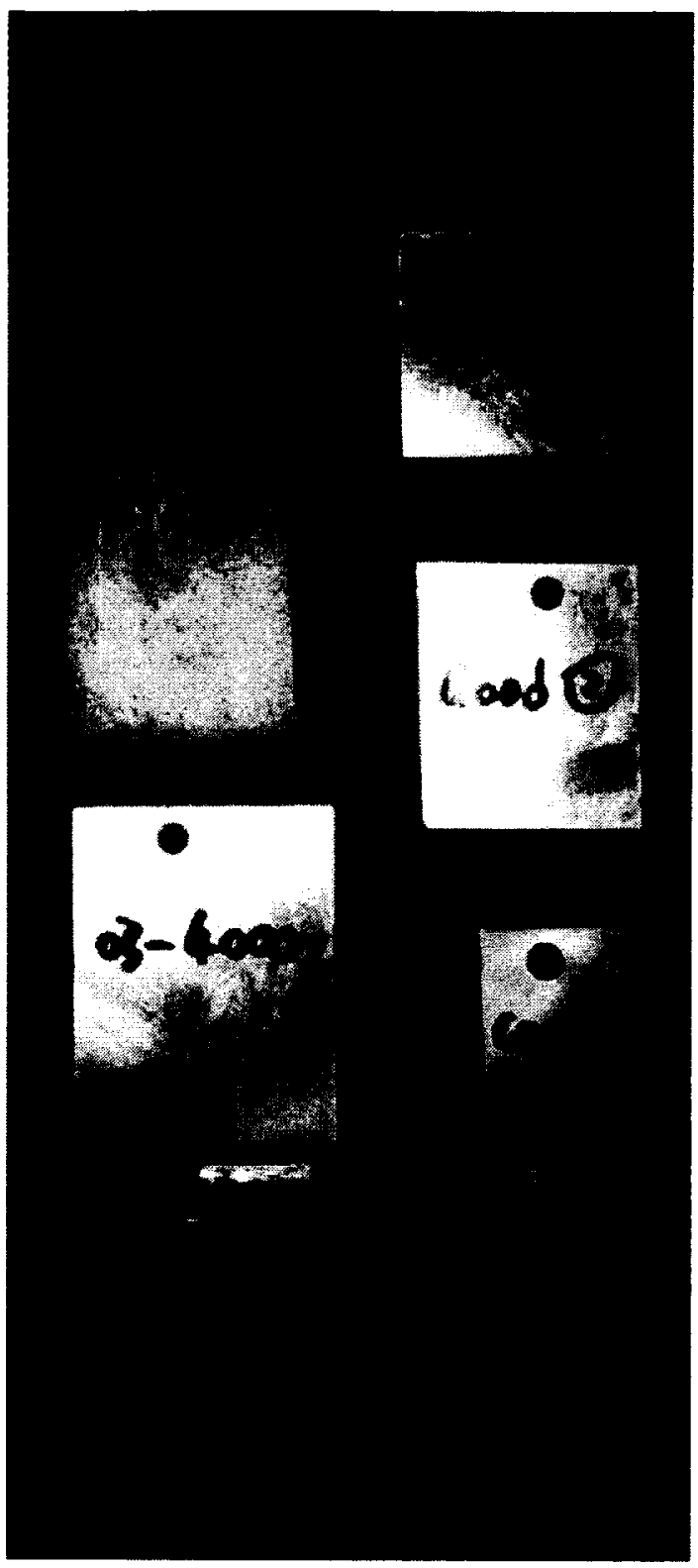

(c)

Figure 1-2: Stellite 6K knives from different batches of manufacturing:

(a) pitting found during service; (b) no pits found during service and (c) after $120 \mathrm{~h}$ immersion test. 
With more and more applications of Stellite alloys in corrosive environments, only wear test data cannot satisfy existing and potential customers, therefore there is a strong demand from the material industry, for example, Kennametal Stellite Inc. — the main producer and supplier of Stellite alloys in the world, for various test data that pertain to corrosion properties of these materials. However, according to literature review, the corrosion behaviour of Stellite alloys have been rarely studied, and the database record of Kennametal Stellite Inc. shows the lack of these data. These have limited the application of these alloys.

\subsection{Present research}

\subsubsection{Objectives}

In order to understand the corrosion problems and explore the corrosion mechanisms of Stellite alloys, and thereby to employ these materials properly, a project titled "Investigation of Corrosion Behavior of Stellite Alloys" has been initiated by Kennametal Stellite Inc. As a part of this project, the present research was aimed to investigate the corrosion behaviour of wrought Stellite alloys - Stellite $6 \mathrm{~B}$ and Stellite $6 \mathrm{~K}$, because these two alloys possess superior mechanical properties in addition to excellent wear resistance, owing to the nature of the hot working process, and are used the most popularly among Stellite alloys. The objectives of this research are (1) to investigate the corrosion behavior of Stellite $6 \mathrm{~B}$ and Stellite $6 \mathrm{~K}$ in a typical industry corrosive environment - Green Death solution through polarization test and immersion 
test; (2) to explore the corrosion mechanisms of Stellite $6 \mathrm{~B}$ and Stellite $6 \mathrm{~K}$ in Green Death solution, and thereby prepare for the study of corrosion mechanisms of other Stellite alloys in future research; (3) to find out the influence of microstructure (carbide volume fraction and carbide size) on the corrosion resistance of Stellite alloys.

\subsubsection{Tasks and methodologies}

Two wrought Stellite alloys, Stellite $6 \mathrm{~B}$ and Stellite $6 \mathrm{~K}$, having similar chemical compositions were selected in this study. Stellite $6 \mathrm{~B}$ contains $1.0 \mathrm{wt} \%$ carbon, which belongs to medium-carbon class; Stellite $6 \mathrm{~K}$ contains $1.6 \mathrm{wt} \%$ carbon, which belongs to high-carbon class. They contain the same amount of chromium (30 wt\%), and almost same amount of other alloying elements, such as tungsten and molybdenum. The main tasks implemented to achieve the objectives are summarized below:

(1) The microstructures of Stellite $6 \mathrm{~B}$ and Stellite $6 \mathrm{~K}$ were analyzed using a Scanning Electron Microscope (SEM) with Energy Dispersive X-ray (EDX) spectrum. Each phase in the microstructures was identified.

(2) Polarization test was performed on Stellite $6 \mathrm{~B}$ and Stellite $6 \mathrm{~K}$ to investigate their electrochemical corrosion behaviour. Both potentiodynamic polarization and cyclic polarization were conducted on these alloys to study their general and localized corrosion behaviour, respectively. Two types of electrolytes were used as the test environment: $3.5 \mathrm{wt} \% \mathrm{NaCl}$ and Green Death solution. The former is a common 
corrosive medium that is used to rank materials for corrosion resistance; the latter is a typical industry corrosive environment.

(3) Immersion test was conducted on Stellite 6B and Stellite 6K in Green Death solution, in order to further investigate the corrosion behaviour of these alloys. The following types of data were obtained from this test: critical pitting temperature (CPT), mass loss, thickness change and the Extreme Value from the Extreme Value Analysis (EVA) model.

(4) The EVA model, which was derived from the Gumbel Distribution, was applied to predicting the minimum thickness (the Extreme Value) of the alloys for a given service life, based on the measured data of maximum pit depth using a surface texture and contour measuring instrument.

(5) The pitted specimens from the immersion tests were analyzed using SEM/EDX to determine the pitting area fraction and the chemical composition of the pits in each specimen.

(6) The comparison of corrosion behaviour between Stellite $6 \mathrm{~B}$ and Stellite $6 \mathrm{~K}$ was made to investigate the influence of microstructure (carbide volume fraction and carbide size) on the corrosion resistance of Stellite alloys.

(7) The experimental data, calculated values from the EVA model and the SEM/EDX analysis results were integrated and discussed to explore the corrosion mechanisms of Stellite 6B and Stellite 6K in Green Death solution. 


\subsubsection{Outcomes}

With the completion of these tasks, the following outcomes were derived:

(1) Potentiodynamic polarization curves of Stellite $6 \mathrm{~B}$ and Stellite $6 \mathrm{~K}$ in $\mathrm{NaCl}$ electrolyte;

(2) Potentiodynamic polarization curves of Stellite $6 \mathrm{~B}$ and Stellite $6 \mathrm{~K}$ in Green Death electrolyte;

(3) Cyclic polarization curves of Stellite 6B and Stellite 6K in Green Death electrolyte;

(4) Critical Pitting Temperature (CPT) of Stellite 6B and Stellite 6K in Green Death solution;

(5) Mass loss, thickness change, minimum thickness (the Extreme Value from the EVA model) of Stellite 6B and Stellite 6K in Green Death solution;

(6) Pitting area fractions of Stellite 6B and Stellite 6K in Green Death solution;

(7) Maximum pit depths of Stellite 6B and Stellite 6K in Green Death solution;

(8) Chemical compositions of pits in Stellite 6B and Stellite $6 \mathrm{~K}$ in Green Death solution;

(9) Effects of microstructure (carbide volume fraction and carbide size) on the corrosion behaviour of Stellite 6B and Stellite 6K in Green Death solution.

\subsection{Organization of the thesis}

This thesis is a comprehensive report of the present research. It consists of six chapters that cover the introduction of this research, literature review related to this research, polarization test details and results, immersion test details and results, discussion on the 
experimental results, conclusions and future work. The contents of each chapter are summarized below:

Chapter 1 is an introduction to the present research, including background, significance and objectives of this research. The tasks implemented toward the objectives and the methodologies used in this research are described. The outcomes of this research are summarized. Finally, the structure of this thesis is outlined.

Chapter 2 is the literature review, covering a brief introduction to corrosion of materials, the materials developed for corrosion resistance, and Stellite alloys including their chemical composition, classification, microstructures, various properties such as tribological, mechanical and corrosion properties that were investigated in previous research. The methods commonly used for corrosion studies of materials are also summarized.

Chapter 3 describes the details of the polarization test and data analysis, including the microstructural analysis of the testing alloys - Stellite $6 \mathrm{~B}$ and Stellite $6 \mathrm{~K}$, specimen preparation, testing facilities and their setup, experimental procedures, data acquisition and analysis. 
Chapter 4 describes the details of the immersion test and data analysis, including specimen preparation, testing facilities and their setup, experimental procedures, data acquisition and analysis, SEM/EDX analysis of pitting area fraction and the chemical composition of pits, application of the EVA model in data analysis of immersion corrosion test.

Chapter 5 is the discussion on experimental results. The results of microstructural analysis, polarization test, immersion test, the EVA model, SEM/EDX analysis are integrated and discussed. The relationships between these results and the corrosion mechanisms of the tested alloys are explored.

Chapter 6 summarizes this research. The conclusions drawn from this research are provided. The main contributions of this research are outlined. The future work toward to the goals of the entire project is presented. 


\section{Literature Review}

\subsection{Corrosion of Materials}

Corrosion can be defined as the deterioration of material by reaction to its environment in different ways. With respect to corrosion media, corrosion of metals can be divided into three categories: wet corrosion, molten matter corrosion and dry corrosion $[5,6]$. Wet corrosion, a typical electrochemical process, is the most common type of corrosion occurring in water based electrolytes. Corrosion can also occur in other fluids, such as fused salts or molten metal. In a dry corrosive environment, corrosion is an oxidation process. With respect to corrosion modes, corrosion can be defined as either general corrosion or localized corrosion [7]. In general corrosion, chemical reactions take place randomly across the whole surface of the material. Localized corrosion concentrates on particular areas and also takes various forms [8]. Crevice corrosion and pitting corrosion belong to this category. Crevice corrosion usually occurs at interfaces or on a metal surface, for example, underneath a gasket, at lap joints under bolts or under rivet heads. Pitting corrosion is an extremely localized corrosion, and is typically characterized by forming a depth of penetration that is much greater than the diameter of the affected area [8]. 


\subsubsection{Mechanical components in corrosion environments}

Mechanical components often operate and wear down in corrosive, wet and high temperature environments where conventional materials would fail or cause frequent replacement. Typical applications involving these environments cover aerospace, automotive, oil production and oil refining, chemical, nuclear, mining, and manufacturing industries. An example of mechanical components operating in such environments can be witnessed in the aerospace industry, where a variety of degradation problems occur in aircraft gas turbine engines as a result of metal to metal hot corrosion, wear, fretting and particle erosion [9]. Hot path components, such as stator vanes and turbine blades, are required to resist high temperature oxidation and corrosion resistance [10]. This kind of degradation process is accelerated under high temperature conditions, and the failure of such critical equipment can be catastrophic. Another typical example is relevant to the petroleum industry, where pipes and containers suffer high corrosion potentials, and where pitting constitutes one of the main failure mechanisms of corroded structures [11]. Failure of these components can cause a loss of service life of the process system and reduce pipeline conveyance efficiencies. In the oil production and refining industry, mining and the nuclear industry, the pumping of slurries and hydraulic fluids containing emulsions can wreck conventional impellers, pumps, valves, casings, etc., due to corrosion and wear attacks [12]. The failure of any of the equipment components can have disastrous effects on the entire hydraulic system, and consequently can potentially impact the environment, surrounding workers, and have hefty economic consequences. Finally, in the processing industry, treating of products is affected by the equipment and 
materials used. In some cases, cutting not only involves wear through sliding between the cutting tool and the work part but also corrosion, especially in causticity acid contained working condition. Furthermore, this operation also involves temperature variations due to friction heat, which can accelerate the corrosion and wear of the cutting tool [13].

\subsubsection{Materials developed for corrosion resistance}

In order to extend the service lives of the mechanical components that suffer from corrosion, and to maximize the efficiencies of the machines and engines containing the mechanical components, various materials have been designed and developed to combat corrosion. The most well-known corrosion resistant material is the stainless steel family, which is normally defined as steels with a minimum of $11 \mathrm{wt} \%$ chromium $(\mathrm{Cr})$. They do not produce rust, corrode or stain lightly with water as ordinary steels do, but they are not entirely stain-proof.

Another notable family is superalloys, which can be categorized and divided into three main classes: iron (Fe)-based, nickel (Ni)-based, and cobalt (Co)-based. Superalloys, owing to their unique combinations of mechanical, corrosion, tribological and high temperatures properties, are widely used for various high temperature and wear/corrosion-resistance applications. The whole superalloy family shares the austenitic $\gamma^{\prime \prime}$ phase in the face-centered cubic (fcc) matrix with a number of dispersed secondary strengthening phases. Among these three categories, cobalt-based alloys are used where 
the hot corrosion is a major concern due to their higher chromium contents; such applications include vanes and other stationary components of gas turbine engines [14]. However, none of these materials can excel in all these properties over a wide range of temperature; their operating ranges can be optimized by processing (including heat treatment) and by the adjustment in chemical composition.

In many industry applications, the need to reduce life cycle/maintenance costs is necessitating greater reliance on and interest in superalloys. In the manufacturing industry, for example, cutting tools and the mechanical components in high wear and corrosive environments that are traditionally made of hardened steel, can be substituted with superalloys, in order to extend their service lives while reducing maintenance and costs. In the oil industry, superalloys and superalloy-contained coatings have been employed for some of the crucial components, such as valves, elbows, etc. The development, usage and reliance of superalloys, can have a significant impact on extending the service lives of components and structures in various industries such as gas turbine engine, oil production, chemical process, mechanical manufacturing, etc. [15]. 


\subsection{Stellite Alloys}

\subsubsection{Chemical compositions and microstructures}

Over the years, superalloys have been largely developed and widely applied. The base alloying elements of these alloys consist of transition metals with consecutive positions in the periodic table of elements [1]. These alloys are either solid solution strengthened or precipitation hardened. The former are strengthened by solid solution hardening, and the latter are strengthened by the combination of precipitates, solid solution hardening, and the presence of carbides or intermetallic compounds - Laves phase $[1,16,17]$.

Stellite alloys are a group of cobalt-based superalloys designed for wear and corrosion resistance applications such as cutting tools, jet engine turbine blades, poppet valves, and high corrosion resistant machine parts. Basically they are derived from the Co-Cr-tungsten (W)-carbon (C) or Co-Cr-molybdenum (Mo)-C family [18, 19]. The main chemical compositions of Stellite alloys are typically comprised of $50-60 \% \mathrm{Co}, 20$ $-30 \% \mathrm{Cr}, 5-15 \% \mathrm{~W}$ or Mo, and $0.1-3 \% \mathrm{C}$ (in weight) [1], as summarized in Table 2-1[1]. The main differences in Stellite alloy grades are due to carbon and tungsten contents, which dictate the amount and type of carbide formation and the microstructure during solidification [1]. 
Table 2-1: Compositions (wt \%, Co in balance) of various Stellite alloys

\begin{tabular}{|c|c|c|c|c|c|c|c|c|c|c|}
\hline Alloy & Process & $\mathrm{Cr}$ & $\mathbf{W}$ & Mo & C & $\mathbf{F e}$ & $\mathrm{Ni}$ & $\mathbf{S i}$ & Mn & Others \\
\hline Stellite 1 & Cast & 30 & 13 & 0.5 & 2.5 & 3 & 1.5 & 1.3 & 0.5 & \\
\hline Stellite 3 & $\mathrm{P} / \mathrm{M}$ & 30.5 & 12.5 & & 2.4 & 5 & 3.5 & 2 & 2 & $1 B$ \\
\hline Stellite 4 & Cast & 30 & 14 & 1 & 0.57 & 3 & 3 & 2 & 1 & \\
\hline Stellite 6 & Cast & 29 & 4.5 & 1.5 & 1.2 & 3 & 3 & 1.5 & 1 & \\
\hline Stellite 6 & $\mathrm{P} / \mathrm{M}$ & 28.5 & 4.5 & 1.5 & 1 & 5 & 3 & 2 & 2 & $1 B$ \\
\hline Stellite 12 & Cast & 30 & 8.3 & & 1.4 & 3 & 1.5 & 0.7 & 2.5 & \\
\hline Stellite 21 & Cast & 27 & & 5.5 & 0.25 & 3 & 2.75 & 1 & 1 & \\
\hline Stellite 20 & Cast & 33 & 17.5 & & 2.45 & 2.5 & 2.5 & & 1 & \\
\hline Stellite 22 & Cast & 27 & & 11 & 0.25 & 3 & 2.75 & 1 & 1 & \\
\hline Stellite 28 & & 24 & & 12 & 0.35 & & 4 & & & $2 \mathrm{Nb}$ \\
\hline Stellite 25 & Cast & 20 & 15 & & 0.1 & 3 & 10 & 1 & 1.5 & \\
\hline Stellite 31 & Cast & 22 & 7.5 & & 0.5 & 1.5 & 10 & 0.5 & 0.5 & \\
\hline Stellite 80 & Cast & 33.5 & 19 & & 1.9 & & & & & 1B \\
\hline Stellite 188 & Cast & 22 & 14 & & 0.1 & 3 & 22 & 0.35 & 1.25 & $0.03 \mathrm{La}$ \\
\hline Stellite 190 & Weld & 27 & 14 & 1 & 3.3 & 3 & 3 & 1 & 1 & \\
\hline Stellite $\mathbf{3 0 0}$ & Cast & 22 & 32 & & 1.5 & & & & & \\
\hline Stellite 694 & Cast & 28 & 19 & & 1 & 5 & & 1 & 1 & \\
\hline Stellite 712 & Cast & 29 & & 8.5 & 2 & 3 & 3 & 1.5 & 1.5 & \\
\hline Stellite 720 & Cast & 33 & & 18 & 2.5 & 3 & 3 & 1.5 & 1.5 & $0.3 \mathrm{~B}$ \\
\hline Stellite 703 & Cast & 32 & & 12 & 2.4 & 3 & 3 & 1.5 & 1.5 & \\
\hline Stellite 706 & Cast & 29 & & 5 & 1.2 & 3 & 3 & 1.5 & 1.5 & \\
\hline $\begin{array}{c}\text { Stellite } \\
706 \mathrm{~K} \\
\end{array}$ & Wrought & 29 & & 6 & 1.4 & 3 & 3 & 1.5 & 1.5 & \\
\hline Stellite 6B & Wrought & 30 & 4 & 1.5 & 1 & 3 & 2.5 & 0.7 & 1.4 & \\
\hline Stellite 6K & Wrought & 30 & 4.5 & 1.5 & 1.6 & 3 & 3 & 2 & 2 & \\
\hline $\begin{array}{c}\text { Stellite } \\
98 \mathrm{M} 2\end{array}$ & $\mathrm{P} / \mathrm{M}$ & 30 & 18.5 & 0.8 & 2 & 5 & 3.5 & 1 & 1 & $\begin{array}{c}4.2 \mathrm{~V} \\
1 \mathrm{~B}\end{array}$ \\
\hline
\end{tabular}


Stellite alloys exhibit superior hot corrosion, oxidation, and sulfidation resistance at elevated temperatures, compared with Ni-based superalloys due to their relatively high chromium contents [20]. The solid-solution hardeners including chromium, tungsten, and molybdenum and a combination of carbides as the primarily strengthening phase provide Stellite alloys with super strength. The absence of intermetallic compounds in Stellite alloys, such as aluminide precipitate $\gamma^{\prime}$, results in large strength increase with the same degree of ductility in nickel- or iron-nickel-based superalloys $[1,21,22]$. The crystallographic nature of cobalt offers Stellite alloys attractive properties, such as good response to stress from the low stacking-fault energy (SFE) of cobalt allotropes, extended solubility and excellent ductility from alloying elements in the cobalt-based fcc matrix $[16]$.

The chemical composition and microstructure of Stellite alloys are the basis for understanding and predicting the mechanical behavior, corrosion properties and tribological performances of the materials. The carbon content in Stellite alloys is responsible for the microstructure and the type of carbides formed in these materials, it is also a key factor of Stellite alloys for both corrosion and wear resistance. This element is crucially present in Stellite alloys with content from 0.1 to $3.3 \mathrm{wt} \%$. Considering the carbon content, Stellite alloys may be categorized into three application areas as follows [1]: 
1) Low-carbon alloys $(<0.5 w t \%)$ designed for high-temperature service;

2) Low to medium-carbon alloys $(0.5-1.2 \mathrm{wt} \%)$ designed to combat corrosion or simultaneous corrosion and wear;

3) High-carbon alloys (1.2 - $3 \mathrm{wt} \%$ ) designed for wear service.

From a metallurgical point of view, carbon content determines the amount of carbides in Stellite alloys. For example, Stellite $6 \mathrm{~B}$ contains $1 \mathrm{wt} \%$ carbon, the carbides constitute about $13 \mathrm{wt} \%$ of the alloy, while Stellite 3 containing $2.4 \mathrm{wt} \%$ carbon presents about 30 wt $\%$ carbides of the material [1]. In general, there are four typical classes of carbides: $\mathrm{M}_{7} \mathrm{C}_{3}, \mathrm{M}_{23} \mathrm{C}_{6}, \mathrm{M}_{6} \mathrm{C}$, and $\mathrm{MC}$, where $\mathrm{M}$ represents the metal components, in Stellite alloys; the main carbides are $\mathrm{Cr}$-rich, such as $\mathrm{M}_{7} \mathrm{C}_{3}, \mathrm{M}_{23} \mathrm{C}_{6}$ carbides. $\mathrm{M}$ corresponds to $\mathrm{W}$ or $\mathrm{Mo}$ in $\mathrm{M}_{6} \mathrm{C}$, for example, when $\mathrm{W}$ is present in large quantities, it participates in the formation of $\mathrm{M}_{6} \mathrm{C}$ carbides during alloy solidification $[1,17,24]$. The typical microstructures of Stellite alloys consist of complex carbides distributed in a tough Co solid solution matrix, as shown in Figure 2-1 [23]. According to previous research, the metal carbides not only improve tribological properties of Stellite alloys, in particular, wear resistance, but also affect the mechanical properties such as tensile strength, hardness, fatigue strength of these alloys $[16,20,24]$. In the Co-Cr-W-C quaternary system, the carbides are mostly chromium-rich and tungsten-rich [1]. 


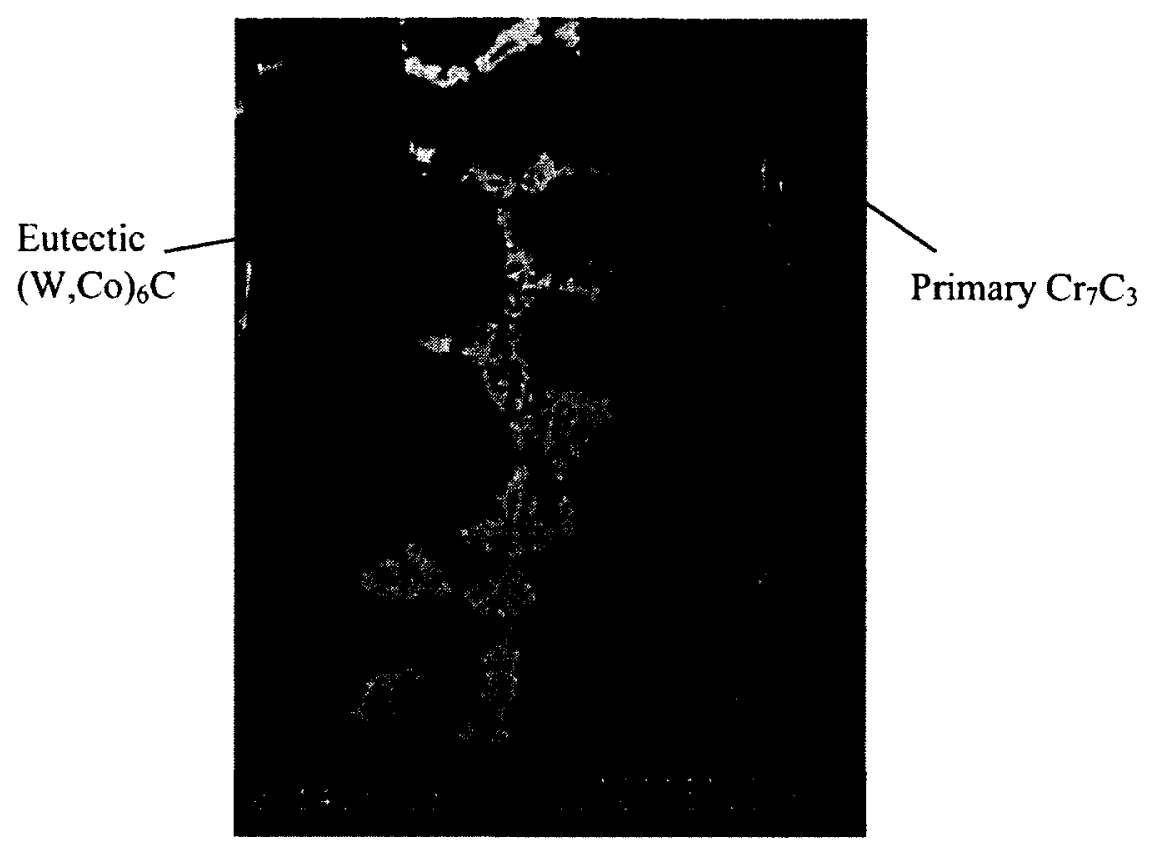

(a)

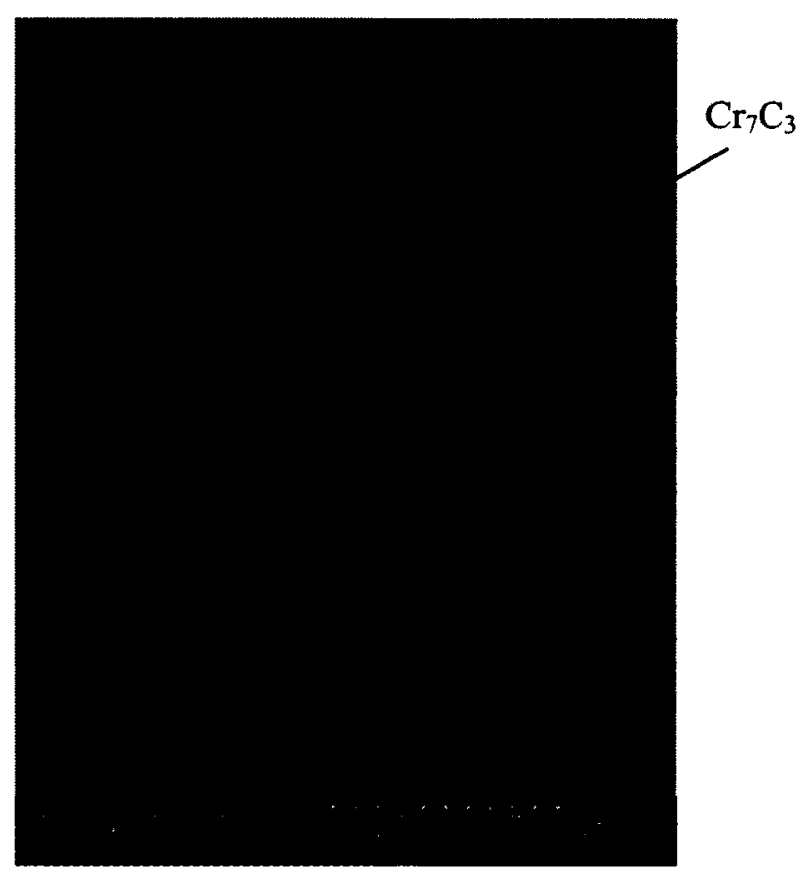

(b) 


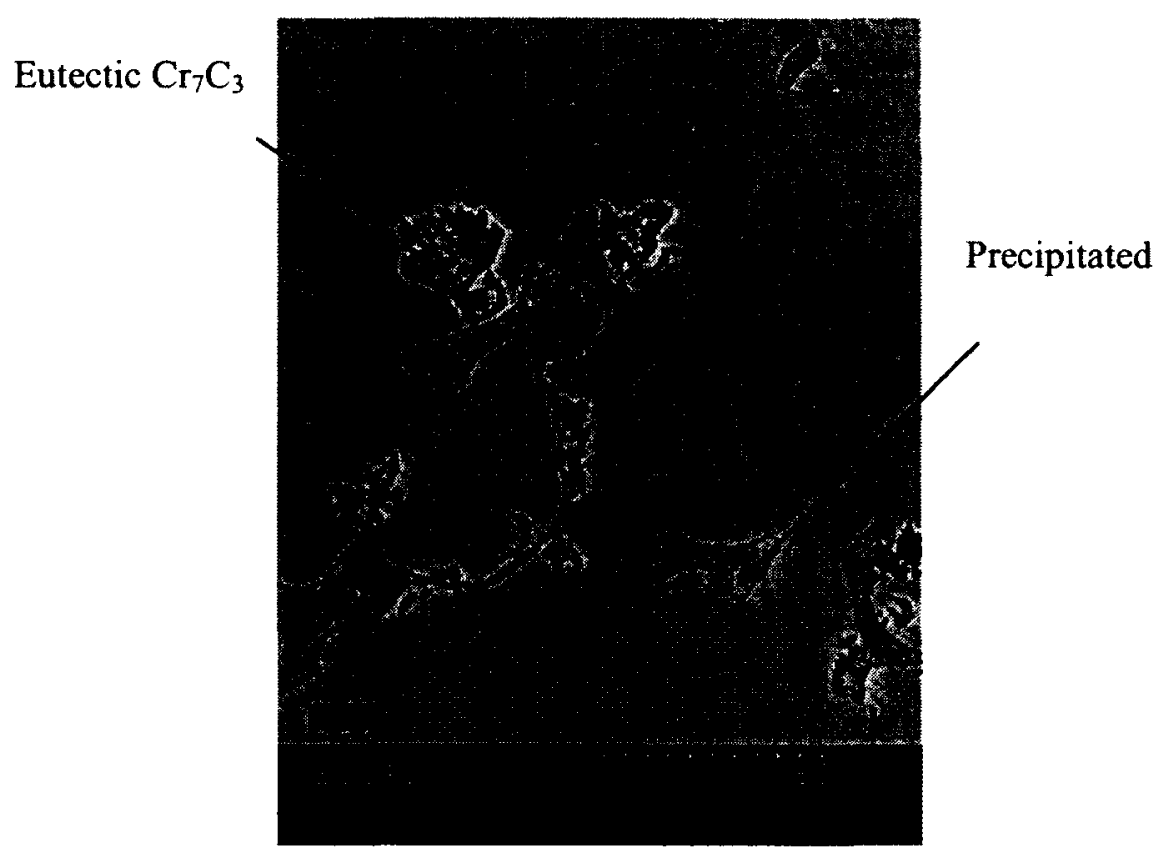

(c)

Figure 2-1: Typical microstructures of cast Stellite alloys: (a) Stellite 3,

(b) Stellite 6 and (c) Stellite 21.

With an approximate range from 18 to $32 \mathrm{wt} \%$, chromium is the most important alloying element in the cobalt matrix and the main former of carbides of Stellite alloys. Chromium itself is known to be highly resistant to corrosion and erosion [12, 26]. Chromium in Stellite alloys contributes as a solid-solution strengthener, significantly improves corrosion, oxidation and sulfidation resistance, and serves as the primary carbide former 
imparting wear resistance [28]. $\mathrm{Cr}_{7} \mathrm{C}_{3}$ is the most common carbide in Stellite alloys, and $\mathrm{Cr}_{23} \mathrm{C}_{6}$ is abundant in low-carbon Stellite alloys [2].

Tungsten and molybdenum are known as common alloying elements of Stellite alloys. These elements have similar effects in Stellite alloys. The effects of Mo (up to $28 \mathrm{wt} \%$ ) and $\mathrm{W}$ (between 4 to $7 \mathrm{wt} \%$ ) are known to contribute to the solid-solution hardening and also add to the strength of the material by forming primarily $\mathrm{M}_{6} \mathrm{C}$ carbides along with $\mathrm{MC}$ carbides and inter-metallic phases, such as $\mathrm{Co}_{3} \mathrm{Mo}$ or $\mathrm{Co}_{3} \mathrm{~W}$ [25], when the W content is high (>5 wt\%) [2]. The addition of molybdenum can improve resistance to non-oxidizing acids $[1,28]$.

There are a large number of Stellite alloys containing various amounts of other alloying elements such as iron, nickel, aluminum, manganese, boron, phosphorus, silicon, sulphur, and titanium, but most Stellite alloys contain only four to six elements with various proportions. These other elements all contribute desirable properties for Stellite alloys. For example, addition of iron up to a maximum of $5 \mathrm{wt} \%$ helps stabilize the fcc matrix [21]; and nickel up to $4 \mathrm{wt} \%$ is used as a solid-solution strengthener and the fcc matrix stabilizer [1]. 


\subsubsection{Corrosion properties}

In general, Stellite alloys are resistant to various corrosive media and oxidation due to their high contents of chromium. Typically, single-phase alloys (low carbon) are more resistant to corrosion than multi-phase alloys (medium and high carbon) due to the lack of interfaces between phases. From a corrosion standpoint, Stellite alloys can be broadly classified into two categories:

1) The alloys that contain a low level of carbon (between 0.025 to $0.15 \mathrm{wt} \%$ ) are intended for use in severely corrosive environments, at high temperatures, or where ductility is an important consideration, due to less interfaces in their microstructures.

2) The alloys that have a high carbon content ( 1 to $>3 \mathrm{wt} \%$ ) exhibit high hardness, and provide resistance to low-stress abrasion, in addition to other forms of wear, but low ductility [1].

Other alloying additions, such as chromium, molybdenum, and tungsten, have their contributions to the solution matrix. The wide range of $\mathrm{Cr}$ in Stellite alloys provides passivity potentials and resistance to oxidation, while $\mathrm{W}$ and Mo enhance resistance to corrosion within the active regime. In reducing acids and complex or pitting circumstances, Mo has an impressive performance to resist corrosion [2]. In addition, Ni serves to stabilize the fcc structure with a view toward improving ductility during service and also improves resistance to mineral acids and stress-corrosion cracking [26]. 
Stellite alloys have been investigated in some corrosive media. In general, corrosive environments can be classified into two categories: reducing environment such as sulfuric and hydrochloric acid, and oxidizing environment like nitric acid contained solution. It is suggested that low-carbon content Stellite alloys tend to have better corrosion resistance [2]. Stellite 6 , Stellite 706 , Stellite 12 , and Stellite 712 have been studied in sulphuric acid $\left(\mathrm{H}_{2} \mathrm{SO}_{4}\right)$, hydrochloric acid $(\mathrm{HCl})$ and nitric acid $\left(\mathrm{HNO}_{3}\right)$ [2]. In Figure 2-2, it is shown that in oxidizing $10 \% \mathrm{HNO}_{3}$ at boiling temperature for $72 \mathrm{~h}$, W-containing Stellite alloys, e.g., Stellite 6 and Stellite 12, have better corrosion resistance; in reducing $10 \%$ $\mathrm{H}_{2} \mathrm{SO}_{4}$ at $66^{\circ} \mathrm{C}$ and $5 \% \mathrm{HCl}$ at $40^{\circ} \mathrm{C}$ for $72 \mathrm{~h}$, Mo-containing Stellite alloys, e.g., Stellite 706 and Stellite 712 , show an admirable corrosion resistance. These results indicate that Mo exhibits a better effect on corrosion resistance than $\mathrm{W}$ at the same content level in Stellite alloys [2]. 


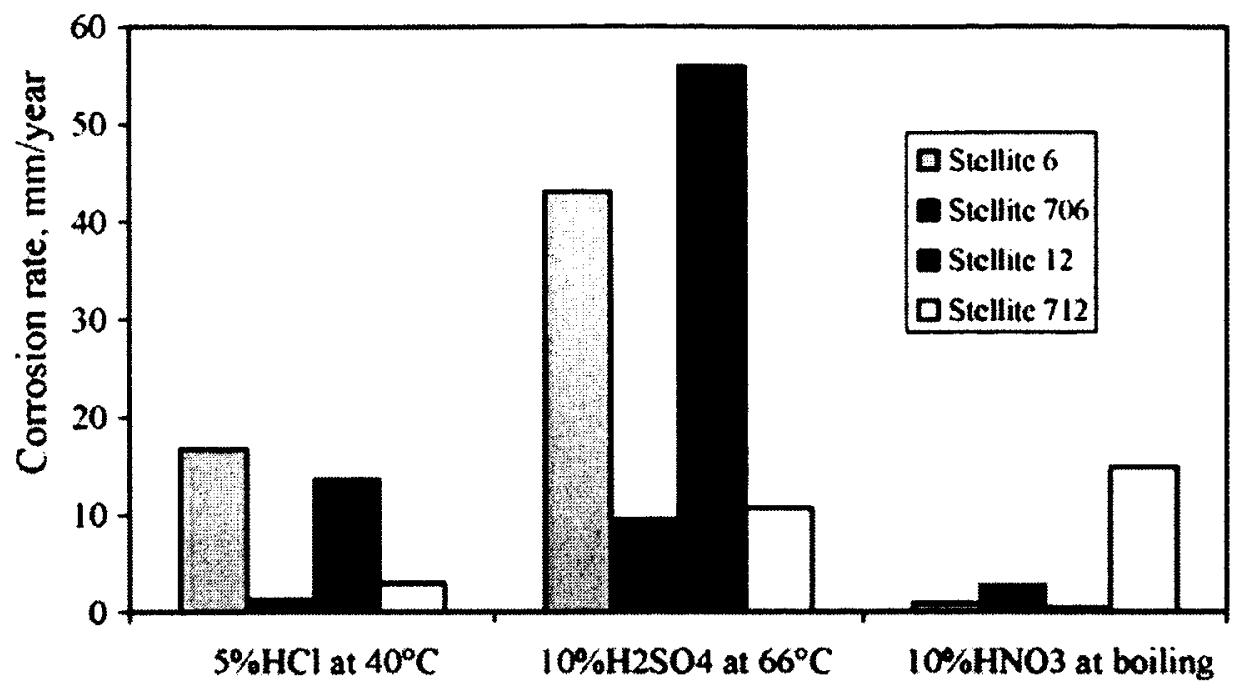

Figure 2-2: Corrosion resistance of W-containing Stellite 6 and Stellite 12 and

Mo-containing Stellite 706 and Stellite 712 [2].

As reported from another research, other alloying additives, such as $\mathrm{Cu}, \mathrm{Ni}$ or $\mathrm{Mo}$, were studied in order to understand the corrosion and oxidation behavior of Stellite alloys [27]. Six alloys containing similar amounts of carbon, chromium, and tungsten but different levels of nickel, copper and molybdenum, see Table 2-2, were tested in $10 \% \mathrm{H}_{2} \mathrm{SO}_{4}$ and in a composite aqueous solution according to the formula: $28 \% \mathrm{P}_{2} \mathrm{O}_{4}+13 \% \mathrm{H}_{2} \mathrm{SO}_{4}+2 \%$ $\mathrm{HF}$ at room temperature for $192 \mathrm{~h}$ plus at $60^{\circ} \mathrm{C}$ for $140 \mathrm{~h}$. 
Table 2-2: Chemical compositions (wt \%, Co in balance) of Stellite alloys for corrosion tests

\begin{tabular}{|c|c|c|c|c|c|c|}
\hline Alloy & C & Cr & W & Ni & Cu & Mo \\
\hline Specimen 1 & 2.1 & 31 & 12.3 & & & \\
\hline Specimen 2 & 2.1 & 32.2 & 12.5 & 19.5 & & \\
\hline Specimen 3 & 2.2 & 32.2 & 13.9 & 18.8 & & 8.9 \\
\hline Specimen 4 & 2.3 & 32 & 14 & & & 9.4 \\
\hline Specimen 5 & 2.1 & 32.2 & 13.1 & 17.6 & 4.3 & \\
\hline Specimen 6 & 2.2 & 31 & 15.2 & 18.2 & 4 & 8.7 \\
\hline
\end{tabular}

The experimental data plotted in Figure 2-3 illustrate the corrosion performances of the alloys in terms of weight loss. Although the alloy with additions of $\mathrm{Ni}, \mathrm{Cu}$ and $\mathrm{Mo}$, specimen 6 , shows an extremely high weight loss at room temperature, it exhibits higher corrosion resistance at $60^{\circ} \mathrm{C}$, compared to specimen 5 . This indicates that Mo has the ability to improve the corrosion resistance of the alloy at elevated temperatures. 


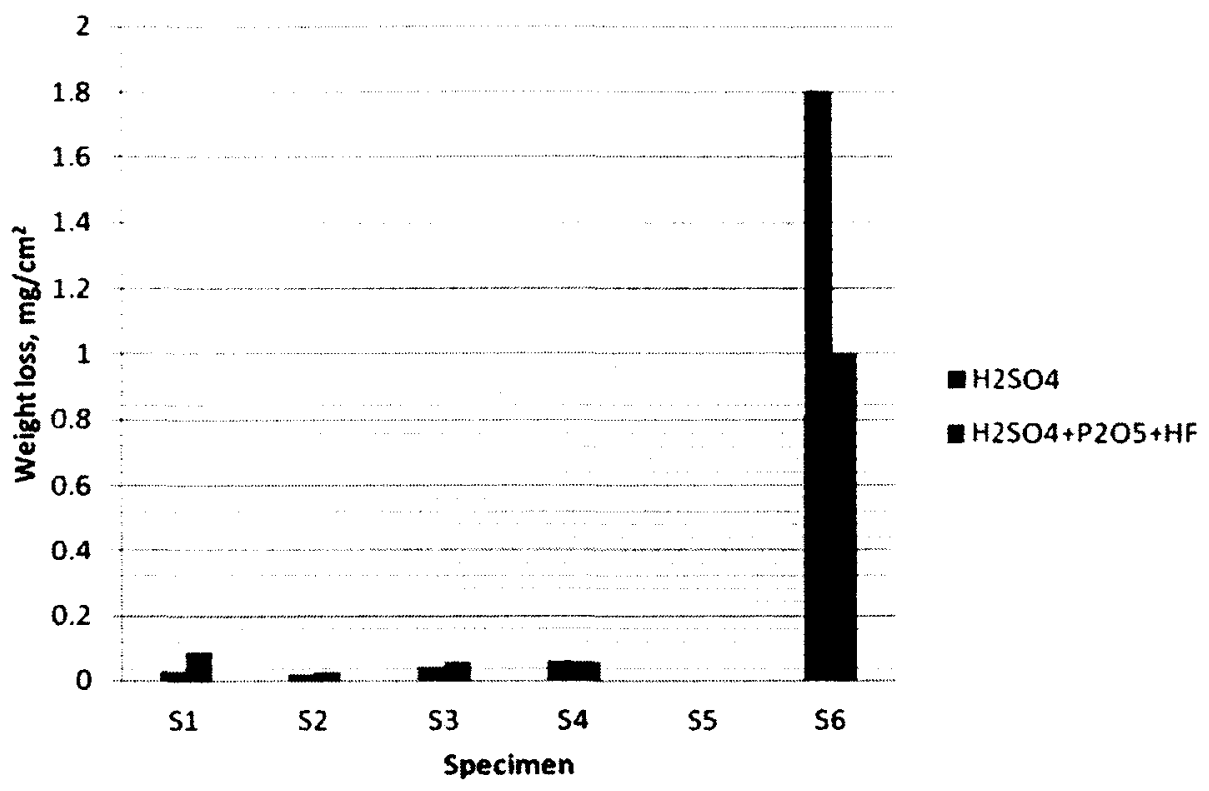

(a)

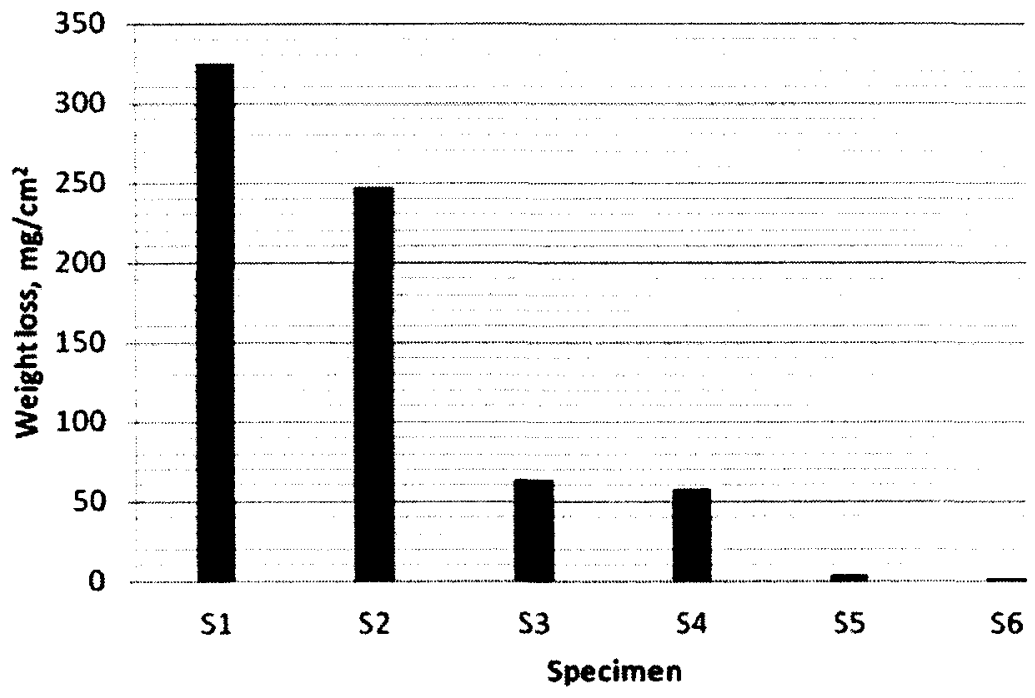

(b)

Figure 2-3: Corrosion resistance of Stellite alloys with $\mathrm{Ni}, \mathrm{Cu}$ and $\mathrm{Mo}$ contents:

(a) at room temperature; (b) at $60^{\circ} \mathrm{C}$ in $28 \% \mathrm{P}_{2} \mathrm{O}_{4}+13 \% \mathrm{H}_{2} \mathrm{SO}_{4}+2 \%$ HF [27]. 


\subsubsection{Tribological properties and hardness}

The major application of Stellite alloys is wear resistance. Therefore, Stellite alloys are all wear-resistant, compared to other metallic materials, such as stainless steel, carbon steel, copper alloys, and so on. The excellent wear resistance of Stellite alloy is attributed to both the tough solid solution matrix and the hard carbides. Wear can occur in a number of modes, but traditionally three main types of wear include abrasive wear, adhesive wear and erosive wear, which categorize the field of tribology [28]. For abrasive wear, the wear resistance of Stellite alloys generally increases as the volume fraction of the hard phase increases. Abrasion resistance is, however, strongly influenced by the size and shape of the hard phase precipitates within the microstructure, and the size and shape of the abrading species. Sliding wear generally occurs by three mechanisms: oxide control, contact stress and subsurface fatigue. Therefore, the Stellite alloys which perform well under sliding conditions do so either by virtue of their oxidation behavior or their ability to resistance deformation and fracture; thus their sliding-wear properties are controlled predominantly by the matrix, instead of the hard phases, and the resistance to galling is generally independent of hard-particle volume fraction and overall hardness. Erosion wear can be classified into solid-particle erosion, slurry erosion or liquid-solid particle erosion, liquid-droplet erosion and cavitation erosion. With the complex mechanisms of the erosions, however, the general abrasion mechanism may not be warranted. For example, in solid-particle erosion, ductility of Stellite alloys can also be a factor. As for the last two types of erosion, the performance of Stellite alloys largely depend on their ability to absorb the shock (stress) waves without, essentially, microscopic fracture. The 
carbide volume fraction, hence bulk hardness, has very little effect on resistance to these erosions [29].

Most of Stellite alloys exhibit very high hardness, i.e., between HRC 40 to $\mathrm{HRC} 63$, as they contain a high proportion of hard, wear-resistant carbides and the hard solid-solution interface, which makes them very suitable to serve in wear conditions. Stellite alloys can retain their hardness at temperatures in excess of $760^{\circ} \mathrm{C}$ [29].

\subsubsection{Mechanical properties}

Stellite alloys generally possess high Young's modulus and tensile strength but low elongation due to the nature of their microstructures. Because of the presence of a large volume fraction of carbides, most of Stellite alloys are very brittle, except low-carbon Stellite alloys such as Stellite 21 and Stellite 25 . By measuring the short-time tensile properties, Stellite alloys mechanical strength can be evaluated. A previous study of Stellite 21 has reported its mechanical properties [24]. As shown in Figure 2-4, in the as-cast condition the tensile elongation is about $8 \%$ at room temperature and rises fairly steadily with increasing temperature. After the alloy was aged for $50 \mathrm{~h}$ at $732^{\circ} \mathrm{C}$, however, hardening by carbide precipitation reduced the room-temperature elongation to $1 \sim 2 \%$ and the recovery of the ductility only occurred at temperatures above the aging temperature. Wrought alloys generally have better tensile elongation than cast alloys, 
owing to the hot working process, the high ductility makes them particularly suitable for manufacturing sheet metal components by either hot or cold forming.

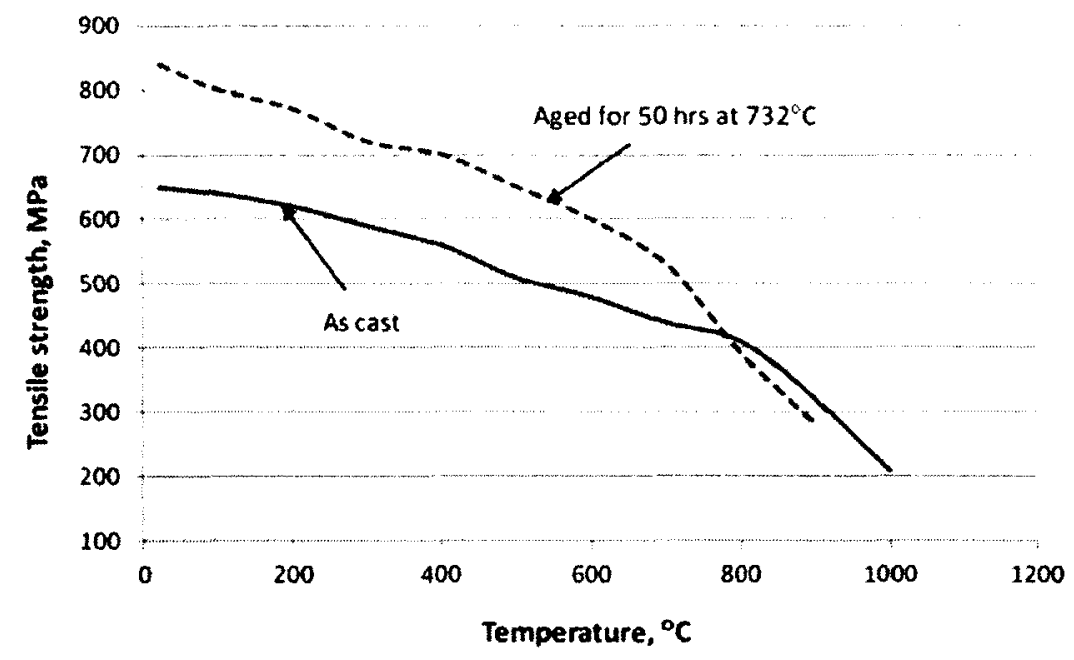

(a)

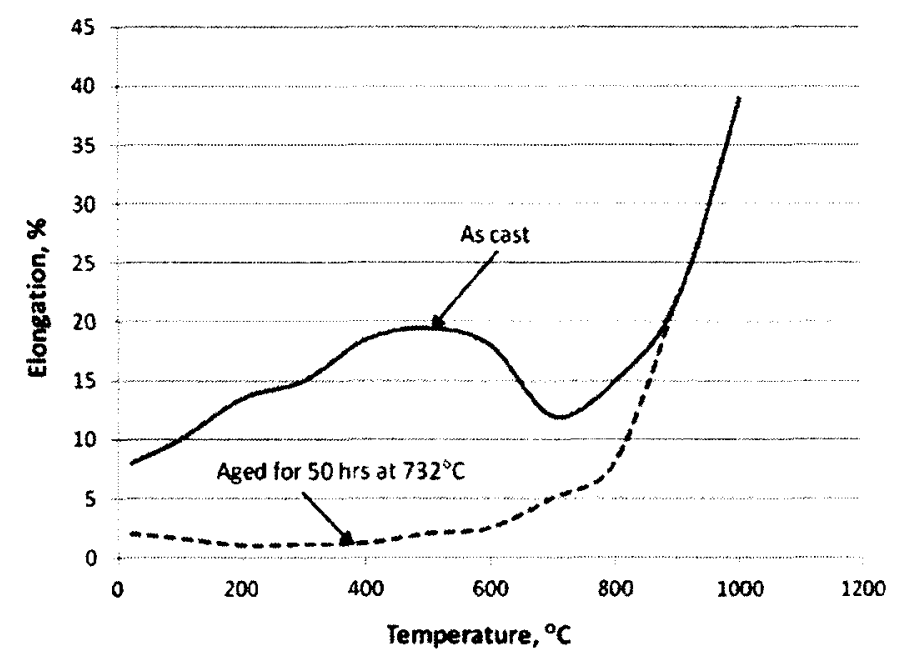

(b)

Figure 2-4: Tensile properties of Stellite 21: (a) tensile strength and (b) elongation [24]. 


\subsection{Methods of corrosion studies}

There are commonly two approaches to investigating the corrosion behavior of materials. One is referred to as electrochemical methods and the other is immersion tests. Other optical analysis technologies, such as Scanning Electron Microscope (SEM), Energy Dispersive X-ray Detector (EDX), X-Ray Diffraction (XRD), X-ray Photoelectron Spectroscopy (XPS), etc., are usually combined with the above two main methods in order to analyze materials regarding elements and microstructures.

\subsubsection{Electrochemical methods}

Corrosion is an electrochemical reaction process, accompanying simultaneously two opposite reactions based on redox reactions, i.e., reduction and oxidation. In such a corrosion process, metal ions in the electrolyte are reduced and then deposited on the electrode surface (cathode); while the corroding metal atoms oxidize, becoming ions, and dissolving from the electrode (anode) surface into the electrolyte. Corrosion is basically governed by electrochemical kinetics [7]. The driving force is the difference in potentials of the electrodes, and the corrosion rate is related to the flow rate of electrode current through a metal-electrolyte interface. The electrode current $(I)$ is the quantity monitored in investigating a corrosion process by means of electronic measurement. Figure 2-5 shows schematically a typical electrochemical measurement system with three electrodes: working electrode, counter electrode, and reference electrode [7]. In a potentiostatic approach, a fixed working electrode potential to reference electrode is maintained 
regardless of the variations in the current corresponding to the changes in the rates of corrosion. This method can investigate the potential behavior of metals easily and is favored in many applications. A typical hypothetical polarization curve, obtained from an electrochemical measurement method is shown in Figure 2-6. On this curve, there are two major portions: cathodic region and anodic region. The linear polarization relation covers both anodic and cathodic regions of the polarization curve (potential vs. current density). From the turning point of two regions, the corrosion potential $\left(E_{\text {corr }}\right)$, current density $\left(I_{c o r r}\right)$ and polarization resistance $\left(R_{p}\right)$ can be calculated by following Tafel extrapolation method. $\beta_{a}$ and $\beta_{c}$ are two Tafel parameters, also named anodic slope and cathodic slope respectively. Other parameters list on Table 2-3 also can be defined from the polarization curve.

Table 2-3: Polarization relevant parameters

\begin{tabular}{|l|l|}
\hline $\boldsymbol{i}_{p}$ & passive current density \\
\hline $\boldsymbol{i}_{c o r r}$ & corrosion current density \\
\hline $\boldsymbol{i}_{s}$ & secondary current density \\
\hline $\boldsymbol{i}_{c}$ & critical current density \\
\hline $\boldsymbol{i}_{\max }$ & maximum current density \\
\hline $\boldsymbol{E}_{p a}$ & passive potential \\
\hline $\boldsymbol{E}_{c o r r}$ & corrosion potential \\
\hline $\boldsymbol{E}_{o 2}$ & oxygen evolution potential \\
\hline $\boldsymbol{E}_{p p}$ & primary passive potential \\
\hline $\boldsymbol{E}_{p}$ & pitting potential \\
\hline
\end{tabular}




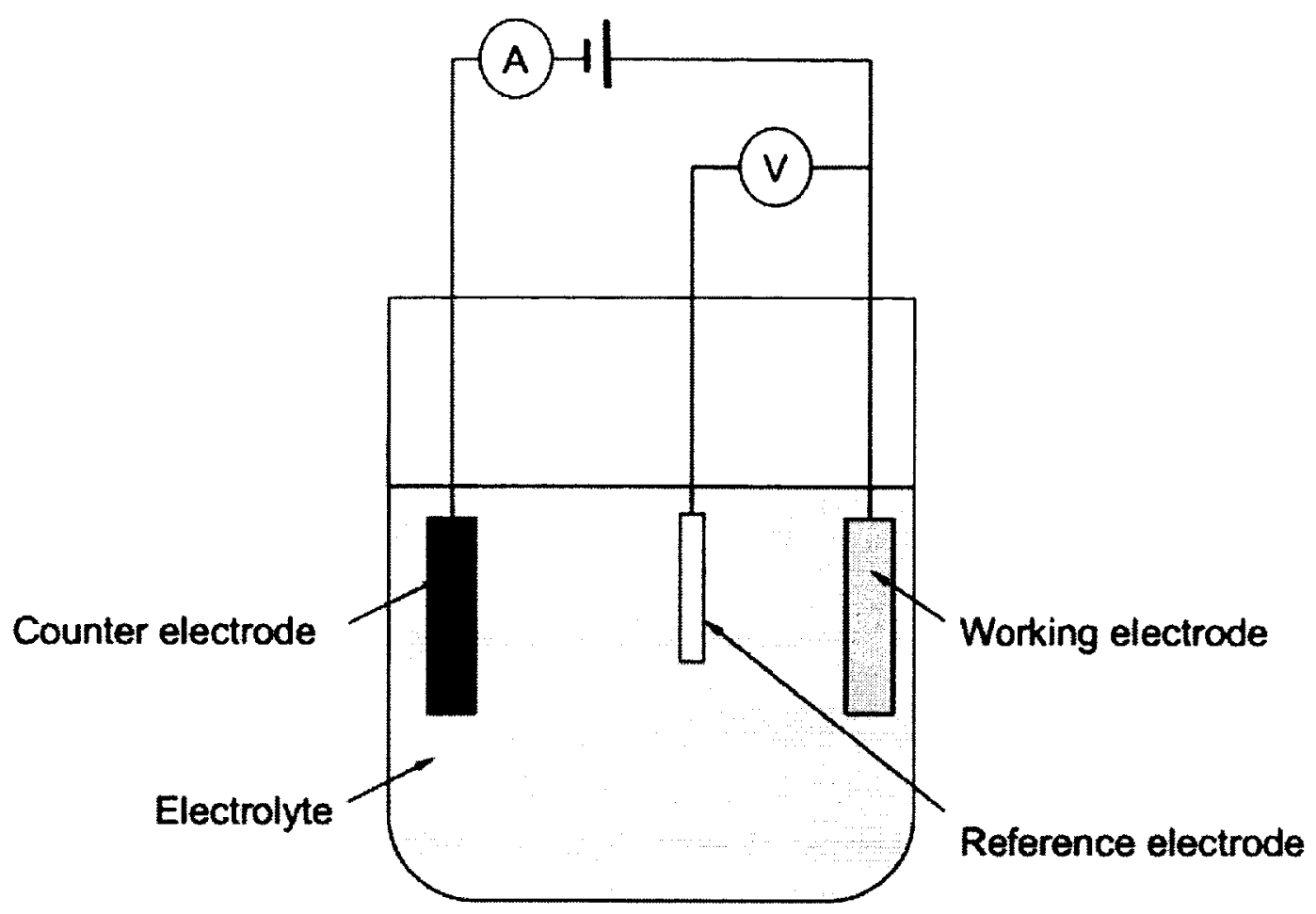

Figure 2-5: Schematic diagram of three-electrode electrochemical cell [7]. 


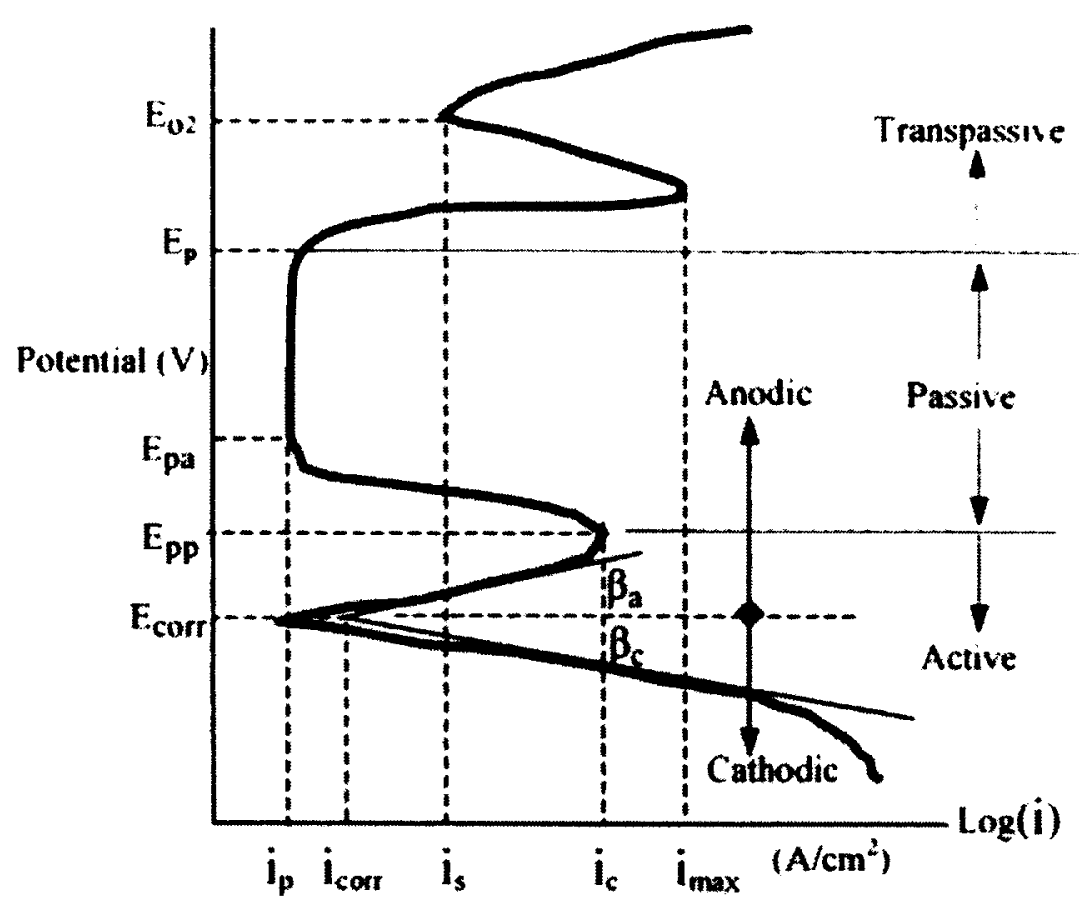

Figure 2-6: A typical hypothetical polarization curve defining the parameters [7].

Electrochemical Impedance Spectroscopy (EIS) test is also popular in many corrosion studies. It is an alternating current polarization experimental technique characterizing electrochemical systems. This technique measures the impedance of a system over a range of frequencies corresponding to different interfaces in an electrolytic cell system. A series of electrochemical parameters can be determined in this method, including double ohmic resistance and capacitance of double layer, charge transfer resistance, etc. Typical EIS data are plotted in Nyquist plots, Bode plots $(\log |Z| v s \cdot \log f)$ and Bode plots ( phase angle vs. $\log f$ ), as shown in Figure 2-7. 

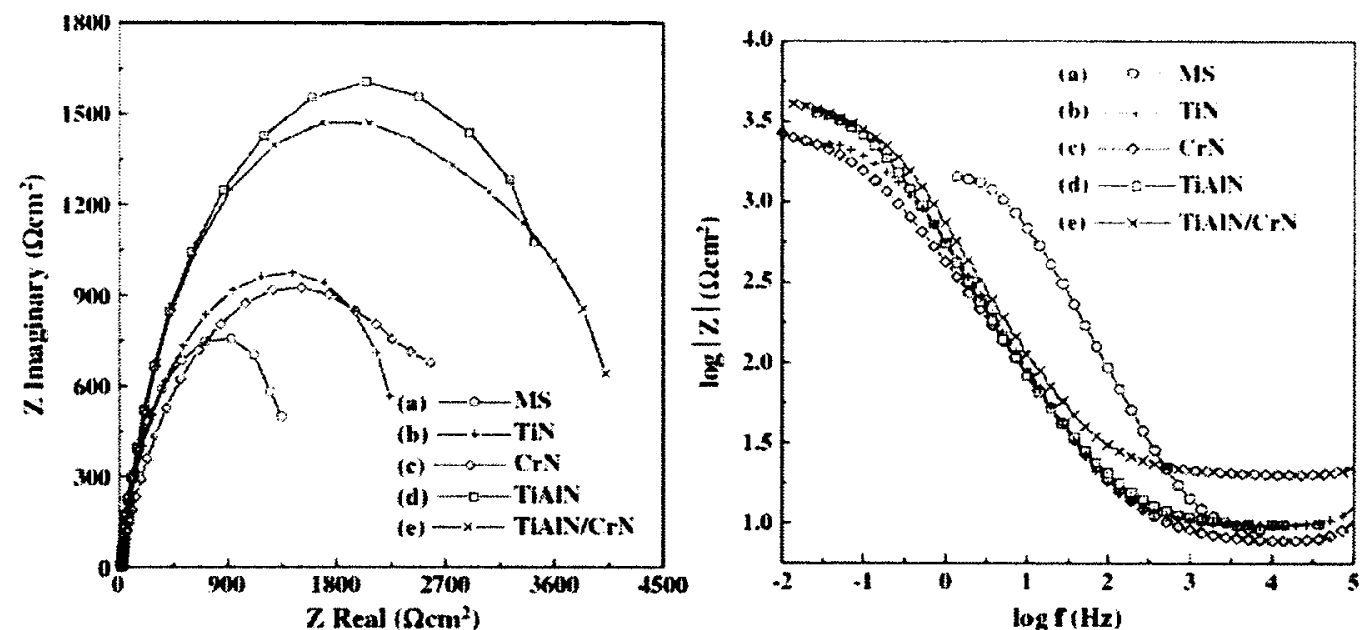

(a) Nyquist plots

(b) Bode plots $(\log |Z|$ vs. $\log n$

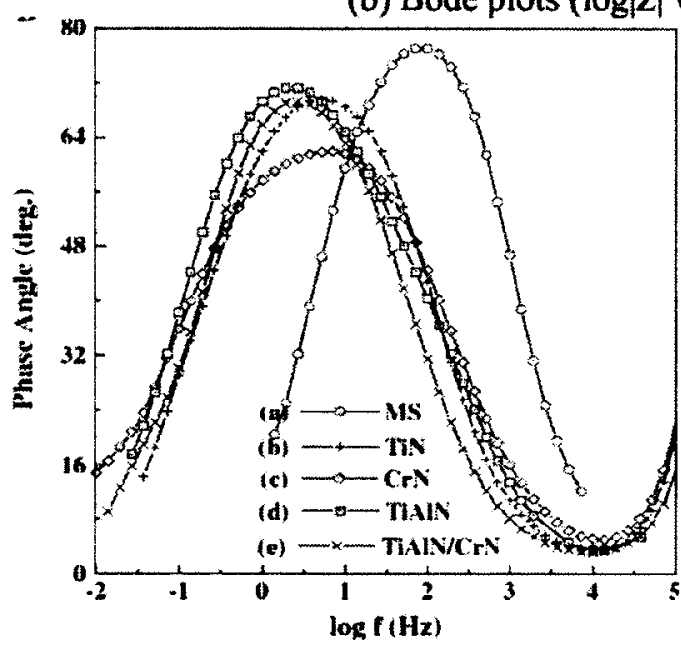

(c) Bode plots (phase angle vs. $\log f$ )

Figure 2-7: EIS curves for $\mathrm{Ti}-$ and $\mathrm{Cr}$-based nitride coatings in $3.5 \mathrm{wt} \% \mathrm{NaCl}$ solution [30]. 


\subsubsection{Immersion test methods}

Immersion test method is a traditional approach for corrosion study. The basis of this method is to simulate real work circumstances as much as possible, or use strong corrosive media to accelerate corrosion process in order to collect corrosion data or compare different materials in one discipline. In this method, the concentrated corrosive media, $\mathrm{pH}$ value, test temperature, exposure time, and pressure, etc., are selected as control variables in the studies. As shown in Figure 2-2 and Figure 2-3, the testing data can be assessed in various ways, such as weight change (loss or gain), volume change (loss or gain), pits depth, and so on. From the micro-morphology standpoint, the immersion-tested specimen can also be examined and analyzed using SEM and XRD, EDX and XPS. The last two enable the investigation of chemical element transformation.

\subsection{Extreme Value Analysis (EVA) models}

\subsubsection{Extreme value theory and models}

The Extreme Value Analysis (EVA) is a statistics tool that can be used to analyze the immersion test data and thus to provide a life prediction for the tested material.

The Gumbel distribution, named after Emil Julius Gumbel (1891-1966), has been used for setting up distribution models of the maximum (or the minimum) of a number of samples of various distributions. When this probability theory was developed, it was 
expected to predict several types of nature calamities by analyzing the historical data, such as flood, wind, earthquake, and so on, but this theory has also been used in data analyses of corrosion tests. It was reported that the extreme value theory (or block maxima) and peak over threshold approaches were applied to processing pitting and crevice corrosion data from various laboratory-simulated situations $[31,32,34]$. The examples of various experiments utilizing this analysis tool include the test of carbon steel BS 4360 50D in simulated sea water [31]; investigation of the crevice depths of 380 cast aluminum and 2024-T3 aluminum under salt spray environment [32]; the corrosion immersion test of AP-5L X52 pipeline steel in a simulated real working soil surroundings environment [11], etc. The procedure of this analysis method is described below:

Let $X_{1}, \ldots, X_{n}$ be a sequence of independent and identically distributed variables with distribution function $F$ and let $M_{n}=\max \left(X_{1}, \ldots, X_{n}\right)$ denote the maximum. In theory, the exact distribution of the maximum can be derived:

$$
P_{r}\left(M_{n} \leq z\right)=P_{r}\left(X_{1} \leq z, \ldots, X_{n} \leq z\right)=P_{r}\left(X_{1} \leq z\right) \ldots P_{r}\left(X_{n} \leq z\right)=(F(z))^{n}
$$

However, in practice, we might not know the distribution function $F$. On the other hand, according to Fisher-Tippett-Gnedenko theorem, if a sequence of pairs of real numbers $\left(a_{n}, b_{n}\right)$ exists such that each $a_{n}>0$ and: $\lim _{n \rightarrow \infty} P\left(\frac{M_{n}-b_{n}}{a_{n}} \leq x\right)=F(x)$ then if $F$ is a non-degenerate distribution function, it belongs to one of the following families: Gumbel, Fréchet and Weibull. A generalized extreme value distribution is expressed as: 


$$
F(z)=\exp \left\{-\left[1+\xi\left(\frac{z-\mu}{\sigma}\right)\right]^{-\frac{1}{\xi}}\right\}, 1+\xi\left(\frac{z-\mu}{\sigma}\right)>0, \xi \neq 0
$$

where: $z$ zis the extreme value of the depth;

$\mu$ is the location parameter of the extreme value distribution;

$\sigma$ is the scale parameter of the extreme value distribution;

$\xi$ is the shape parameter of the extreme value distribution.

When $\xi=0$, or interpret it as the limit of Eq. (2-2) as $\xi \rightarrow 0$, the Gumbel distribution is obtained as described by Eq. (2-3). If $\xi>0$ and $\xi<0$, the Fréchet and Weibull distributions are obtained respectively. These distributions are special cases of a more general extreme value distribution.

$$
F(z)=\exp \left\{-\exp \left[-\frac{z-\mu}{\sigma}\right]\right\}, \quad-\infty<z<\infty
$$

$\mu$ and $\sigma$ are the location and shape parameters respectively.

\subsubsection{Application of EVA to corrosion tests}

Corrosion test results are often more scattered than many other test results because of a variety of factors, including the fact that minor impurities often play a decisive role in controlling corrosion rates. Statistical analysis methods can be very helpful in allowing 
the investigators to interpret such results, especially in determining when test results differ from one another significantly. This can be a difficult task when a variety of materials are under test, but statistics methods provide a rational approach to this problem.

In corrosion tests, it is generally observed that average values are useful in characterizing corrosion rates. However, in cases of penetration from pitting and cracking, failure is often defined as the first through penetration and then in such cases, average penetration rates or times are of little value. In these cases, extreme value analysis may provide more reasonable information to understand corrosion behavior.

Pitting corrosion cannot be evaluated correctly only by mass loss, unless general corrosion is trivial and pitting is fairly severe. It would not obtain entire phenomena that may occur in the specimen surface when using small test specimens, since the occurrence of pitting is often a statistical phenomenon and its incidence can be directly related to the area of metal exposed. If uniform corrosion is significant, the contribution of pitting to total metal loss is small, and pitting damage cannot be determined accurately from mass loss. In any cases, mass loss can only provide information about total metal loss due to pitting but nothing about depth of penetration. However mass loss should not be neglected in every case because it also has effects; for example, mass loss along with a 
visual comparison of pitted surfaces may be adequate to evaluate the pitting resistance of a group of alloys in laboratory tests.

Pitting can occur on an unshielded metal surface and lead to failure of the material, but displaying a low general corrosion rate. Pitting often occurs in passive type materials such as some grades of aluminum and stainless steel; it may also occur on some copper base and nickel base alloys. The environment for pitting usually contains an aggressive ion, such as chloride, and the environment can be more aggressive if it is oxidizing [33].

Pitting test data should include a measurement of the maximum pit depth within the test period and a description of the following characteristics of the pit: (1) shape - jagged, circular, elongated, (2) cross section - shallow, deep, rounded, conical, undercut, and (3) amount - superficial, scattered, profuse, isolated [33].

Pits may have various sizes and shapes. Visual examination of the metal surface may show a round, elongated, or irregular opening, but it seldom provides an accurate indication of corrosion beneath the surface. Therefore, it is often necessary to cross section the pit to view its internal shape and thus to determine its true depth. Several variations in the cross-sectioned shape of pits are shown in Figure 2-8 [33]. 


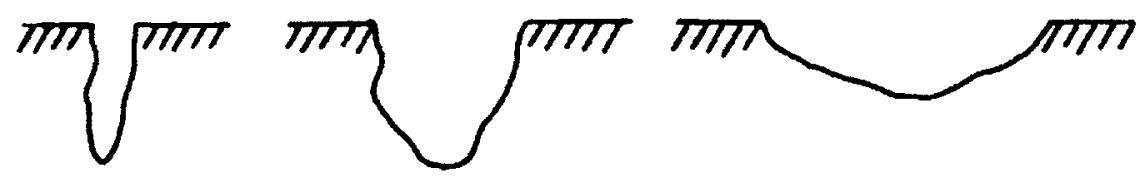

(a) Narrow, Deep

(b) Elliptical

(c) Wide, Shallow

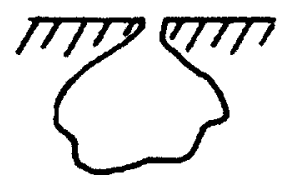

(d) Subsurtace

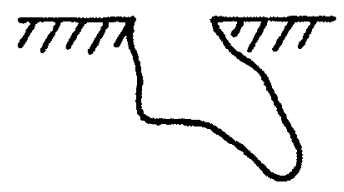

(e) Undercutting

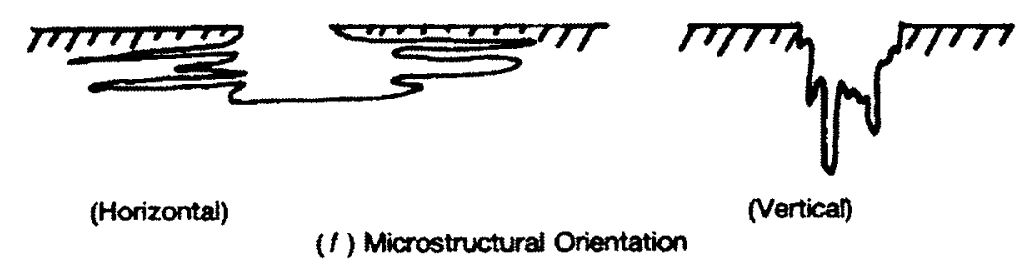

Figure 2-8: Variations in the Cross-Sectional profile of Pits [33].

Pit depth can also be expressed in terms of a pitting factor, which is the ratio of the deepest pit depth to the average pits depth, the larger the number, the greater the depth of penetration, as shown in the following relationship [33]:

$$
\text { Pitting Factor }=\frac{\text { deepest pit depth }}{\text { average pits depth }}
$$


Extreme value probability statistics methods have been applied successfully to obtaining the maximum pit depth data that estimate the maximum pit depth of a large area of a material on the basis of examining a small portion of that area.

Making an assumption that corrosion of a surface is uniform is a way to simplify the complex situations of corrosion and make the corrosion parameters easy to be calculated. However, there is still a problem in characterizing the corrosion behavior appropriately. For a material under corrosion, the parameter "penetration" can be the key factor in determining the time to failure of the material. As usual, the mean value of depth can be used to analyze the corrosion data, which neglects the extreme value, but in practice, there are many applications where the environment is well defined and the corroded surface is very rough and pitted severely. In these cases, the extreme value cannot be neglected. Extreme value statistics methods provide a means for assessing material service life at a given level of risk, given sets of thickness data that are taken over the area of interest within a period of time [34].

An alternative of traditional mean value analysis is to fit the maximum tail of the probability density function using an extreme value distribution. It is possible to fit the fraction of data corresponding to the deepest penetration to a type

I extreme value । provided that the maximum tail of the depth probability distribution function decreases at least as rapidly as an exponential function [35]. The distinct benefits of using the 
the probability distribution function and the cumulative distribution function, and the corrosion rate can then be contained. The cumulative distribution function of extreme value function is given by Eq. (2-3) [31]:

Eq. (2-3) has a physical interpretation: $1-F(z)$ is the probability of obtaining a maximum depth measurement greater than some value of depth $(z)$. Consequently, $1-F(z)$ is a measure of the risk of accepting a given value of $z$ as the maximum penetration. Based on Figure 2-9 [31], $D_{R}$ is defined as depth, $\alpha$ is the risk of accepting $D_{R}$ as the maximum penetration, where $\alpha=1-F\left(D_{R}\right)$, then from Eq. (2-3), one can obtain:

$$
D_{R}=\mu+\sigma R
$$

where

$$
R=-\ln [-\ln (1-\alpha)]
$$




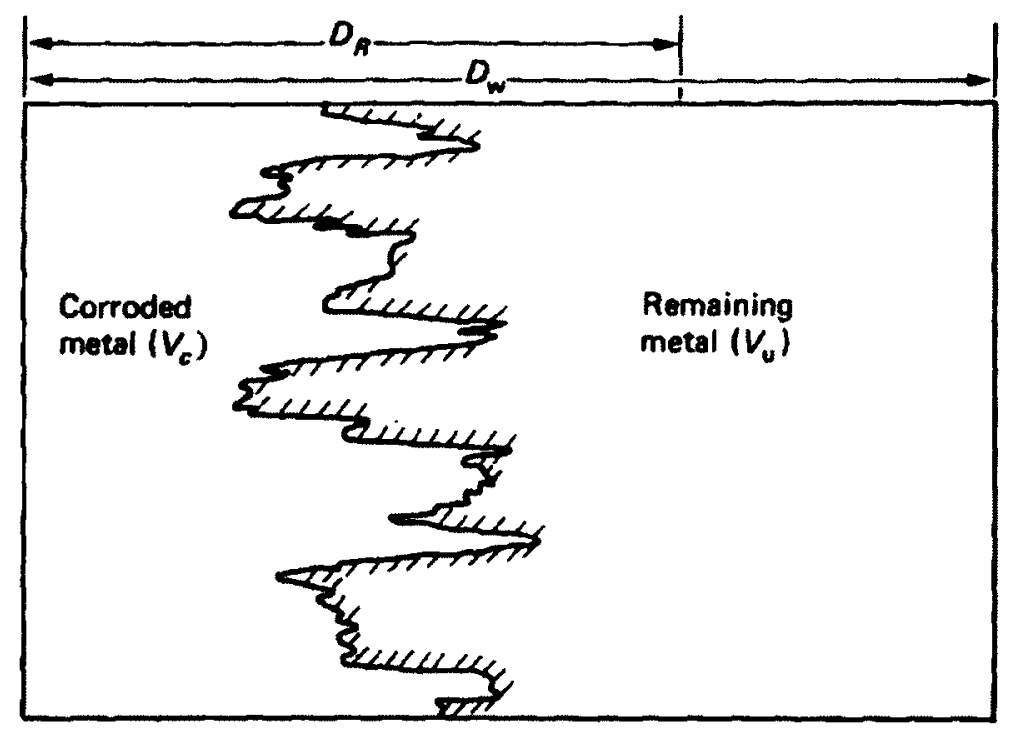

Figure 2-9: Corrosion pit profile [31].

After corrosion, if the total area $(A)$ of a specimen is divided into smaller areas $(a)$, then the maximum pit depths $\left(D_{R}\right)$ in these smaller segments follow an extreme value statistics (type-I, Gumbel distribution). Using the concept of return period-a statistical approach predicting the average recurrence interval over an extended period of time, the value of the cumulative extreme value distribution for the whole specimen is given by [32]:

$$
F=1-\frac{1}{\frac{A}{a}}=1-\frac{1}{n}
$$

where, $n$ is the number of data set. 
Substituting Eq. (2-6) and Eq. (2-7) into Eq. (2-5), the maximum pitting corrosion depth $\left(D_{R}\right)$, that is, the minimum requirement of metal thickness can be obtained from Eq. (2-8):

$$
D_{R}=-\ln \left[-\ln \left(1-\frac{1}{n}\right)\right] \sigma+\mu
$$

The procedure for finding the values of $\sigma$ and $\mu$ are described below. The former is scale parameter and the latter is location parameter.

(1) All extreme pit depth data should be ranked from shallowest to deepest with the shallowest being assigned a rank $r=1$, the next deepest $r=2$, and so on with $r=n$.

(2) The cumulative extreme value distribution is given by [32]:

$$
F=\frac{r}{n+1}
$$

where $r$ is the rank of the data and $n$ is the total number of data.

(3) Once the cumulative distribution is determined, $-\ln (-\ln F)$ is plotted against the pit depth.

(4) From Eq. (2-8), it is clear that the slop of this curve is the inverse of the scale parameter, that is, $\frac{1}{\sigma}$, and location parameter $\mu$ can be obtained from the point of intersection to the $x$-axis. 
Vajo et al. [32] have proved that the size of data used to derive the statistics does not alter the results significantly. Figure 2-10 illustrates the experimental evidence of this conclusion [32].

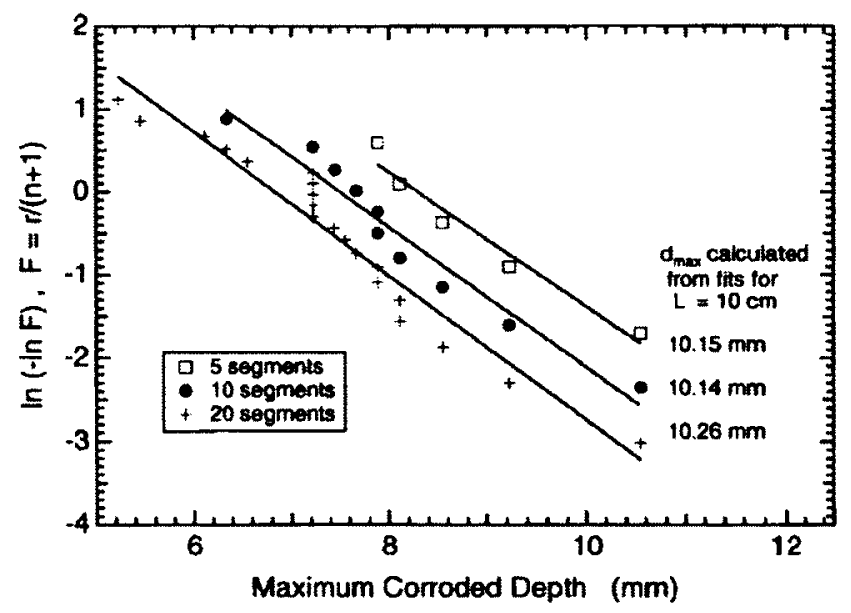

Figure 2-10: Results of three extreme value analyses, obtained by dividing the whole area into 5,10 , and 20 segments [32].

Substituting $\alpha=1-F$ into Eq. (2-8), the following equation can be obtained:

$$
D_{R}=-\ln [-\ln (1-\alpha)] \sigma+\mu
$$

In order to find a formula which can predict material lifetime without time limitation, the time parameter was introduced in the formula by J. E. Strutt et al. [31], they found that $\sigma$ and $\mu$ were linear against time. Figure 2-11 shows this relation. It is interesting to note that not only the most probable maximum depth (location parameter) increases with 
time, but also the width of the distribution (shape parameter). The time dependences of these parameters are shown clearly in Figure 2-12.

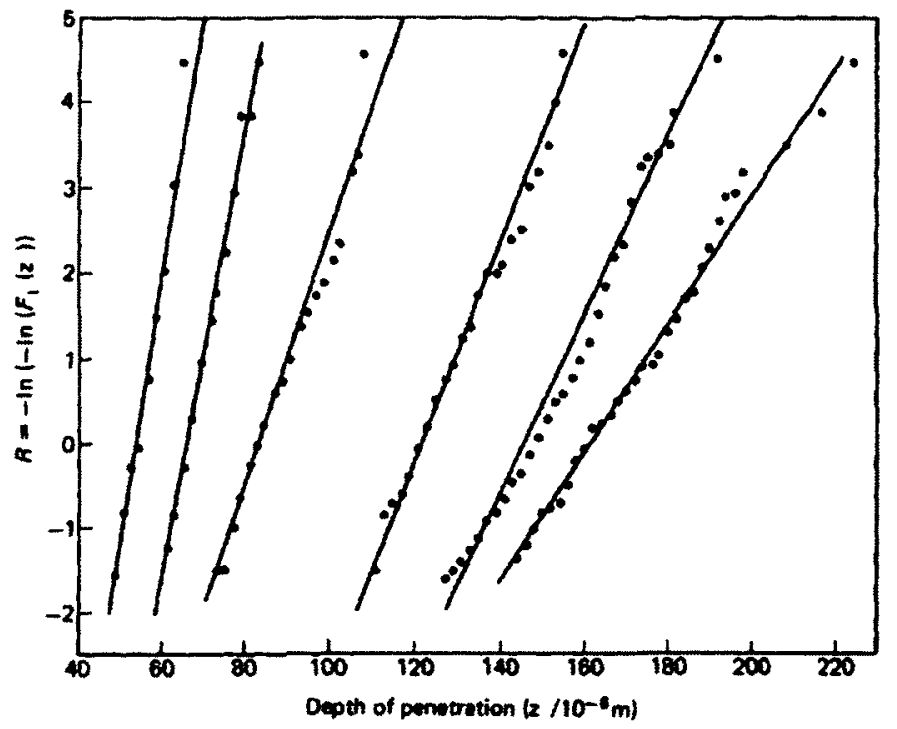

Figure 2-11: Variation of the extreme value function $-\ln [-\ln F(z)]$ with extreme depth $z$ [31].

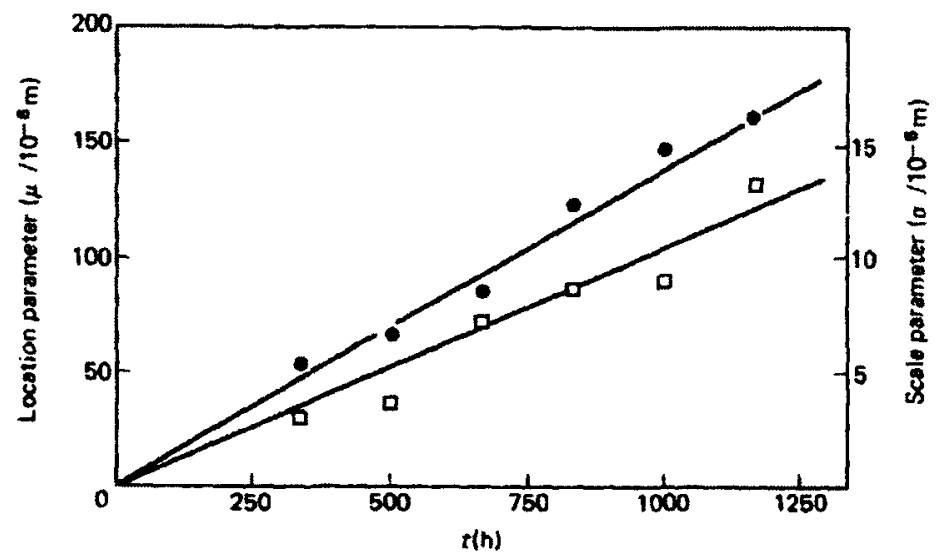

Figure 2-12: Variation of extreme value frequency distribution parameters with time of corrosion $\cdot \mu, \square \sigma[31]$. 
Since these two time-dependence parameters are all linear, a time parameter can be added into Eq. (2-5), giving a new expression [31]:

$$
D_{R}=(\gamma+\beta R) t
$$

where $\gamma$ is the slope of $(\mu, t) ; \beta$ is the slope of $(\sigma, t)$.

In Eq. $(2-11), R$ is determined by Eq. (2-6) which includes the risk $\alpha$. In this time-related form, the time parameter, $t$, is included, and the risk $\alpha$ is also taken into account. For a practical application, if the industry accepts a certain material which has a risk of $1 \%$ in its lifetime of 20 years, the minimum thickness of this material, $D_{R}$, can be predicted from this formula [31].

\section{Polarization test and data analysis}

Potentiodynamic polarization test and cyclic polarization test were conducted on Stellite 6B and Stellite $6 \mathrm{~K}$. The objectives of these tests were to investigate the general corrosion resistance and localized corrosion resistance of these alloys, through analyzing the polarization curves obtained from the tests. Two types of aqueous solution were used as corrosive media in this polarization test; they are $3.5 \mathrm{wt} \%$ sodium chloride $(\mathrm{NaCl})$ aqueous solution and Green Death solution (11.5\% sulfuric acid $+1.2 \%$ hydrochloric acid $+1 \%$ ferric chloride $+1 \%$ cupric chloride) [36]. The former is a common corrosive medium that is used to rank materials for corrosion resistance; the latter is a typical industry corrosive environment. 


\subsection{Specimen preparation}

\subsubsection{Chemical composition and microstructure}

The Stellite $6 \mathrm{~B}$ and Stellite $6 \mathrm{~K}$ specimens used in this research are wrought products. The chemical compositions of these two alloys are given in Table 3-1.

Table 3-1 Chemical Compositions (wt\%, Co in balance) of Stellite alloys

\begin{tabular}{|c|c|c|c|c|c|c|c|c|}
\hline Alloy & Cr & W & Mo & C & Fe & Ni & Si & Mn \\
\hline Stellite 6B & 30 & 4 & 1.5 & 1 & 3 & 2.5 & 0.7 & 1.4 \\
\hline Stellite 6K & 30 & 4.5 & 1.5 & 1.6 & 3 & 3 & 2 & 2 \\
\hline
\end{tabular}

These two alloys contain a same amount of $\mathrm{Cr}$ and a similar content of W, but Stellite $6 \mathrm{~K}$ contains higher $\mathrm{C}$ than Stellite $6 \mathrm{~B}$. Both of the alloys contain small amounts of Mo and Ni. The microstructures of these alloys were examined using a Hitachi Model S-570 Scanning Electron Microscope (SEM) with Backscatter Electron Imaging (BEI), shown in Figure 3-1. The obtained SEM images of microstructure of these two alloys are given in Figure 3-2 and Figure 3-3. The microstructures of these two alloys are similar because of the similar chemical composition and the same fabrication process. They all consist of primary Co solid solution and eutectic $\mathrm{Cr}_{7} \mathrm{C}_{3}$ carbides, but the carbide volume fraction of Stellite $6 \mathrm{~K}$ is obviously larger than that of satellite $6 \mathrm{~B}$ due to the high $\mathrm{C}$ content in the former, but the size of carbides in Stellite $6 \mathrm{~B}$ is larger than that in Stellite 6K. 


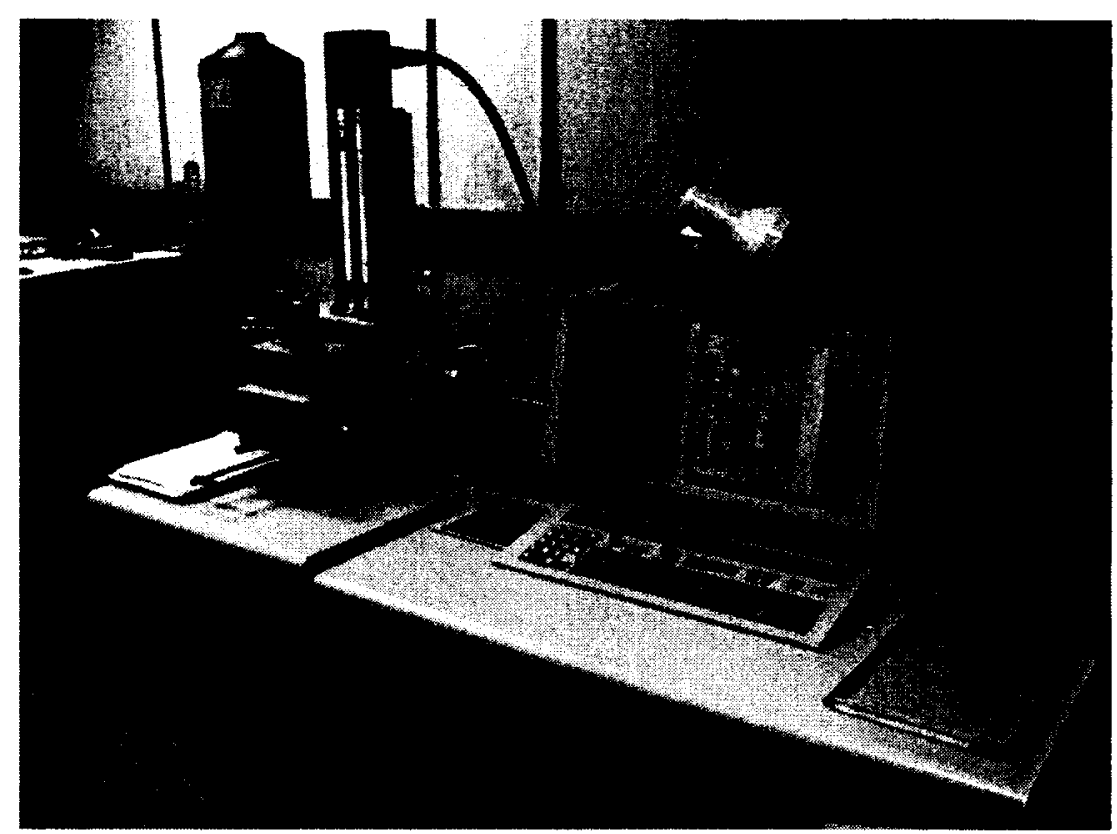

Figure 3-1: Hitachi Model S-570 Scanning Electron Microscope.

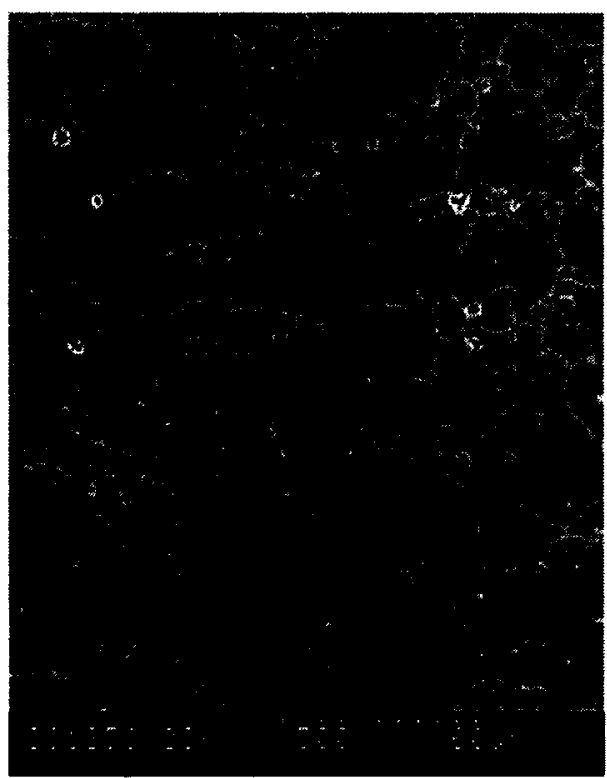

(a) 


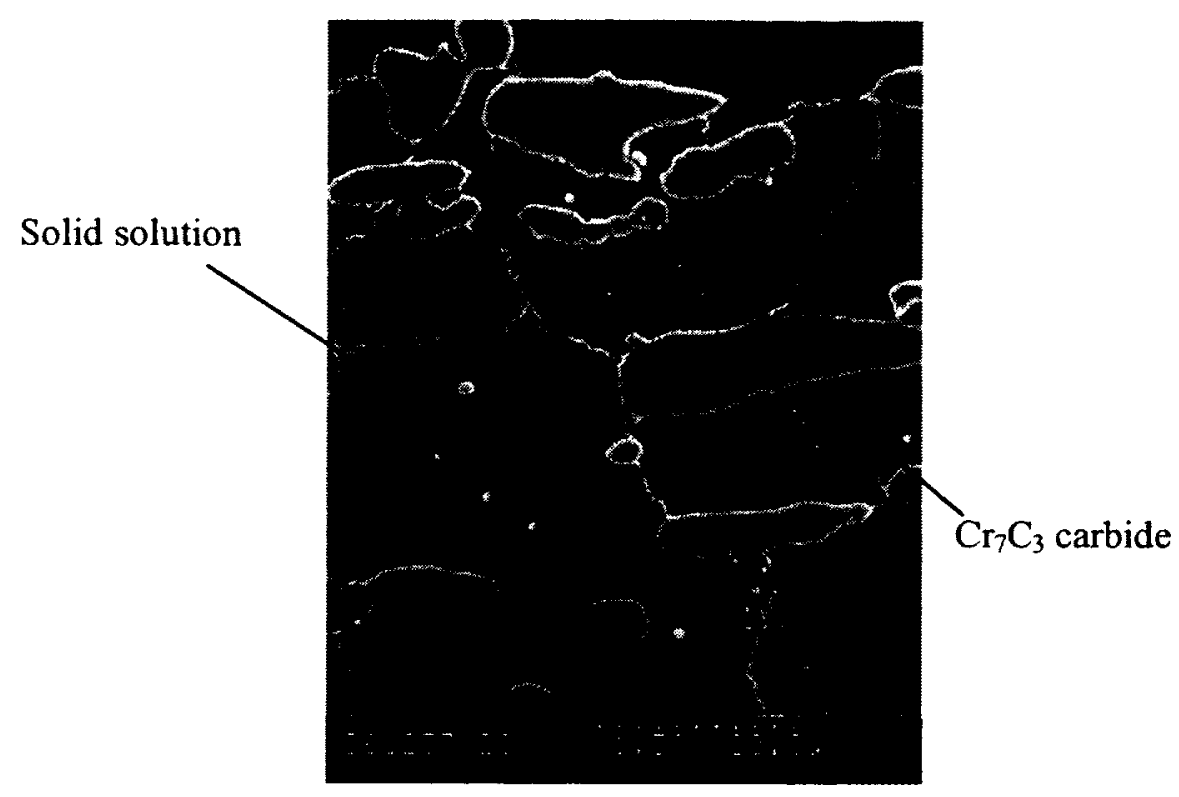

(b)

Figure 3-2: SEM microstructure of Stellite 6B: (a) at low magnification and (b) at high magnification.

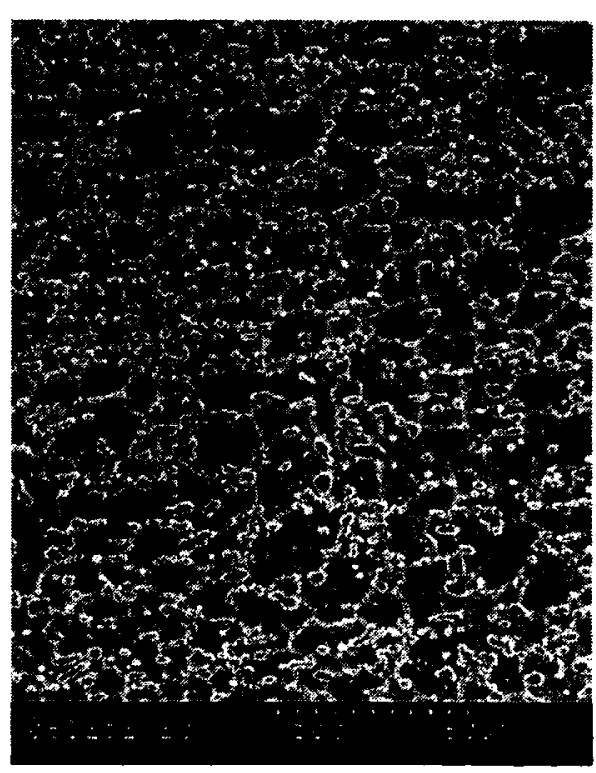

(a) 


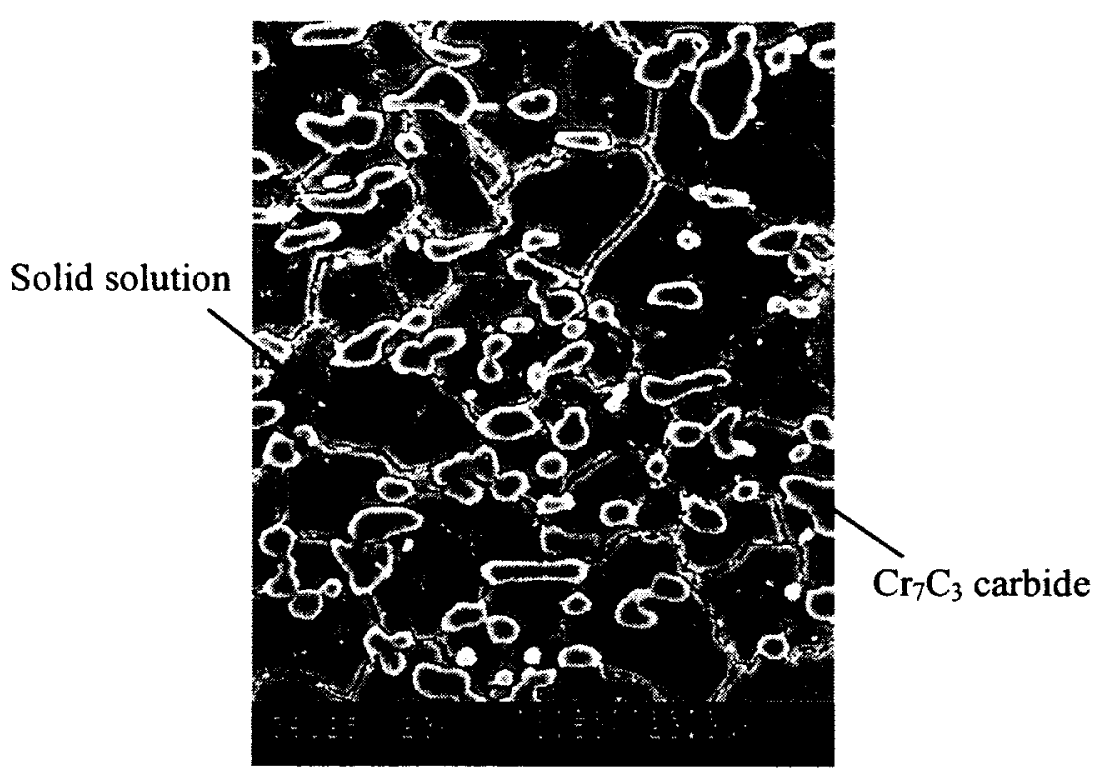

(b)

Figure 3-3: SEM microstructure of Stellite 6K: (a) at low magnification and (b) at high magnification.

\subsubsection{Surface polishing}

The Stellite $6 \mathrm{~B}$ and Stellite $6 \mathrm{~K}$ specimens were manufactured to round plates with a diameter of $16 \mathrm{~mm}$ and thickness of $1.6 \mathrm{~mm}$ for polarization tests. According to ASTM G59-97, Standard Test Method for Conducting Potentiodynamic Polarization Resistance Measurements [38], the specimens must be polished to meet the surface requirements before they are subjected to testing. The purpose of the surface polishing is to produce a mirror-like reflecting or bright surface. A completed polishing operation includes rough and final polishing steps. Rough polishing is performed to remove the damage that is produced during planar grinding. The specimen is roughly polished with sequentially 
decreasing abrasive paper grit sizes. Final polishing is performed to eliminate surface damages. To do this the specimen surface is lightly polished with $1 \mu \mathrm{m}$ diamond suspension on a specific polishing cloth. The specimen is thoroughly cleaned in an ultrasonic bath, before and after each step, since surface quality could be degraded by abrasion of the debris produced in preceding polishing.

The specimens of Stellite $6 \mathrm{~B}$ and Stellite $6 \mathrm{~K}$ were polished following the instructions outlined in the ASTM G59-97 standard. The surface grinding operation was performed automatically on a Buehler Ecomet-4 semiautomatic grinding machine, as photographed in Figure 3-4. In this operation, caution must be taken to ensure the specimens were mounted properly in the holder in order to maintain a flat surface for each specimen in the holder during the polishing process. To achieve this, the specimens had to be placed symmetrically in the holder so that the contact force would be equally applied on the specimen surfaces. After this operation, the surface layers of the wrought specimens were removed, thus the surface damage caused by cutting or punching would be certainly reduced. Four grit sizes of silicon carbide (SiC) abrasive paper (\#240, \#320, \#400, and \#600) were used in the grinding polish process. The following operation parameters were selected: a contact load of $30 \mathrm{~N}$ and a spindle speed of $250 \mathrm{rpm}$ with tap water flush. Water was used as the coolant to reduce the generated friction heat during grinding. The selection of these parameters depended on the hardness of the material being polished. 


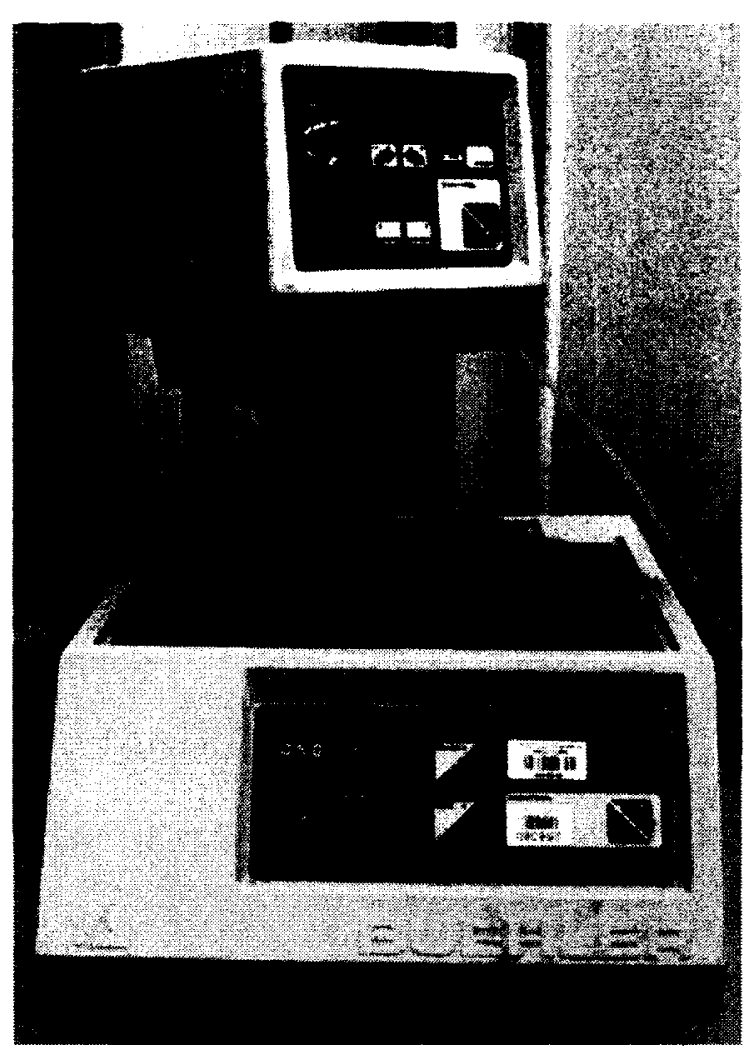

Figure 3-4: Buehler Ecomet-4 semiautomatic grinding machine.

\subsection{Solution preparation}

\subsubsection{Preparation of $3.5 \mathrm{wt} \% \mathrm{NaCl}$}

For each test, $2 \mathrm{~L}$ solution was prepared. The preparation procedures are given below:

(1) Weigh 70 g sodium chloride crystal;

(2) Dilute the sodium chloride with distilled water in a $500 \mathrm{ml}$ beaker, and stir the solution with a glass stick to let the sodium chloride fully dissolved;

(3) Pour the solution from the beaker to a $2 \mathrm{~L}$ long neck glass vessel, and then add distilled water to $2 \mathrm{~L}$; 
(4) Seal the vessel and store it. Shake the solution before using it, in order to get a homogeneous solution.

\subsubsection{Preparation of Green Death solution}

For each test, $2 \mathrm{~L}$ solution was prepared. The preparation procedures are given below:

(1) Pour about $200 \mathrm{ml}$ distilled water into $2 \mathrm{~L}$ long neck glass vessel;

(2) Decant $240 \mathrm{ml} 98 \%$ sulfuric acid slowly into the $2 \mathrm{~L}$ long neck glass vessel;

(3) Add $67 \mathrm{ml} \mathrm{35 \%} \mathrm{hydrochloride} \mathrm{acid} \mathrm{slowly} \mathrm{into} \mathrm{the} \mathrm{solution} \mathrm{in} \mathrm{the} \mathrm{glass} \mathrm{vessel;}$

(4) Weigh $20 \mathrm{~g}$ anhydrous ferric chloride and mix it into the solution;

(5) Weigh 32 g cupric chloride dehydrate and mix it into the solution;

(6) Fill the glass vessel with distilled water to $2 \mathrm{~L}$ and stir the solution to make sure that it is mixed uniformly.

\subsection{Polarization test}

Polarization test is one of electrochemical methods that has been adopted as a common testing method to discover the corrosion properties of metals. Polarization resistance of metals can be related to the rate of general corrosion for metals at or near their corrosion

potential $E_{c o r}$. Polarization resistance measurement provides an accurate and rapid approach to obtaining the general corrosion rate. Real time corrosion monitoring is a common application of this testing method [44]. 


\subsubsection{System setup}

In this research, the corrosion behavior of Stellite $6 \mathrm{~B}$ and Stellite $6 \mathrm{~K}$ was studied under potentiodynamic polarization and cyclic polarization, using a $\mathrm{Gamry}^{\mathrm{TM}} \mathrm{PC} 14^{\mathrm{TM}}$ potentiostat system, shown in Figure 3-5.

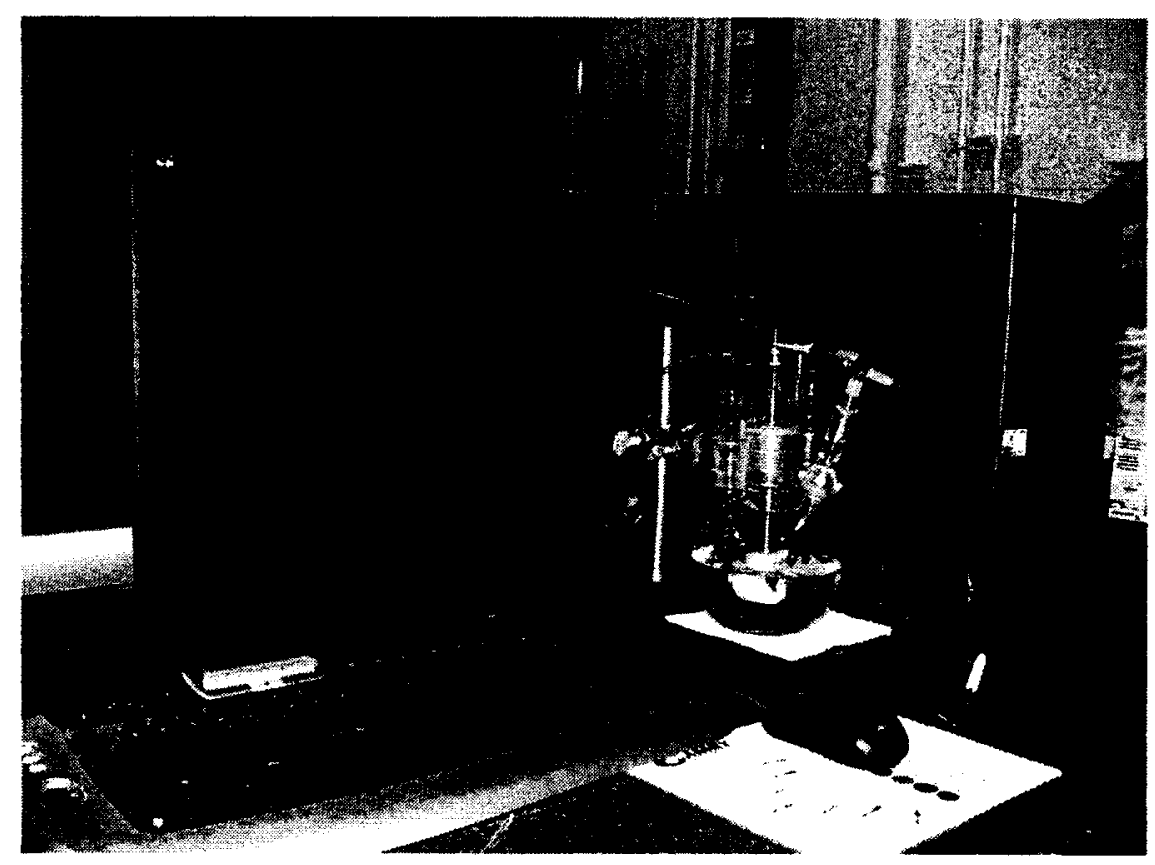

(a) System setup (IAR-NAR Canada) 


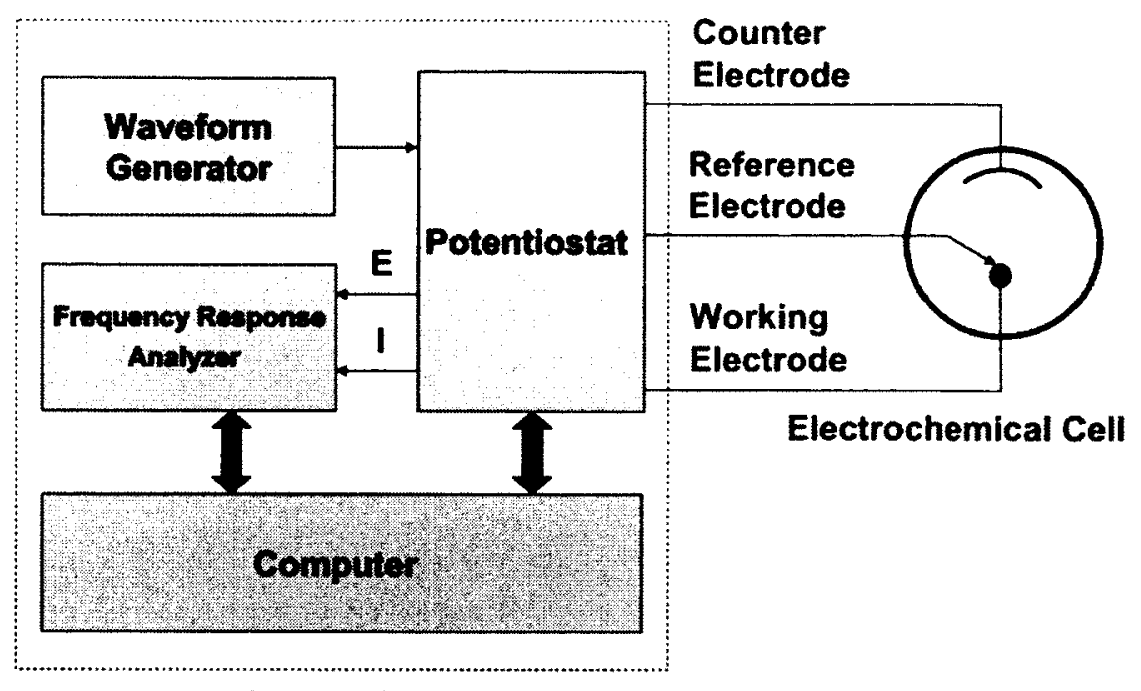

Control System

(b) Schematic diagram of the setup

Figure 3-5: electrochemical experimental setup.

The experimental system consists of an electrochemical cell and a control system that includes a data acquisition and analysis system. The electrochemical cell provides the corrosive environment for the measurement of electrochemical parameters, and consists of four primary components: (1) cell body, (2) electrolyte, (3) electrodes, and (4) devices monitoring and controlling the environment (Figure 3-6). 


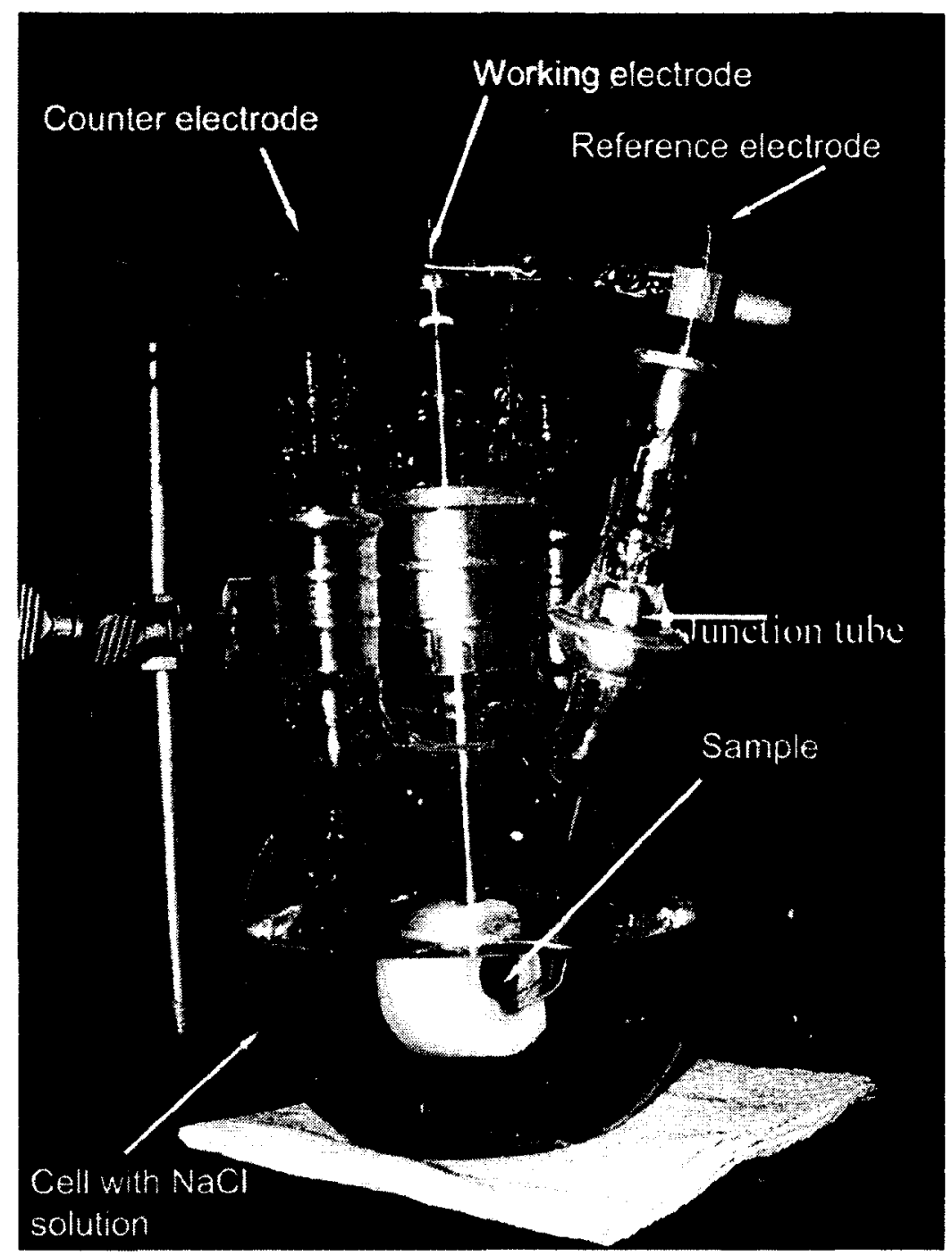

Figure 3-6: Electrochemical cell setup (IAR-NRC Canada).

The cell body is a glass cell, which can be used at temperatures ranging from room temperature to $100^{\circ} \mathrm{C}$ and is inert to the common electrolyte $-3.5 \mathrm{wt} \%$ sodium chloride $(\mathrm{NaCl})$ aqueous solution and Green Death solution $(11.5 \%$ $\mathrm{H}_{2} \mathrm{SO}_{4}+1.2 \% \mathrm{HCl}+1 \% \mathrm{FeCl}_{3}+1 \% \mathrm{CuCl}_{2}$ ). Electrodes include a working electrode (testing 
specimen), auxiliary or counter electrodes (two carbon rods), and a reference electrode. The specimen is mounted on a Teflon holder and the testing surface is pressed against an O-ring, which results in an exposed area of the surface to the electrolyte through the aperture about $10 \mathrm{~mm}$ in diameter.

In order to measure and control the potential across the interface between the specimen surface and electrolyte, termed as interfacial potential, a counter electrode is introduced, which is electrically connected to the working electrode through the electrolyte. To minimize the variation in the interfacial potential, a reference electrode is introduced between the working and counter electrodes. This type of system is referred as to a three-electrode system, which provides a controllable potential between the working and reference electrodes [37]. In this research a saturated mercury-mercury (II) chloride (calomel) electrode (SCE) was used as the reference electrode and all potential values obtained were against SCE. A glass junction tube connects the reference electrode and the working electrode.

The control system in the setup consists of a computer, a potentiostat, a waveform generator, and frequency response analyzer. The potentiostat keeps the working electrode potential at a constant level with respect to the reference electrode. The waveform generator provides the electrical signal that gates the flow of current to the cell. Data are 
collected by the computer, and then output to the frequency response analyzer for processing.

\subsubsection{Experimental procedure}

According to the American Society for Testing Materials ASTM G59 [38], Testing Methods ASTM G102 [39], and ASTM G5-94 [40], the electrochemical experimental procedures were developed as follows.

The specimen was immersed in the surrounding solution (corrosive medium) for a few minutes until the solution reached equilibrium to establish the steady state open-circuit potential $\left(E_{o c p}\right)$ [41]. In the potentiodynamic polarization test, the polarization scan started at $-300 \mathrm{mV}$ vs. open circuit potential and ended at $1500 \mathrm{mV}$ vs. SCE with a scan rate of $1 \mathrm{mV} / \mathrm{s}$. The scan could be terminated if the current density reached $1 \mathrm{~mA} / \mathrm{cm}^{2}$. Experimental data were collected and then analyzed with Gamry Electrochemistry DC105 ${ }^{\mathrm{TM}}$ software.

Additional cyclic potentiodynamic polarization tests were also performed to investigate the localized corrosion susceptibility of the specimens in Green Death solution. The cyclic potentiodynamic polarization measurement is to determine relative susceptibility to localized corrosion, that is, pitting and crevice corrosion, of a metal. The difference 
between potentiodynamic polarization and cyclic potentiodynamic polarization test is that the latter has an additional reverse scan which can provide a hysteresis loop. This hysteresis loop is an evidence of revealing the susceptibility of the tested material, which

is especially useful for comparison and ranking of materials [42]. In the cyclic potentiodynamic polarization test, the polarization scan started at $-500 \mathrm{mV}$ vs. open circuit potential and ended at $1200 \mathrm{mV}$ vs. SCE with a scan rate of $5 \mathrm{mV} / \mathrm{s}$, and the reverse scan was from $1200 \mathrm{mV}$ vs. SCE to $-500 \mathrm{mV}$ vs. SCE.

\subsection{Results and analyses}

\subsubsection{Data processing}

The data obtained from the experiments were analyzed using Microsoft Excel. The potentiodynamic polarization curves could be plotted, as shown in Figure 3-7 as an example, where $x$ - and $y$-axes correspond to the two primary parameters, current density (i) and potential $(E)$, respectively. 


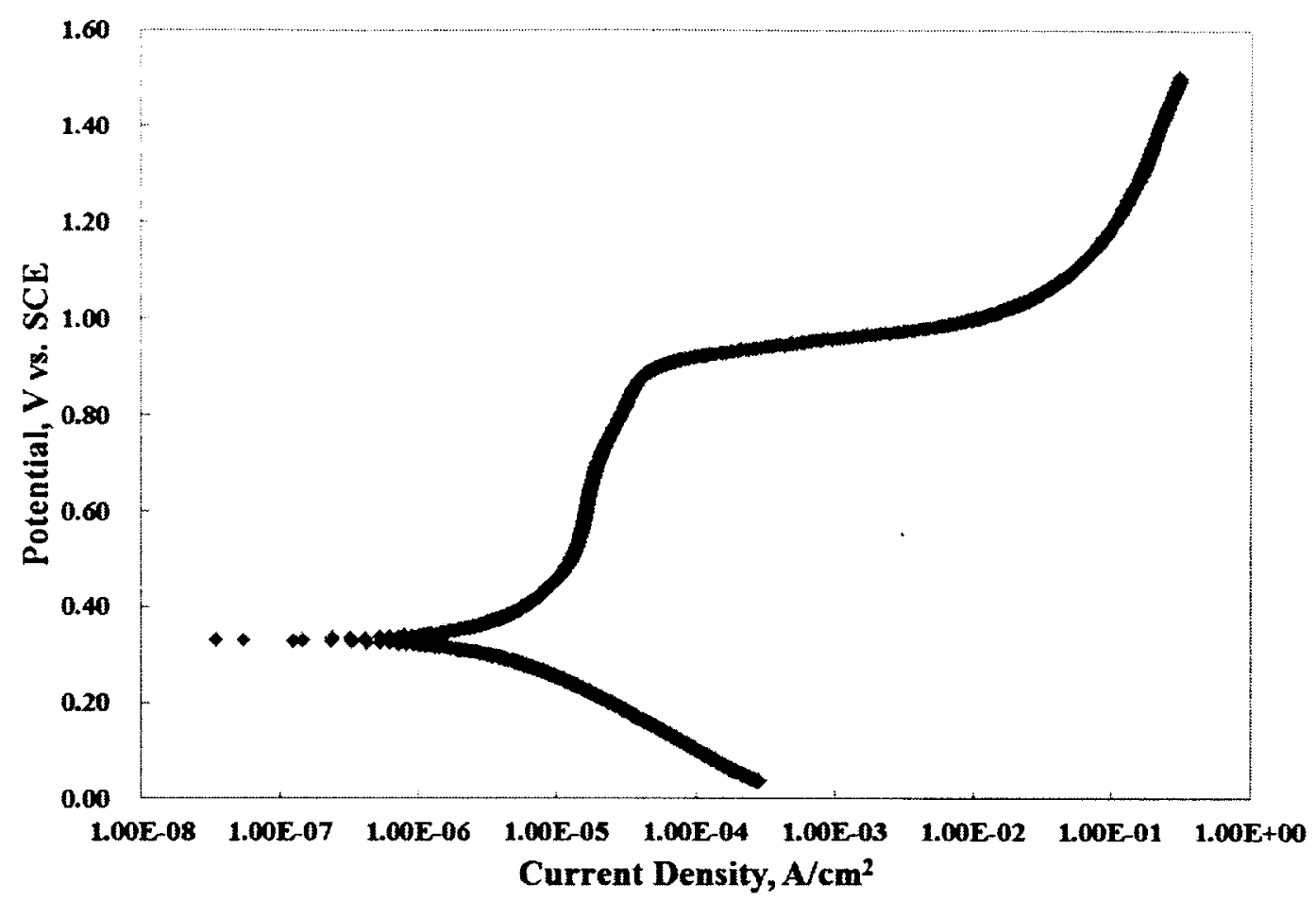

Figure 3-7: A typical potentiodynamic polarization curve obtained from a potentiodynamic polarization test (Stellite 6B in Green Death solution).

Characteristic regions can be identified on the curve, such as active, passive, and transpassive regions as shown in Figure 3-8 [43]. The parameters corresponding to these regions can be determined through the analysis of the curve, including corrosion potential, current density, passivity potential and pitting potential. 


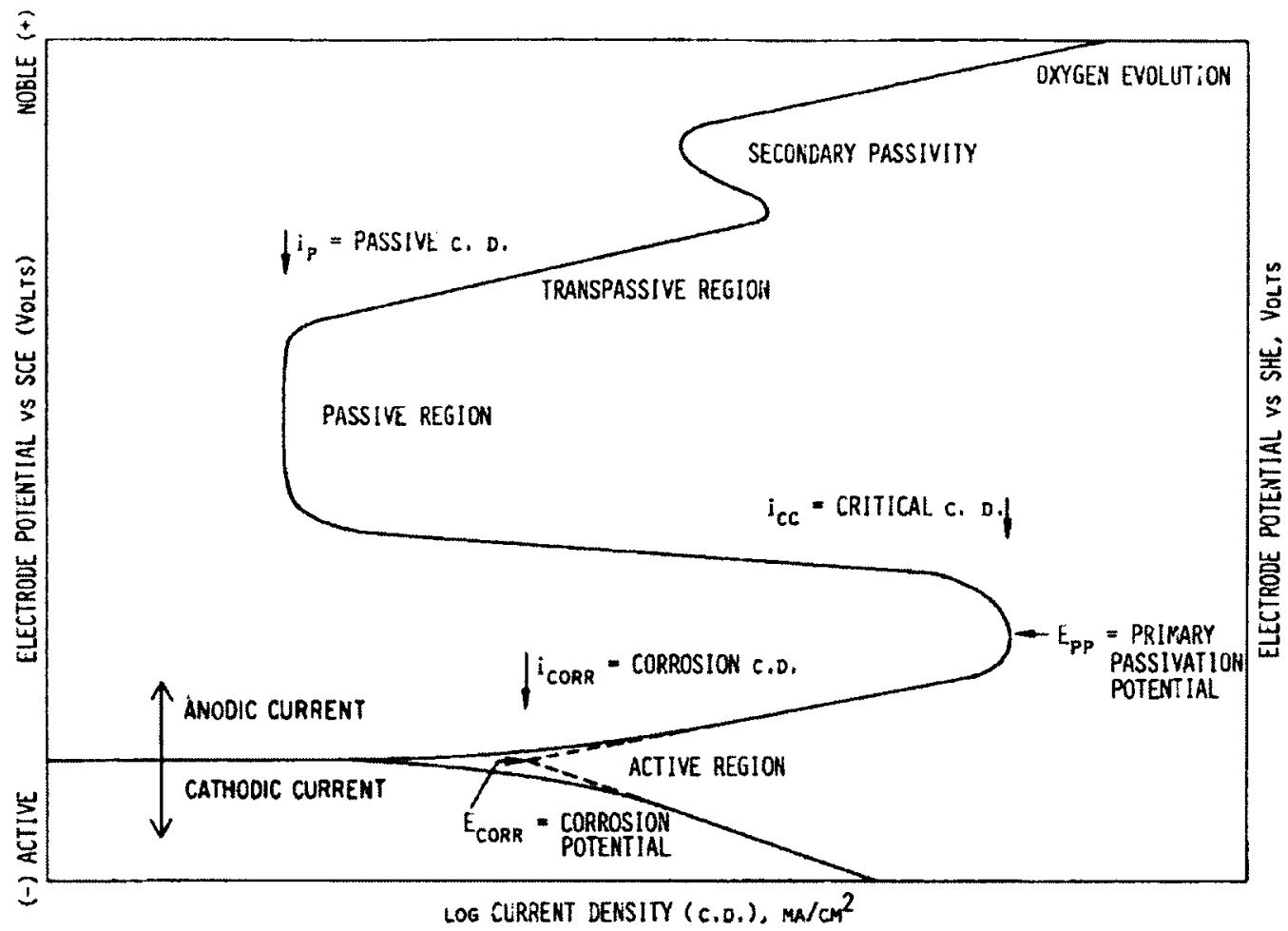

Figure 3-8: Hypothetical cathodic and anodic polarization curve [43].

Utilizing the Tafel extrapolation, the important parameters that characterize the corrosion behavior of the tested material can be obtained. The details about these parameters are described below:

(1) Corrosion current $\left(I_{c o r r}\right)$ can be obtained using Stern-Geary equation [44, 45, 46]:

$$
I_{\text {corr }}=\frac{\beta_{a} \beta_{c}}{2.3039\left(\beta_{a}+\beta_{c}\right) R_{P}}
$$


(2) Tafel slopes $\left(\beta_{a}\right)$ and $\left(\beta_{c}\right)$ corresponding to anode and cathode, respectively, can be obtained from the Tafel plot;

(3) Polarization resistance $R_{p}$ can be obtained from the following relationship:

$$
B=\frac{\beta_{a} \beta_{c}}{2.3039\left(\beta_{a}+\beta_{c}\right)}
$$

where $B$ represents Stern-Geary constant.

$$
R_{p}=\frac{B}{I_{c o r r}}
$$

(4) The Stern-Geary constant $(B)$ can be calculated from the known Tafel slopes.

Since both cathodic and anodic reactions are activation controlled, that is, there are distinct linear regions near the corrosion potential on a polarization plot, it is possible to estimate $\beta_{a}$ and $\beta_{c}$ by taking the derivatives of linearity of the polarization curves. The linear portions of polarization curves can be determined as within a potential interval of $20-50 \mathrm{mV}$, below the corrosion potential for cathodic curve and above for anodic curve [44]. From the linear regions, the slops of the two lines can be determined, which are represented by $\beta_{c}$ (cathodic) and $\beta_{a}$ (anodic) respectively. The intersection of the two lines represents the values of $E_{\text {corr }}$ ( $Y$-axis), defined as corrosion potential, and $I_{\text {corr }}$ ( $X$-axis), which is the corresponding current density. In most cases, the $X$-axis value $\left(I_{\text {corr }}\right)$ obtained from graphing is close to the calculated value from Eq. $(3-1)$. Figure 3-9 shows the characteristic parameters in the hypothetical diagram [43]. 


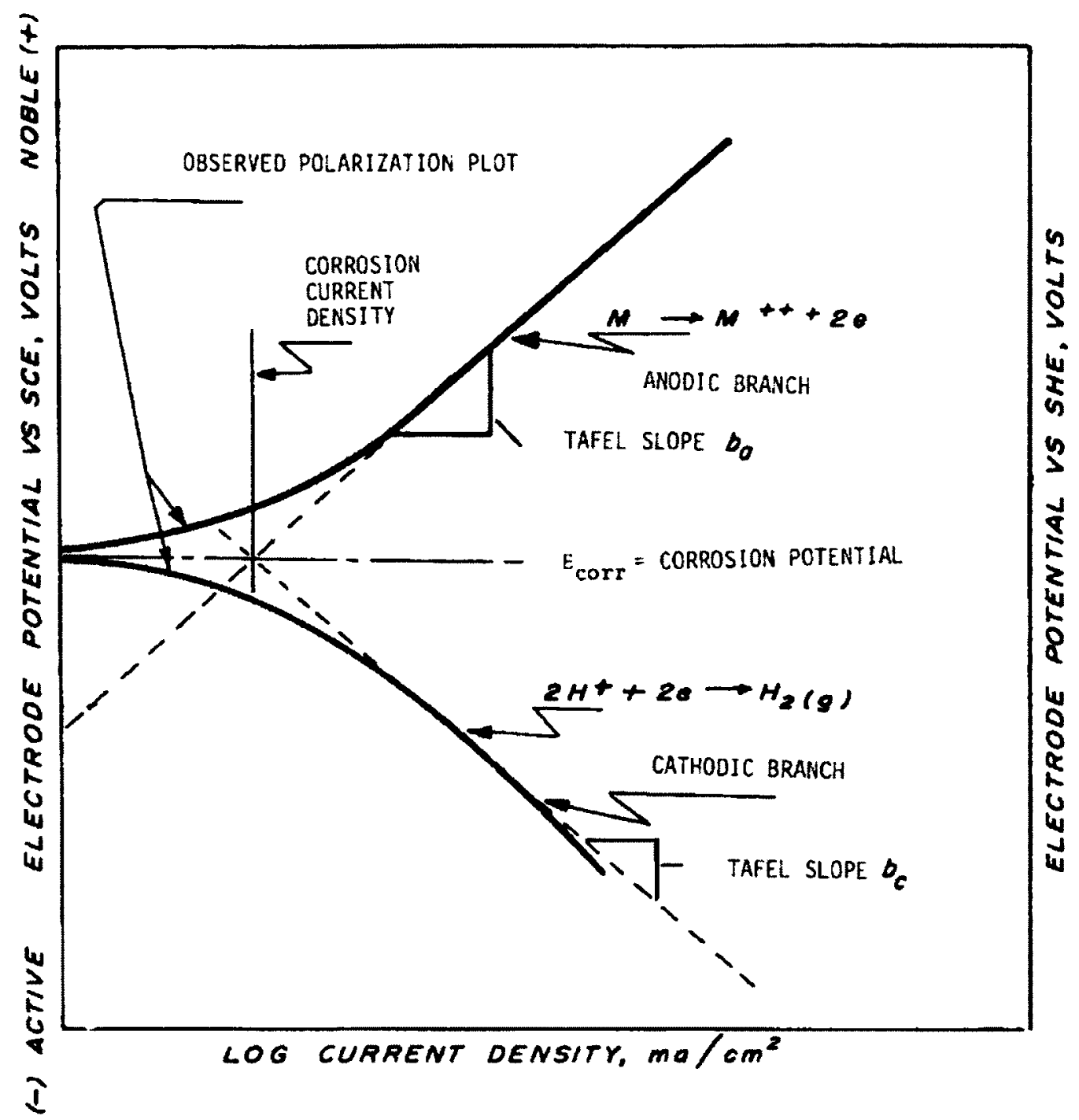

Figure 3-9: Hypothetical cathodic and anodic polarization diagram [43].

Let's take Figure 3-7 as an example to show the calculation process. In practice, $E_{\text {corr }}$ is read from the parallel line of the $X$-axis at the intersection of the two lines, which is $315 \mathrm{mV}$ in Figure 3- 7. Once $E_{\text {corr }}$ is obtained, the linear region of the cathodic curve 
can be determined to be from $E_{c o r r}-50$ to $E_{\text {corr }}-20$, that is, $265-295 \mathrm{mV}$, and the linear region of the anodic curve from $E_{\text {corr }}+20$ to $E_{\text {corr }}+50$, that is, $335-365 \mathrm{mV}$. Figure 3-10 (a) and Figure 3-10 (b) show the plots of the two linear regions of cathodic curve and anodic curve, respectively. Then $\beta_{c}$ and $\beta_{a}$ values can be obtained from the line equations, $\beta_{c}=\log 9424.6=3.974 \mathrm{~V} /$ decade,$\beta_{a}=\log 16031=4.205 \mathrm{~V} /$ decade . Substitute $y=E_{\text {corr }}=315 \mathrm{mV}$ into cathodic line equation, $x=I_{\text {corr }}=0.67907 \mu \mathrm{A}$ can be obtained. Using Eq. (3-2) and Eq. (3-3), $R_{p}=1306 \mathrm{k} \Omega$ is obtained.

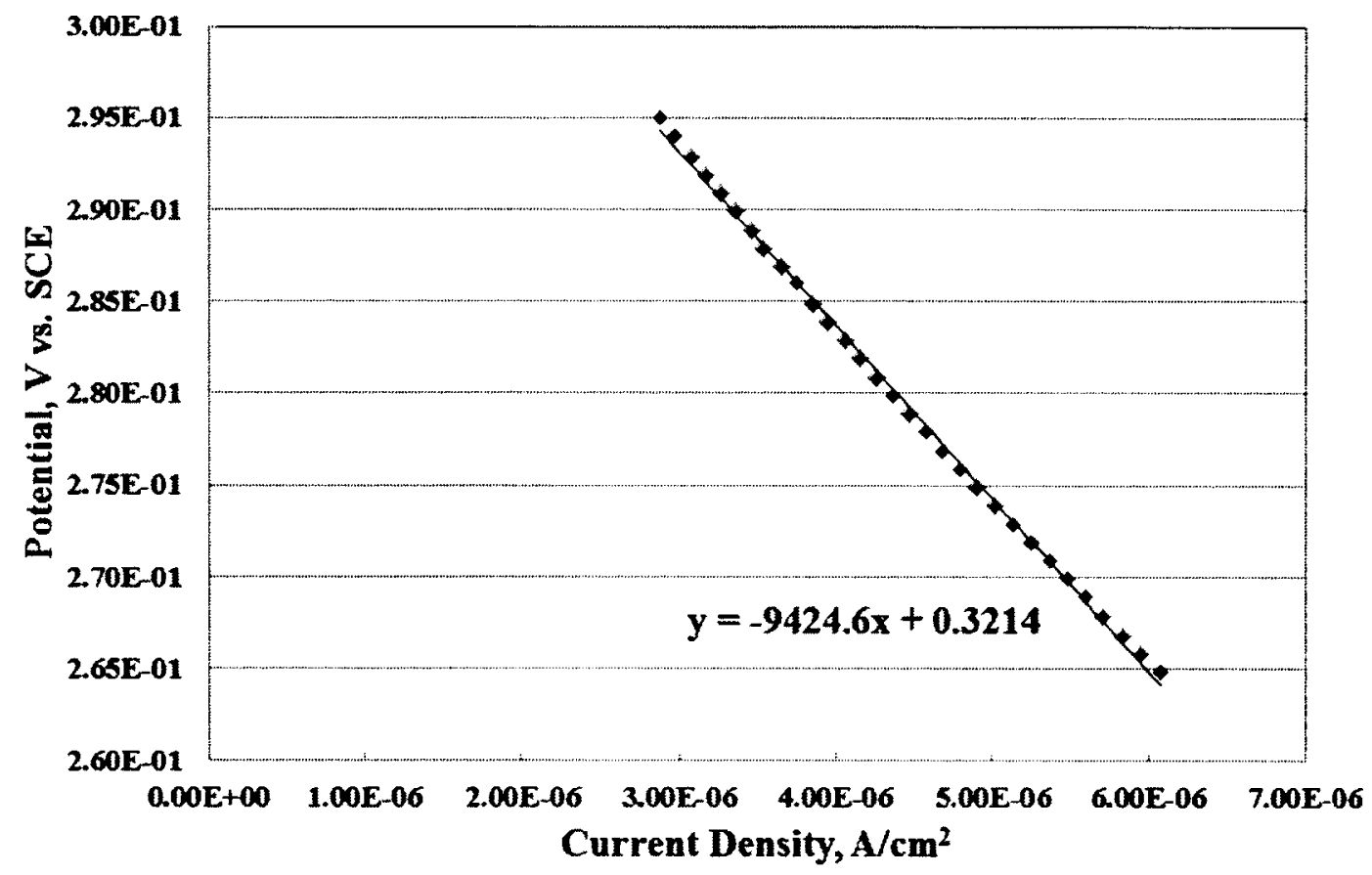

(a) 


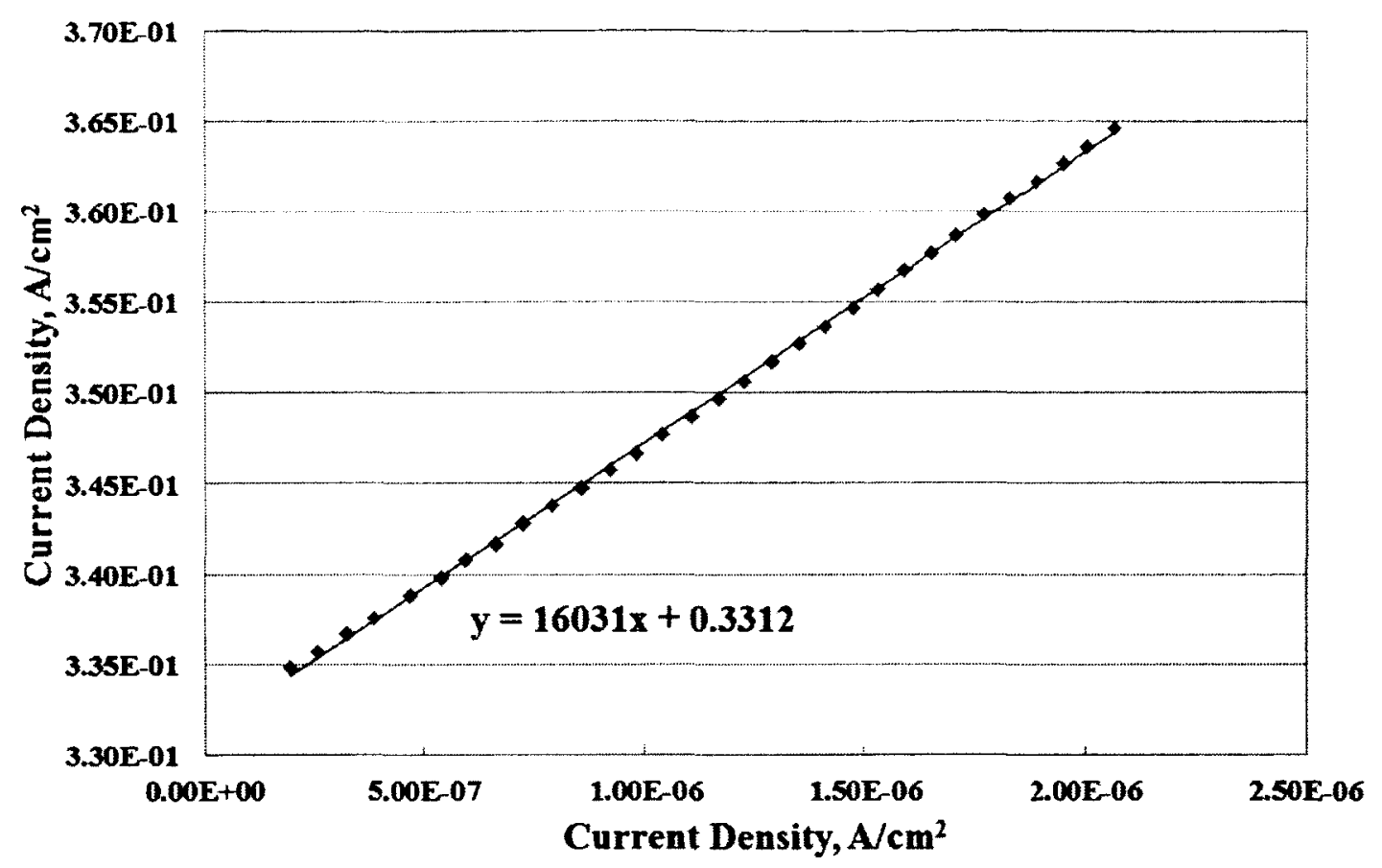

(b)

Figure 3-10: Linear regions of polarization curves: (a) cathodic curve and (b) anodic curve.

In this research, Stellite $6 \mathrm{~B}$ and Stellite $6 \mathrm{~K}$ were tested in two corrosive media: $3.5 \mathrm{wt} \%$ $\mathrm{NaCl}$ solution and a composite solution named Green Death solution $(11.5 \%$ $\mathrm{H}_{2} \mathrm{SO}_{4}+1.2 \% \mathrm{HCl}+1 \% \mathrm{FeCl}_{3}+1 \% \mathrm{CuCl}_{2}$ ). The solution of $3.5 \mathrm{wt} \% \mathrm{NaCl}$ is a common medium that has been used to characterize the general corrosion resistance of metals. Green Death solution is a strong causticity composite solution that is usually adopted to test the corrosion resistance of metals for particular industry applications. 


\subsubsection{Polarization curves for the tests in $3.5 \mathrm{wt} \% \mathrm{NaCl}$ solution}

For the polarization tests in $3.5 \mathrm{wt} \% \mathrm{NaCl}$ solution, as shown in Figure 3-11, the experimental data were plotted in Tafel curve, with the $X$-axis representing the logarithmic value of current density and the $Y$-axis representing potential vs. SCE. The original data were collected in the unit ampere, and they were divided by specimen surface area thus changed to absolute values. The exposed surface area of the specimen was calculated to be $78.5 \mathrm{~mm}^{2}$ based on $\pi \cdot 5^{2} \mathrm{~mm}^{2}$.

The calculated values of parameters from the polarization curves are summarized in Table 3-2. It is shown that Stellite $6 \mathrm{~B}$ and Stellite $6 \mathrm{~K}$ have a similar corrosion potential $\left(E_{\text {corr }}\right)$ that is around $-220 \mathrm{mV}$, the current density $\left(I_{\text {corr }}\right)$ at corrosion potential point of Stellite $6 \mathrm{~B}$ is larger, which indicates that this alloy is easier corroded than Stellite $6 \mathrm{~K}$. Regarding the anodic behavior, both of the alloys have a large passive region, that is, with rapid increase in the potential the current is nearly constant. This behavior indicates better corrosion resistance of these alloys. Furthermore, the curve of Stellite $6 \mathrm{~B}$ has a larger passive region ("straight" portion) than that of Stellite $6 \mathrm{~K}$, which implies that this alloy is more corrosion-resistant in an anodic corrosion circumstance. Compared with Stellite $6 \mathrm{~B}$, Stellite $6 \mathrm{~K}$ is worse in regard of anodic corrosion resistance, because the passive region of Stellite $6 \mathrm{~K}$ is only kept in a certain region, around $I_{c o r r}=10 \mathrm{E}-5$ $\mathrm{A} / \mathrm{cm}^{2}$ the current density $\left(I_{\text {corr }}\right)$ increases rapidly with the increase of the potential beyond the passive region. 


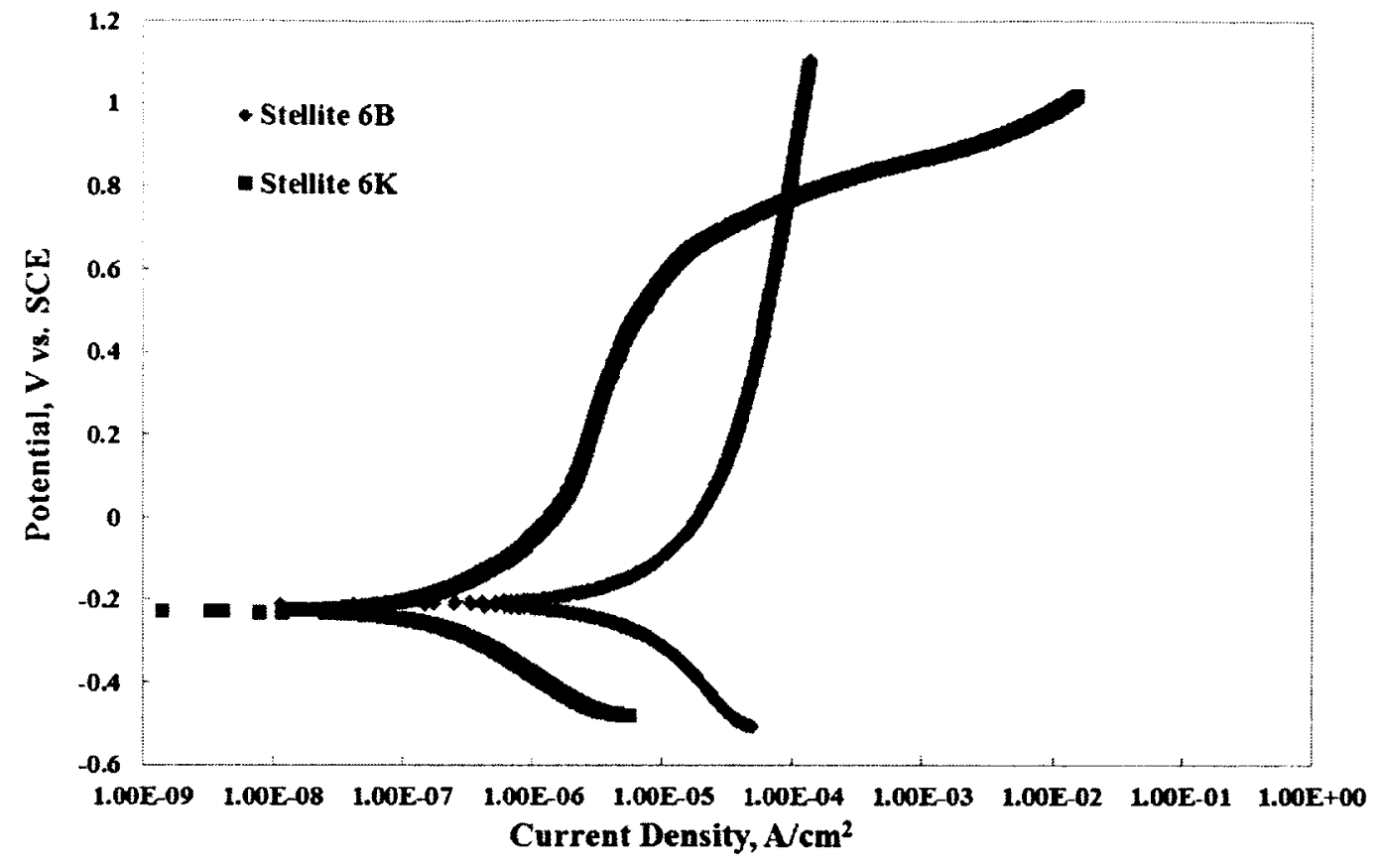

Figure 3-11: Polarization curves of Stellite 6B and Stellite 6K

in $3.5 \mathrm{wt} \% \mathrm{NaCl}$ solution.

Table 3-2: Summary of polarization test results of Stellite 6B and Stellite 6K

in $3.5 \mathrm{wt} \% \mathrm{NaCl}$ solution

\begin{tabular}{|c|c|c|c|c|c|}
\hline Specimen & $\begin{array}{c}E_{\text {corr }} \\
(m V \text { vs. } S C E)\end{array}$ & $\begin{array}{c}I_{\text {corr }} \\
\left(\mu \mathrm{A} / \mathrm{cm}^{2}\right)\end{array}$ & $\begin{array}{c}R_{p} \\
\left(\mathrm{k} \Omega \cdot \mathrm{cm}^{2}\right)\end{array}$ & $\begin{array}{c}\beta_{a} \\
(V / \text { decade })\end{array}$ & $\begin{array}{c}\beta_{c} \\
(V / \text { decade })\end{array}$ \\
\hline Stellite 6B & -213 & 0.11606 & 7554 & 4.014 & 4.066 \\
\hline Stellite 6K & -232 & 0.01668 & 69511 & 5.387 & 5.296 \\
\hline
\end{tabular}




\subsubsection{Polarization curves for the tests in Green Death solution}

For the polarization tests in Green Death solution, three specimens for each alloy were tested to verify the repeatability of the experimental results. The obtained polarization curves are presented in Figure 3-12 and Figure 3-13.

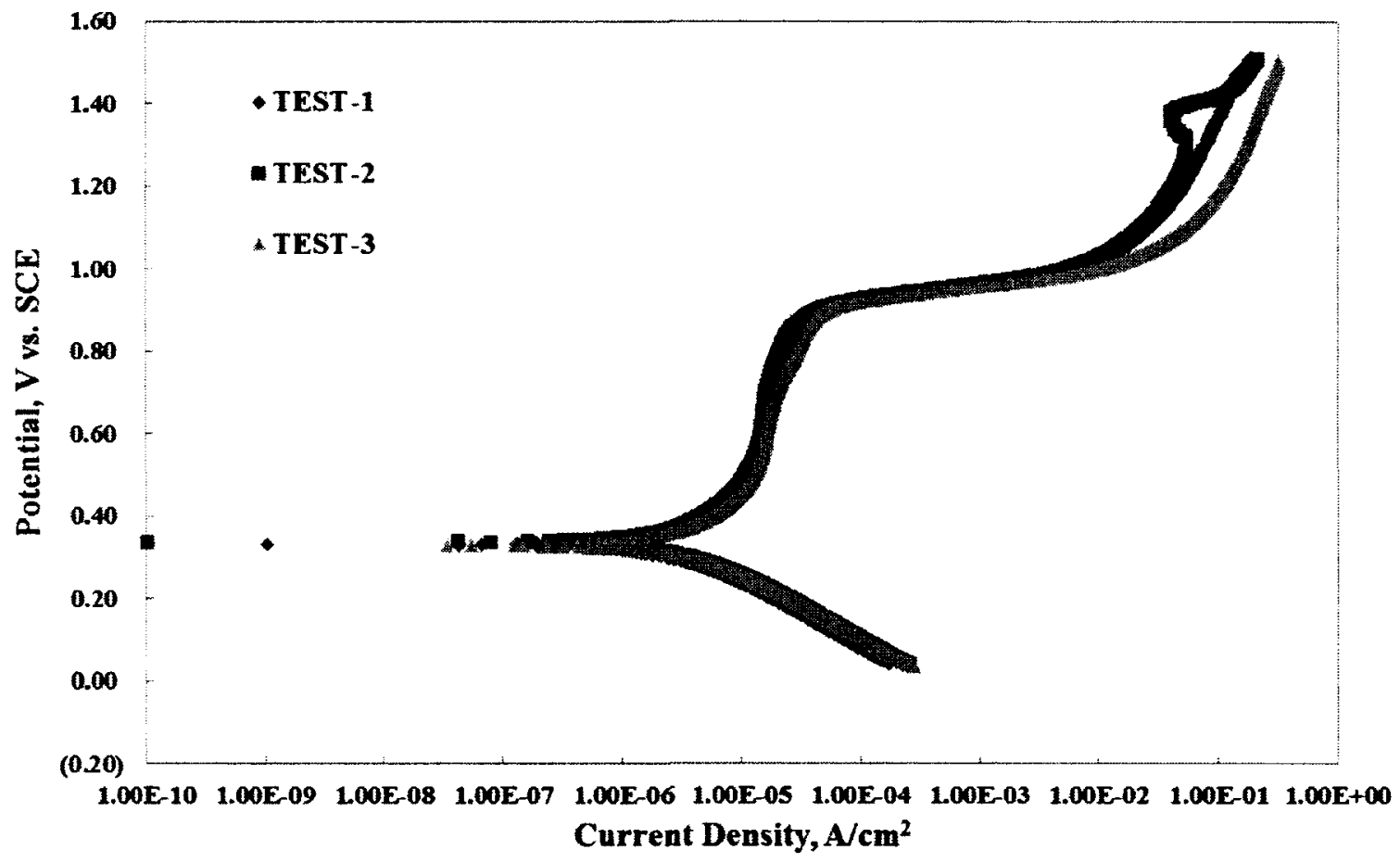

Figure 3-12: Polarization curves of Stellite 6B in Green Death solution. 


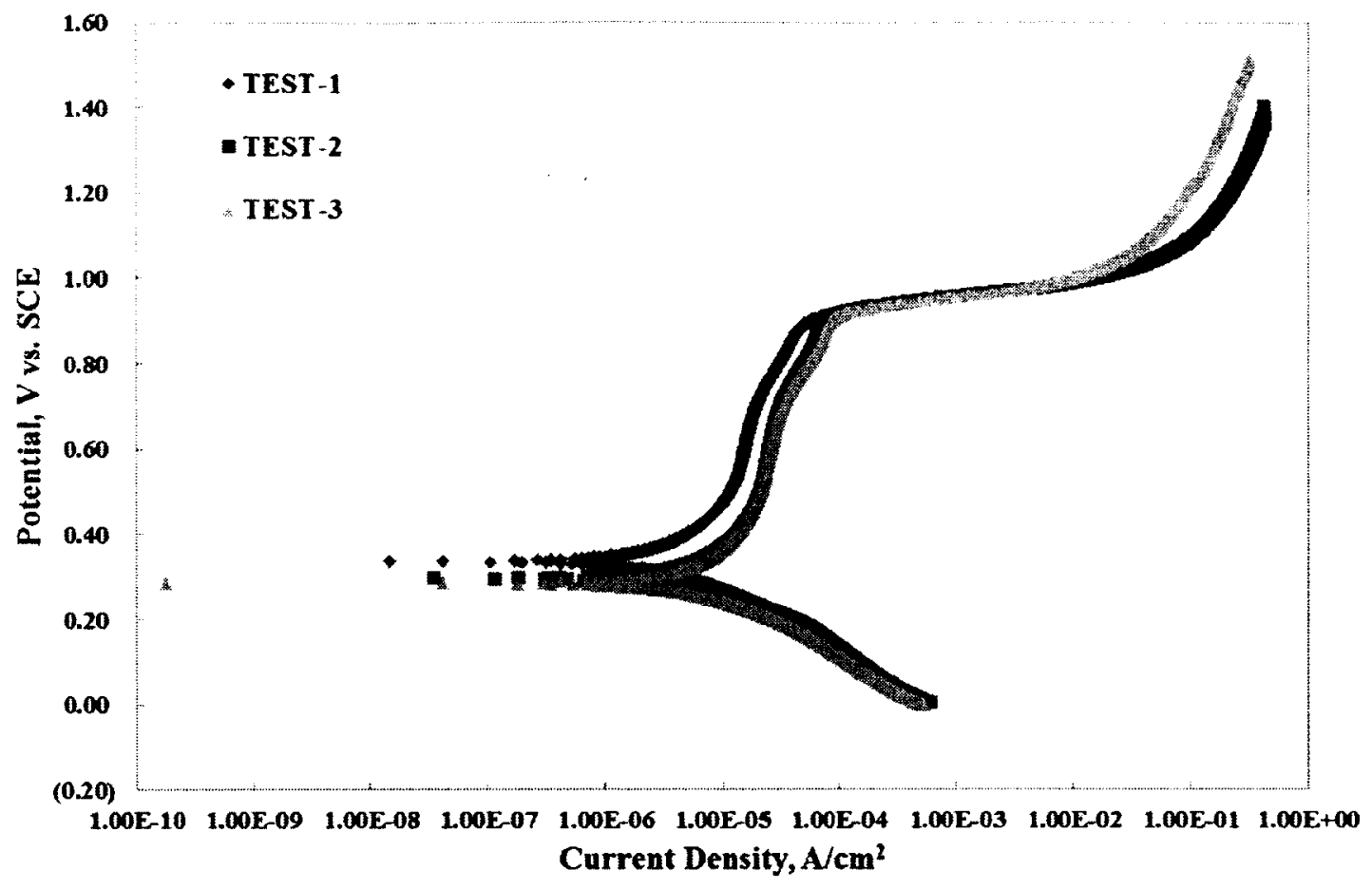

Figure 3-13: Polarization curves of Stellite 6K in Green Death solution.

For comparison, typical polarization curves of Stellite 6B and Stellite 6K in Green Death solution are plotted together in Figure 3-14. It is shown that the polarization curves of these two alloys have a similar shape such that they have a similar passive region ending at almost a same potential level and a new passive region after a rapid increase in current density $\left(I_{c o r r}\right)$. From the summary of the polarization test results in Table 3-3, the $E_{\text {corr }}$ value of Stellite $6 \mathrm{~B}$ is slightly higher than that of Stellite $6 \mathrm{~K}$, and the current density ( $\left.I_{\text {corr }}\right)$ of the former at corrosion potential is smaller than that of the latter. These all mean that Stellite 6B is more corrosion-resistant in the Green Death environment. 


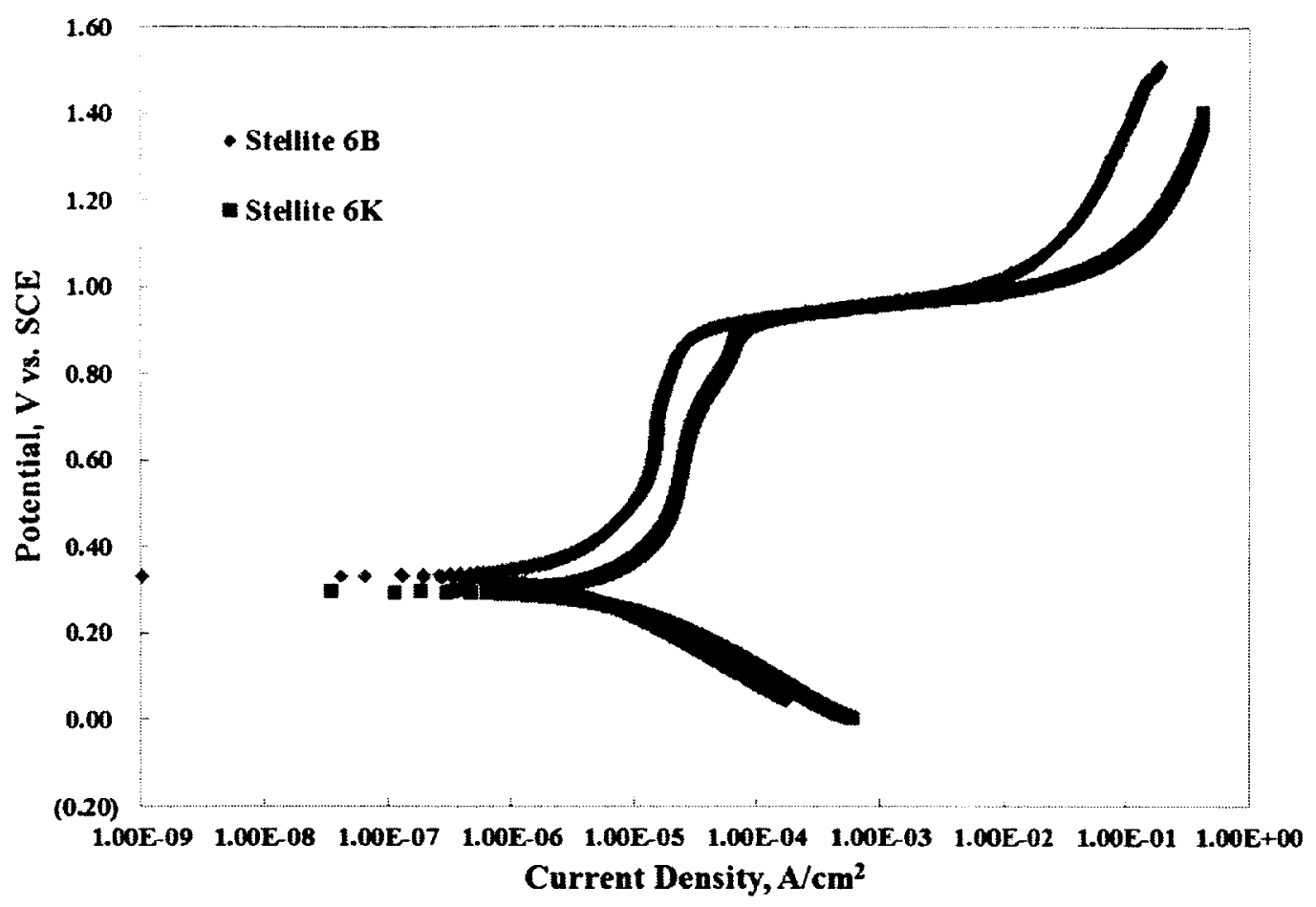

Figure 3-14: Comparison of polarization curves of Stellite $6 \mathrm{~B}$ and Stellite $6 \mathrm{~K}$ in Green Death solution.

Table 3-3: Summary of polarization test results of Stellite 6B and Stellite $6 \mathrm{~K}$ in Green Death solution3.5 wt\% $\mathrm{NaCl}$ solution

\begin{tabular}{|c|c|c|c|c|c|}
\hline Specimen & $\begin{array}{c}E_{c o r r} \\
(\mathrm{~m} V \text { vs. } S C E)\end{array}$ & $\begin{array}{c}I_{\text {corr }} \\
\left(\mu \mathrm{A} / \mathrm{cm}^{2}\right)\end{array}$ & $\begin{array}{c}R_{p} \\
\left(\mathrm{k} \Omega \cdot \mathrm{cm}^{2}\right)\end{array}$ & $\begin{array}{c}\beta_{a} \\
(V / \text { decade })\end{array}$ & $\begin{array}{c}\beta_{c} \\
(V / \text { decade })\end{array}$ \\
\hline Stellite 6B & 315 & 0.67907 & 1306 & 4.205 & 3.974 \\
\hline Stellite 6K & 285 & 1.56085 & 524 & 3.859 & 3.676 \\
\hline
\end{tabular}




\subsubsection{Cyclic polarization curves}

The cyclic polarization curves of Stellite $6 \mathrm{~B}$ and Stellite $6 \mathrm{~K}$ tested in Green Death solution are plotted in Figure 3-15 and Figure 3-16, respectively. I represents forward scan, and II represents reverse scan. The reverse scan is also called hysteresis loop. If the hysteresis loop is electropositive, that is, the current density of curve II is smaller than that of curve I at the same potential ( $Y$-axis), the tested metal exhibits localized corrosion resistance. The more the offset of the electropositive loop, the better the localized corrosion resistance the metal has [42].

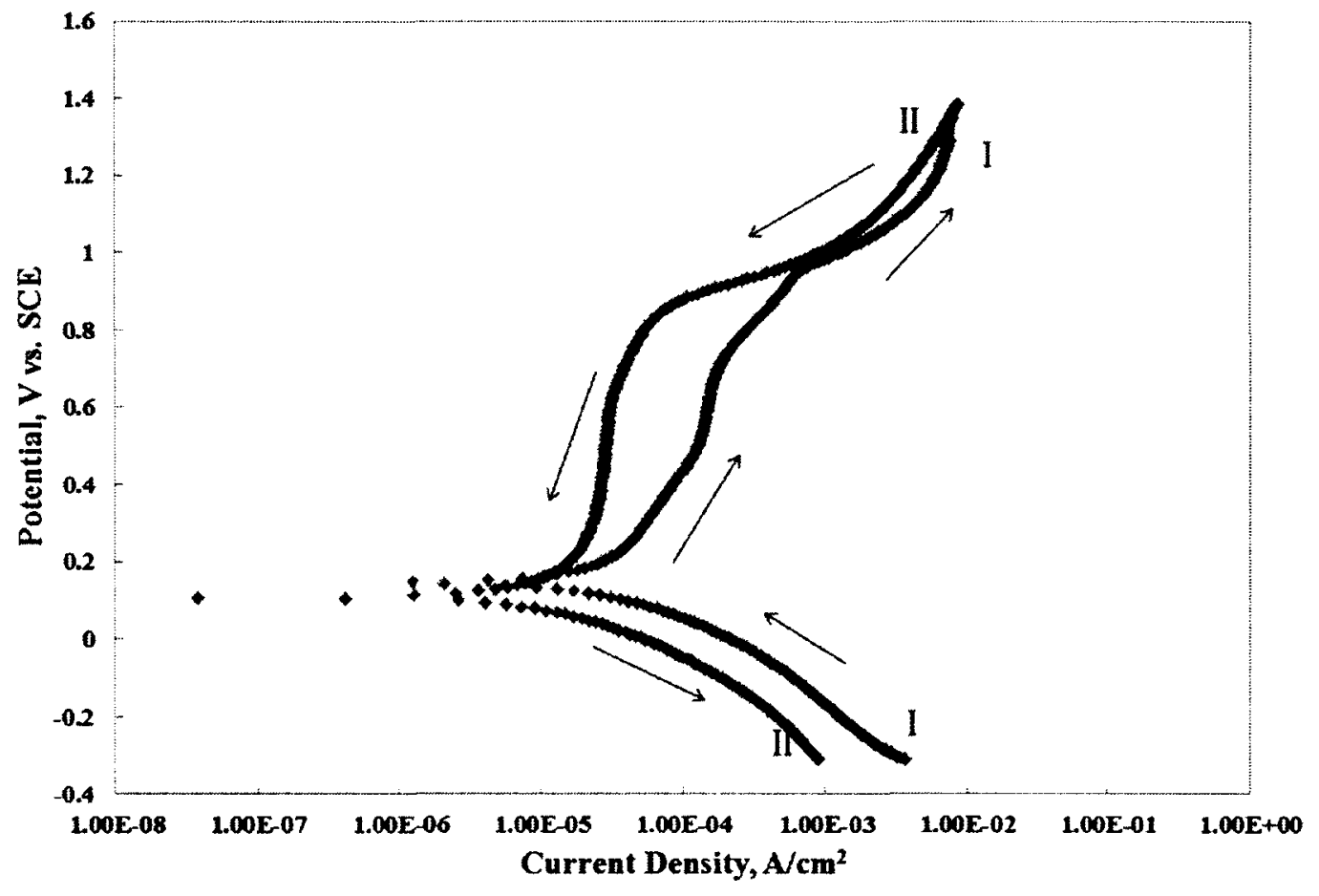

Figure 3-15: Cyclic polarization curves of Stellite 6B in Green Death solution. 


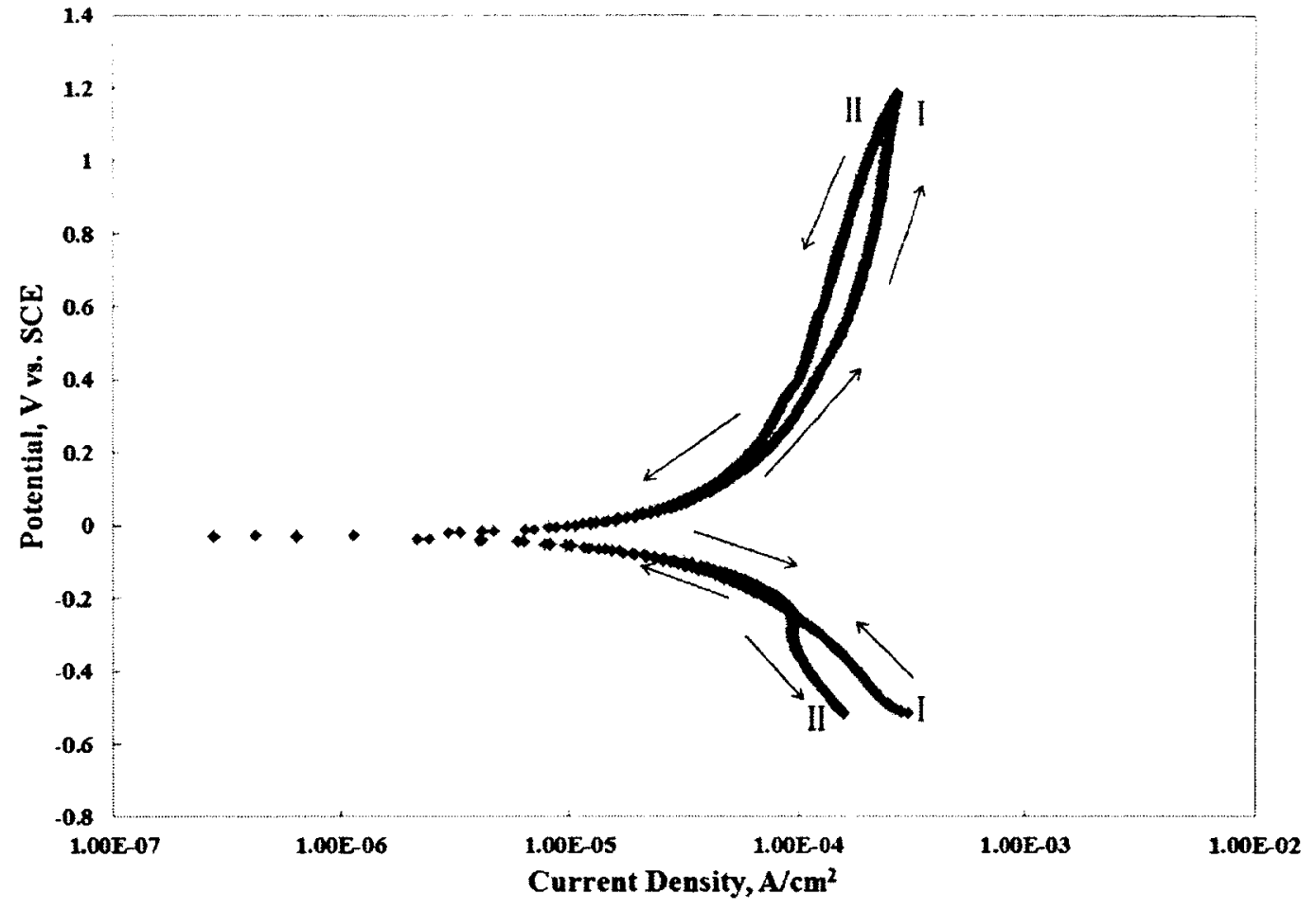

Figure 3-16: Cyclic polarization curves of Stellite 6K in Green Death solution. 


\section{Immersion test and result analysis}

Immersion test was performed on Stellite $6 \mathrm{~B}$ and Stellite $6 \mathrm{~K}$. The objectives of this test were four: for each alloy (1) to find the Critical Pitting Temperature (CPT); (b) to determine corrosion loss, including mass loss, thickness change and maximum pit depth; (3) to obtain the Extreme Value or to predict the minimum thickness of the material for a given service life, based on the Extreme Value Analysis (EVA) model; and (4) to investigate pitting area fraction and the chemical composition of pits. The corrosive medium was Green Death solution.

\subsection{Specimen and equipment}

\subsubsection{Specimen preparation}

The specimens used for the immersion test were prepared following the Standard Practice for Laboratory Immersion Corrosion Testing of Metals, ASTM G31-99 [47]. The Stellite $6 \mathrm{~B}$ and Stellite $6 \mathrm{~K}$ specimens for this test are a round plate with a diameter of $38 \mathrm{~mm}$ and thickness of $3 \mathrm{~mm}$. This geometry offers the specimen a large surface-to-mass ratio and a small ratio of edge area to total area, which are desirable for immersion corrosion test [47]. Figure 4-1 shows the geometry and dimension of the specimen used for immersion test. The hole of $8 \mathrm{~mm}$ diameter was made for mounting. All the specimens were measured precisely in dimension and weight before and after the test. 

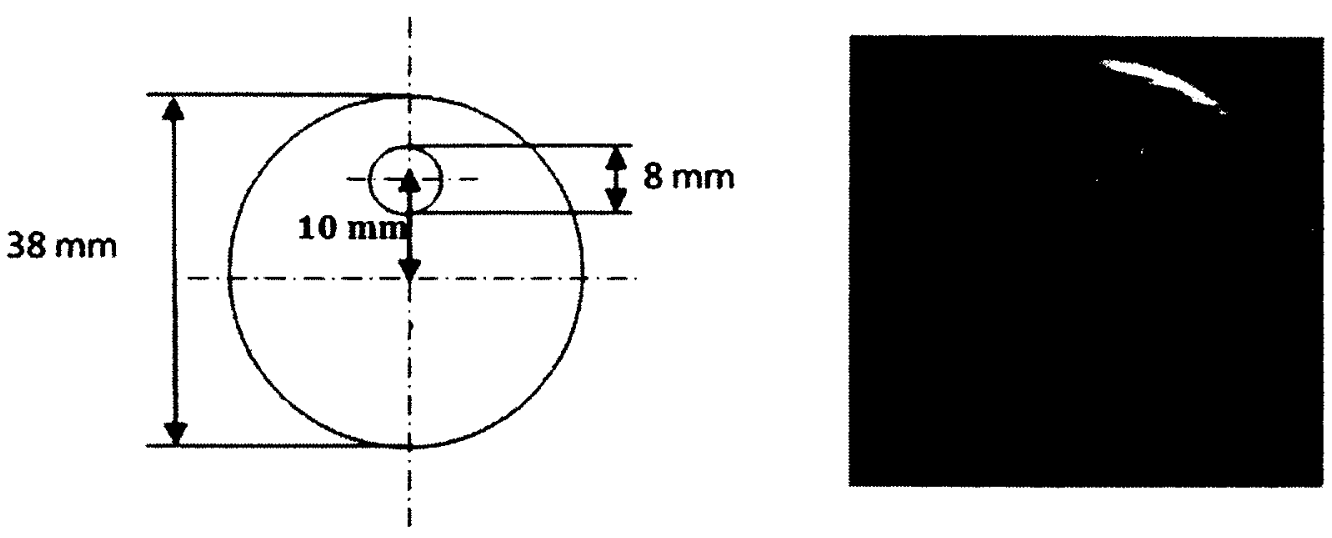

Figure 4-1: Immersion test specimen.

Since corrosion is a surface phenomenon, a high fineness level of specimen surface is required for immersion test. Following the surface preparation instructions in the standard ASTM G31-99 [47]. The surfaces of each specimen were grinded by using $\# 240$, $\# 320$, $\# 400$, \#600, \#800, \#1200-grit silicon sand abrasive paper, and then diamond polished with $3 \mu \mathrm{m}$ polish powder suspension. Contaminations of the specimen surface may influence its corrosion behavior, therefore, chemical cleaning was employed to remove any traces of foreign particles from the specimen surfaces using methanol and the surfaces were dried by a blower [47]. 


\subsubsection{Equipment setup}

The main equipment used in this immersion test consists of a Jeio Tech Model BW-10G water heating bath, shown in Figure 4-2, and a customer-designed flask set, shown in Figure 4-3. The water bath was used to heat the corrosive medium (solution) up to $100^{\circ} \mathrm{C}$ with a temperature stability of $\pm 0.2^{\circ} \mathrm{C}$. The load capacity of the water bath is $10 \mathrm{~L}$.

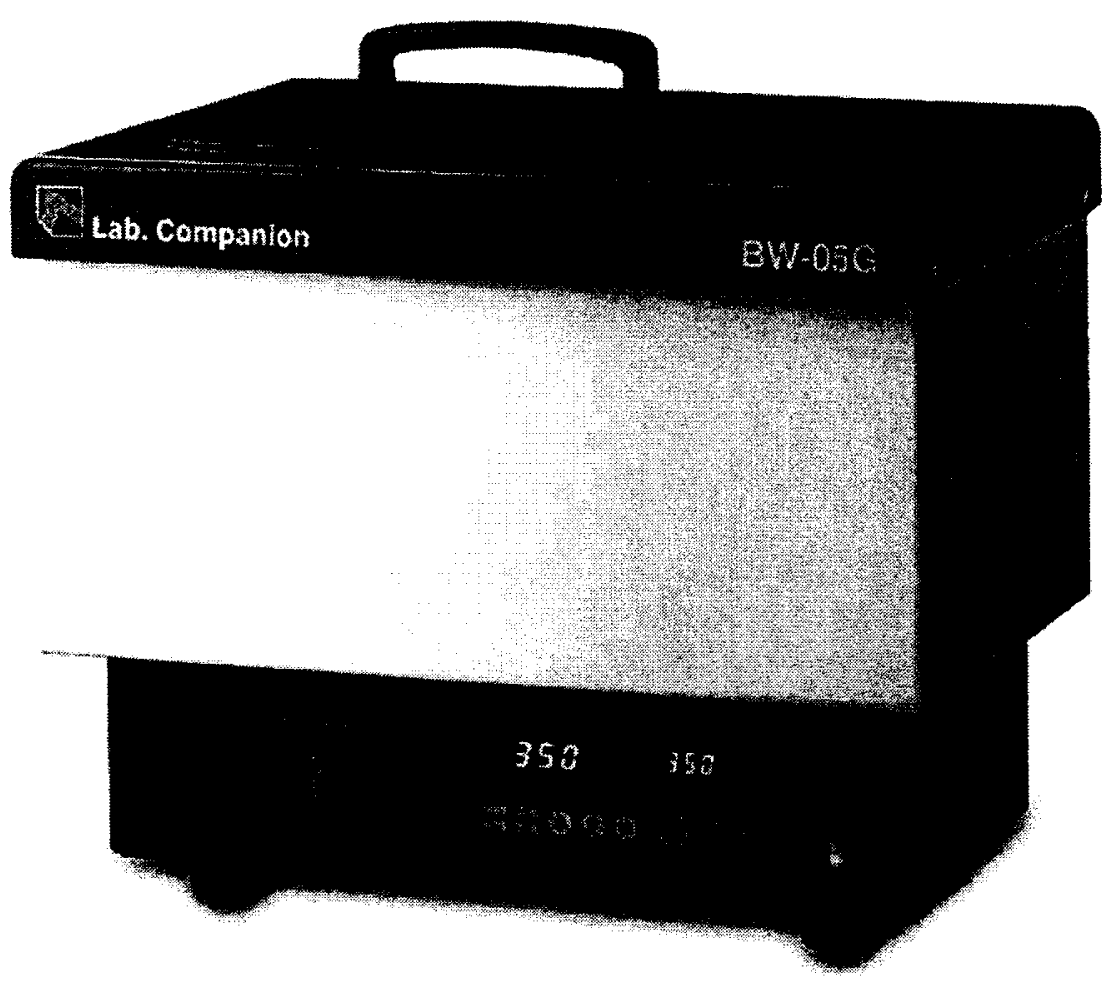

Figure 4-2: Jeio Tech Model BW-10G water heating bath.

The customer-designed flask set was manufactured according to the apparatus scheme of ASTM G31-99 [47]. The components included in the flask set are labeled in Figure 4-3. The reflux condenser serves to cool down the steam which is generated during heating 
the chemical solution in the glass flask. Through the condenser, the steam is converted to a liquid form going back to the glass flask. The advantage of this design is that the concentrations of the chemical solution can be maintained stable at elevated temperatures. The specimen holder was also customer designed with a load capacity of four specimens, as shown in Figure 4-4.

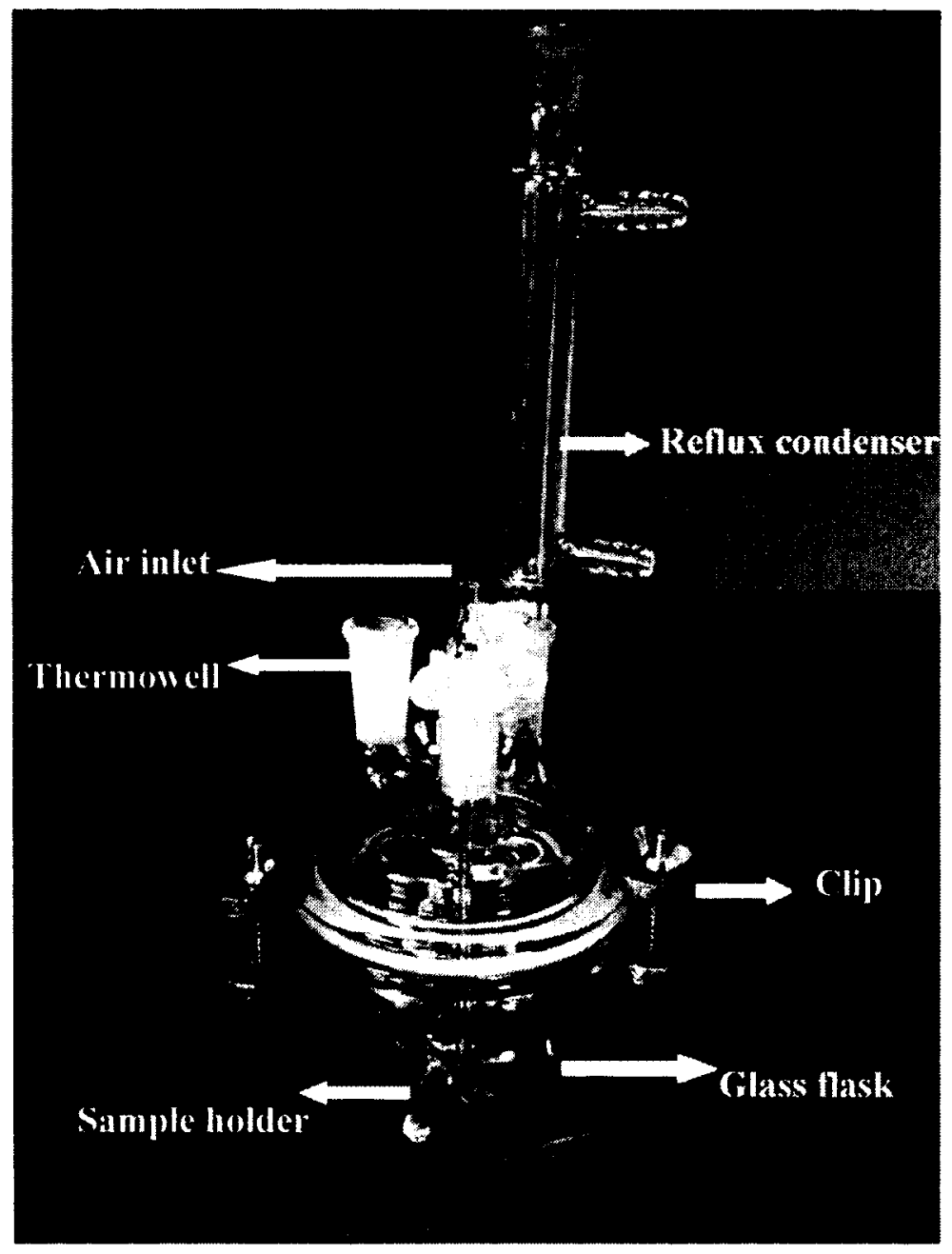

Figure 4-3: Customer-designed flask set. 

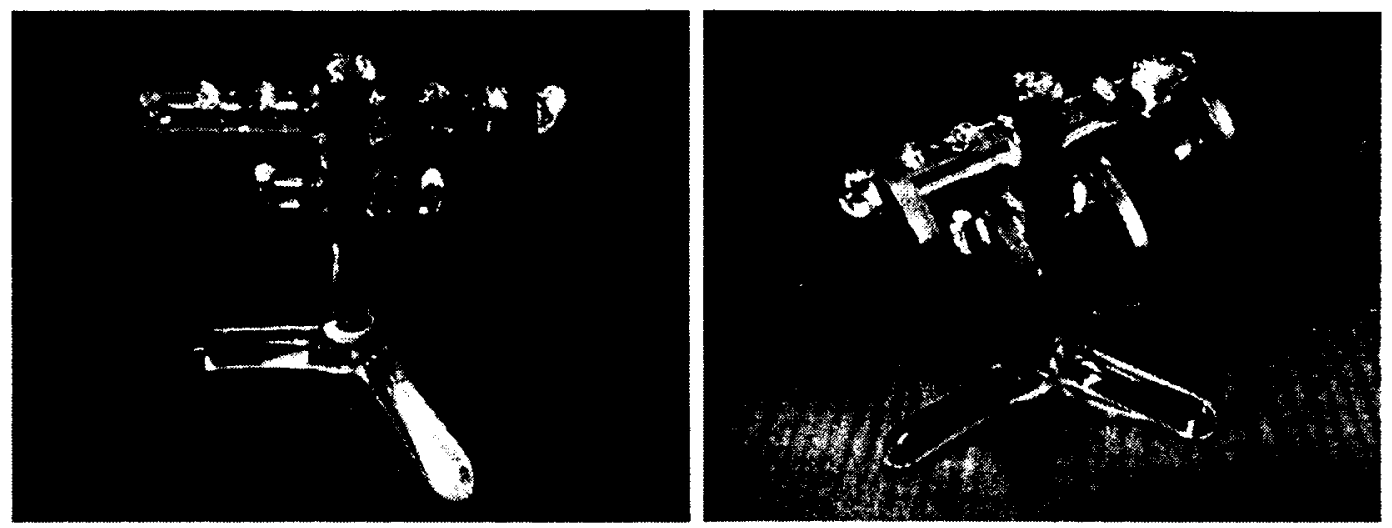

Figure 4-4: Customer-designed specimen holder.

\subsection{Experimental procedures}

\subsubsection{Critical Pitting Temperature (CPT) test}

The CPT is defined as the lowest temperature at which stable disseminative pitting occurs on the specimen surface under prescribed test conditions [48].Therefore, the CPT immersion corrosion test is to find the CPT. The test environment is usually a severely oxidizing acid solution, which can characterize the localized corrosion properties of materials. The CPT test is normally performed in a temperature increment of $5^{\circ} \mathrm{C}$ of the corrosive medium (solution) for a $24 \mathrm{~h}$ exposure period. The specimen is examined under an optical microscope after the CPT test to investigate if pitting corrosion has initiated in the specimen surface. If any pits are observed, pitting corrosion has occurred. Detailed operations of the CPT test are described below:

(1) Clean the polished specimen surface with methanol and dry the surface by a heat 
blower before it is tested.

(2) Mount two specimens of a same alloy onto the specimen holder and then place them into the glass flask.

(3) Pour Green Death solution into the glass flask and make sure that all the specimens are immersed completely.

(4) Fill the heating bath with tap water and set the water temperature to the test temperature. This temperature is the temperature of the corrosive medium in the test, because the glass flask with the specimens is placed in the heating bath during the test. In this research, to find the CPT, the water temperature was set to be at $25^{\circ} \mathrm{C}$ initially, and it was then increased by $5^{\circ} \mathrm{C}$ in each temperature increment. When the water is heated reaching the target temperature, set exposure time to be $24 \mathrm{~h}$, thus the heating bath can shut down after $24 \mathrm{~h}$ automatically.

(5) After $24 \mathrm{~h}$ exposure, take the specimens out from the glass flask. Use methanol to clean the specimens and wash them with an ultrasonic cleaner for about $30 \mathrm{~min}$.

(6) Examine the specimens under an optical microscope at a magnification of $100 \mathrm{X}$. If pits were found, another set of specimens would be tested in the same condition to verify repeatability. If no pits were found in the specimen surfaces increase the water temperature by $5^{\circ} \mathrm{C}$ and mount another pair of specimens onto the holder, repeat the above steps. The CPT of the tested alloy was determined such that two pairs of specimens were found to have pits after the test at the set water temperature. The maximum water temperature in this research was set to be $85^{\circ} \mathrm{C}$, according to the temperature capacity of the heating bath. 


\subsubsection{Long-term immersion test}

Long-term immersion test is designed mainly for determination of the Extreme Value (minimum thickness) using the EVA model based on the measurement of maximum pit depths. The EVA model was derived from the Gumbel Distribution Theory. Other parameters, mass loss, thickness change, and pitting area fraction, can also be determined from long-term immersion test. In this research, six exposure times were selected for one test cycle: $2,4,6,8,10$ and 12 days. The test temperature was selected based on the CPT of the alloy. Two specimens were tested for each time period. Detailed operations of this test are described below:

(1) Clean the polished specimen with methanol and dry it using a heat blower to, remove contaminations from the specimen surface, such as polish suspension powder residual, dust and debris, before the specimen is tested.

(2) Weigh the specimen on a 0.0001 gram accuracy analytical balance.

(3) Measure specimen thickness using a $0.01 \mathrm{~mm}$ accuracy digital caliper.

(4) Mount four specimens onto each holder; three holders were used in this test; place one holder in one glass flask.

(5) Pour Green Death solution into each glass flask containing the specimens and make sure that all the specimens were immersed completely.

(6) Fill the heating bath with tap water and set the water temperature to $50^{\circ} \mathrm{C}$, which is little lower than the CPT of the tested alloys. This temperature was selected because in the CPT test no pitting occurred on both Stellite $6 \mathrm{~B}$ and Stellite $6 \mathrm{~K}$ at $50^{\circ} \mathrm{C}$ for one day test but pitting was observed on the alloys at $60^{\circ} \mathrm{C}$ for the same time period. 
Therefore, it was presumed that pitting may occur at $50^{\circ} \mathrm{C}$ for longer time test, for example, 2 days, 4 days, etc.

(7) Place the three glass flasks containing the specimens in the heating bath. Change Green Death solution every $24 \mathrm{~h}$.

(8) After the test for every 2 days, take two specimens from the flasks. Clean the specimens with methanol and wash them using an ultrasonic cleaner for about 30 min. Some pits may not break through the specimen surface, as shown in Figure 4-5 (a), they are like bubbles and covered by a thin layer. Break the layer with a needle, the specimen surface is like shown in Figure 4-5 (b).

(9) Clean all the pits.

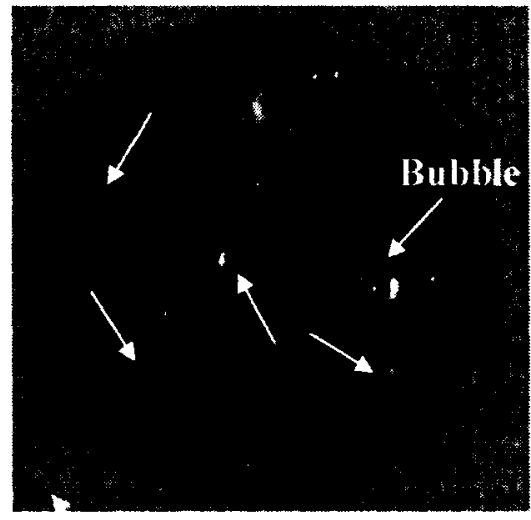

(a)

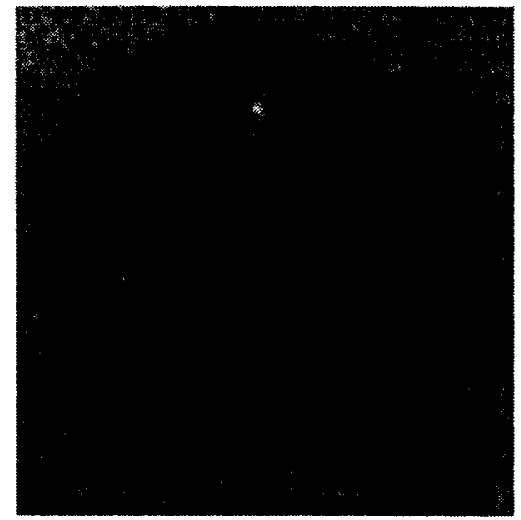

(b)

Figure 4-5: Specimen with pits after immersion test: (a) bubble-like pits and (b) bubbles broken. 
(10) Dry the specimens with a heat blower and then dry them in air for $24 \mathrm{~h}$.

(11) Weigh each specimen; measure specimen thickness; select ten maximum pits on each specimen surface to measure depth.

(12) Measure pitting area fraction on each specimen surface.

\subsection{Experimental results}

\subsubsection{Critical Pitting Temperature (CPT)}

For Stellite $6 \mathrm{~B}$ and Stellite $6 \mathrm{~K}$, the CPT test was started at $25^{\circ} \mathrm{C}$ and continued at increasing temperatures in a $5^{\circ} \mathrm{C}$ increment step. It was found that pitting occurred at the temperature of $60^{\circ} \mathrm{C}$ for both alloys, as shown in Figure 4-6. The CPT test results are summarized in Table 4-1, which indicate that the CPTs of Stellite $6 \mathrm{~B}$ and Stellite $6 \mathrm{~K}$ are all $60^{\circ} \mathrm{C}$. 


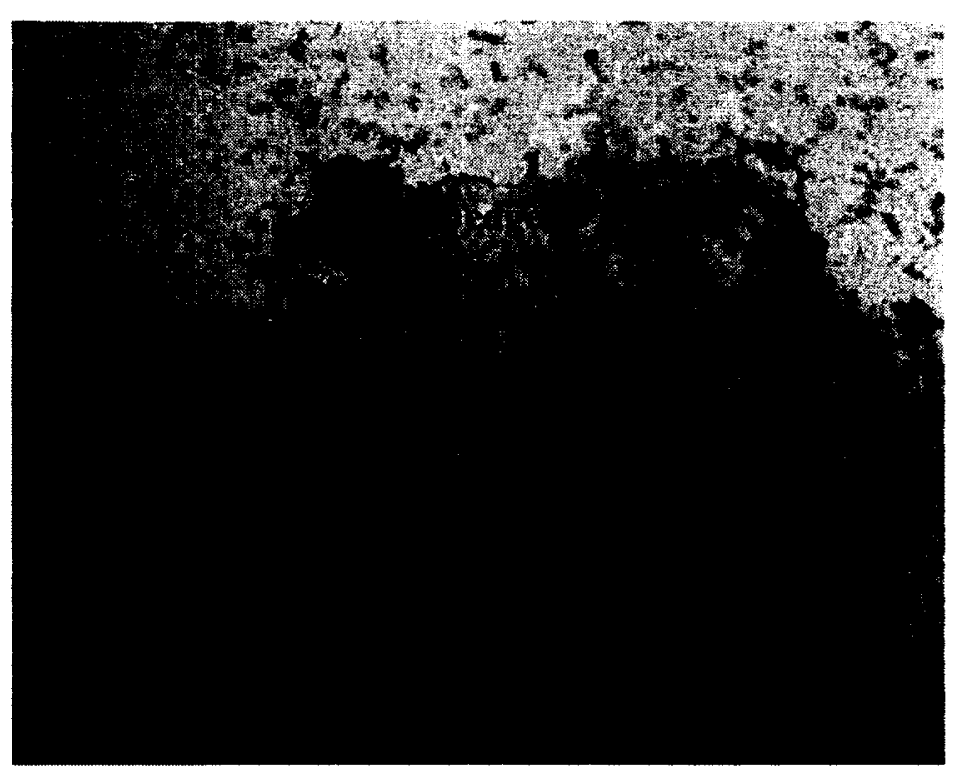

(a)

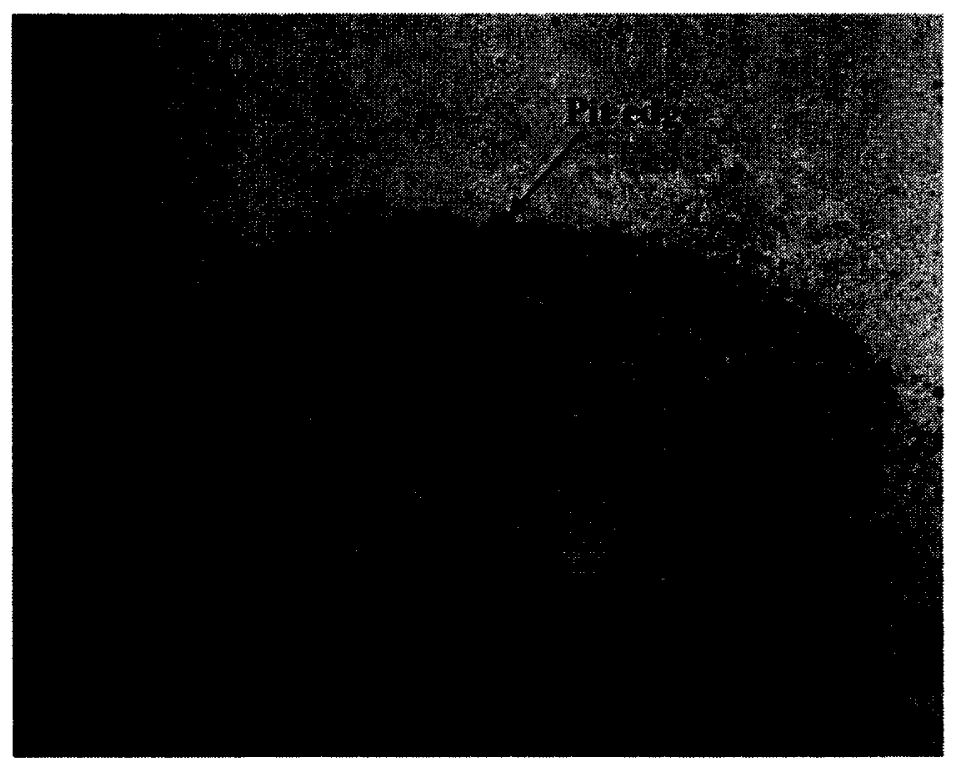

(b)

Figure 4-6: Specimens tested at $60^{\circ} \mathrm{C}$ showing pits (100X magnification):

(a) Stellite 6B and (b) Stellite 6K. 
Table 4-1: CPT test results of Stellite 6B and Stellite 6K in Green Death solution

\begin{tabular}{|c|c|c|c|c|c|c|c|c|}
\hline Temperature & $25^{\circ} \mathrm{C}$ & $30^{\circ} \mathrm{C}$ & $35^{\circ} \mathrm{C}$ & $40^{\circ} \mathrm{C}$ & $45^{\circ} \mathrm{C}$ & $50^{\circ} \mathrm{C}$ & $55^{\circ} \mathrm{C}$ & $60^{\circ} \mathrm{C}$ \\
\hline Alloy & $\begin{array}{c}\text { No } \\
\text { pits }\end{array}$ & $\begin{array}{c}\text { No } \\
\text { pits }\end{array}$ & $\begin{array}{c}\text { No } \\
\text { pits }\end{array}$ & $\begin{array}{c}\text { No } \\
\text { pits }\end{array}$ & $\begin{array}{c}\text { No } \\
\text { pits }\end{array}$ & $\begin{array}{c}\text { No } \\
\text { pits }\end{array}$ & $\begin{array}{c}\text { No } \\
\text { pits }\end{array}$ & $\begin{array}{c}\text { Pits } \\
\text { found }\end{array}$ \\
\hline Stellite 6K & $\begin{array}{c}\text { No } \\
\text { pits }\end{array}$ & $\begin{array}{c}\text { No } \\
\text { pits }\end{array}$ & $\begin{array}{c}\text { No } \\
\text { pits }\end{array}$ & $\begin{array}{c}\text { No } \\
\text { pits }\end{array}$ & $\begin{array}{c}\text { No } \\
\text { pits }\end{array}$ & $\begin{array}{c}\text { No } \\
\text { pits }\end{array}$ & $\begin{array}{c}\text { No } \\
\text { pits }\end{array}$ & $\begin{array}{c}\text { Pits } \\
\text { found }\end{array}$ \\
\hline
\end{tabular}

To investigate the geometry of the pits, the tested specimens were examined under SEM at a high magnification. To study the cross section profiles of the pits, the specimens were sectioned with a precise cutting machine, Stuers Secotom-10 Cutting Device, shown in Figure 4-7. An alumina cut-off wheel, which is suggested for use of cutting hard ferrous metals ( $>$ HV500), was used for cutting Stellite 6B and Stellite 6K specimens with the operation parameters as: spindle speed of $2500 \mathrm{rpm}$ and cutting rate of 0.015 $\mathrm{mm} / \mathrm{s}$. The detailed geometry of a big pit on the Stellite $6 \mathrm{~K}$ specimen surface under SEM is shown in Figure 4-8 as an example. It can be seen that there are also many small pits in the surface, indicated by arrows. 


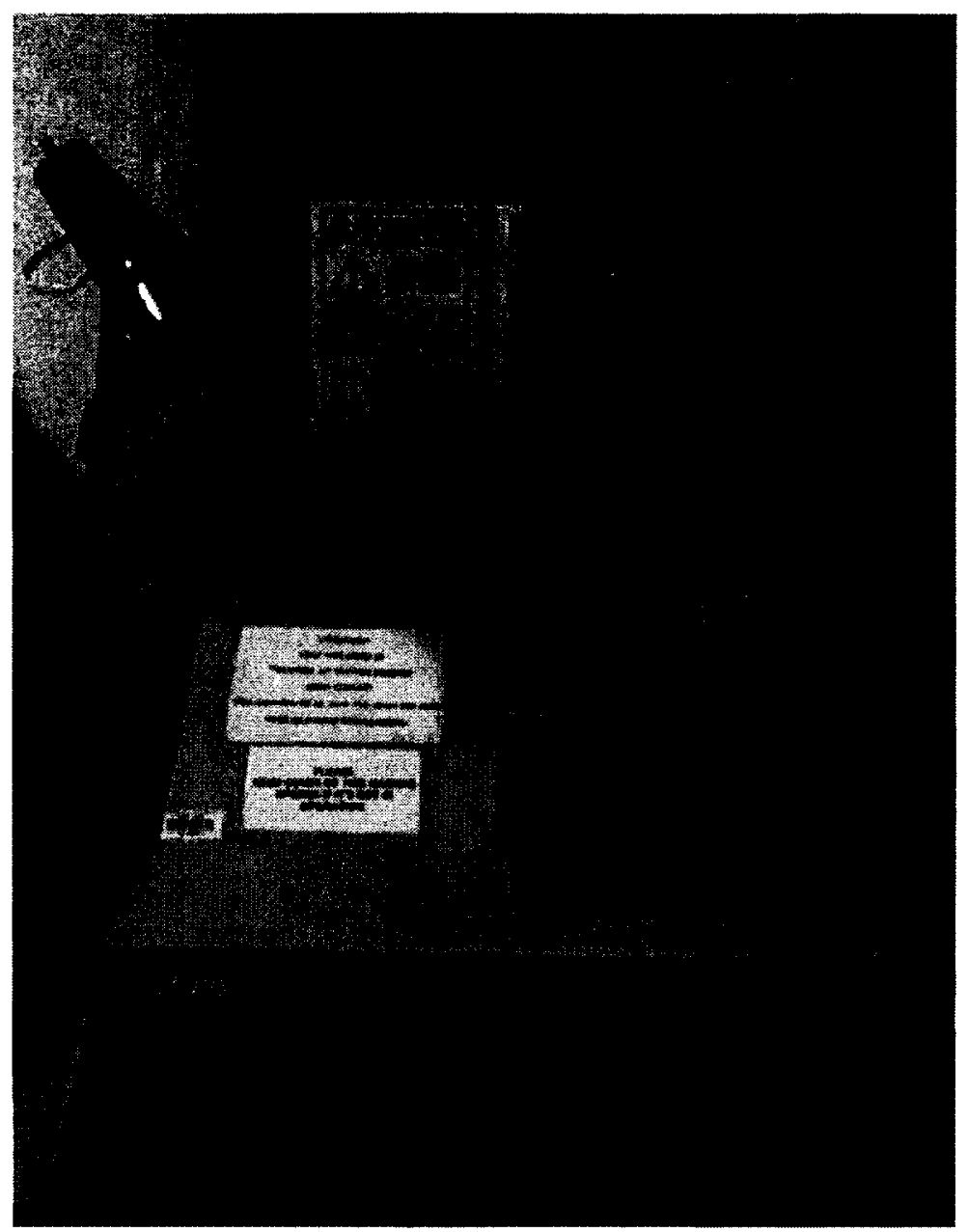

Figure 4-7: Struers Secotom-10 Cutting Device. 


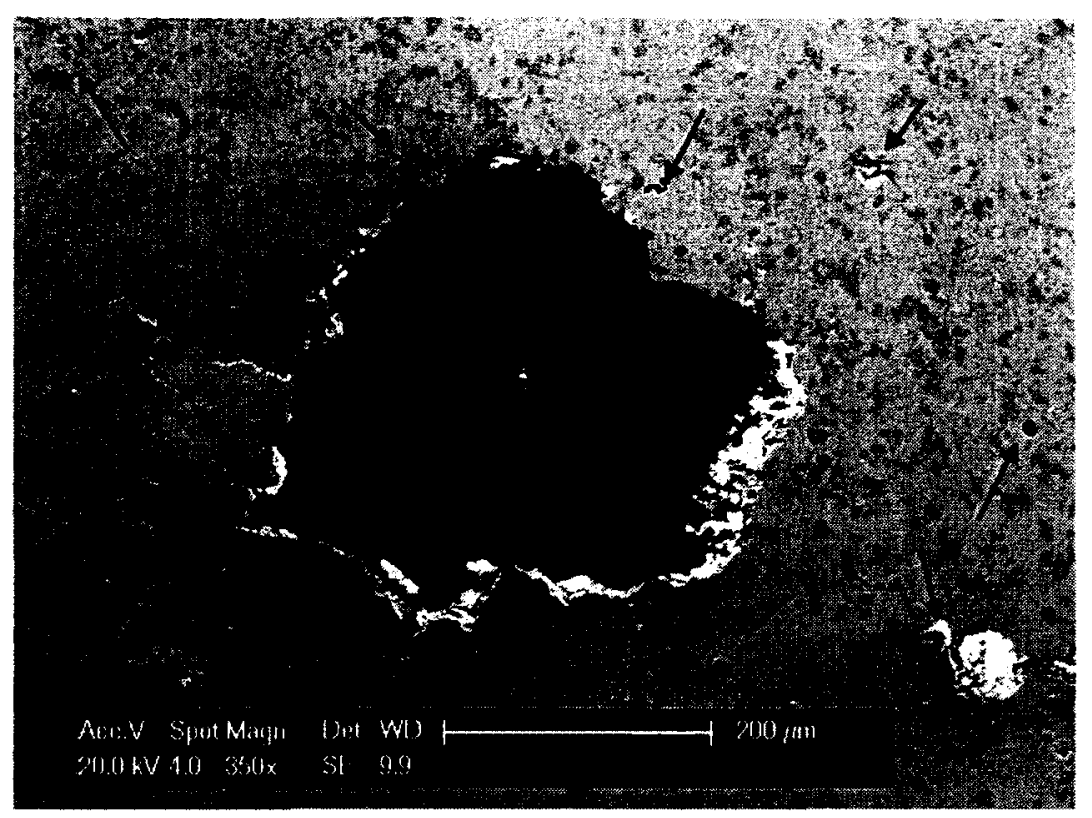

(a)

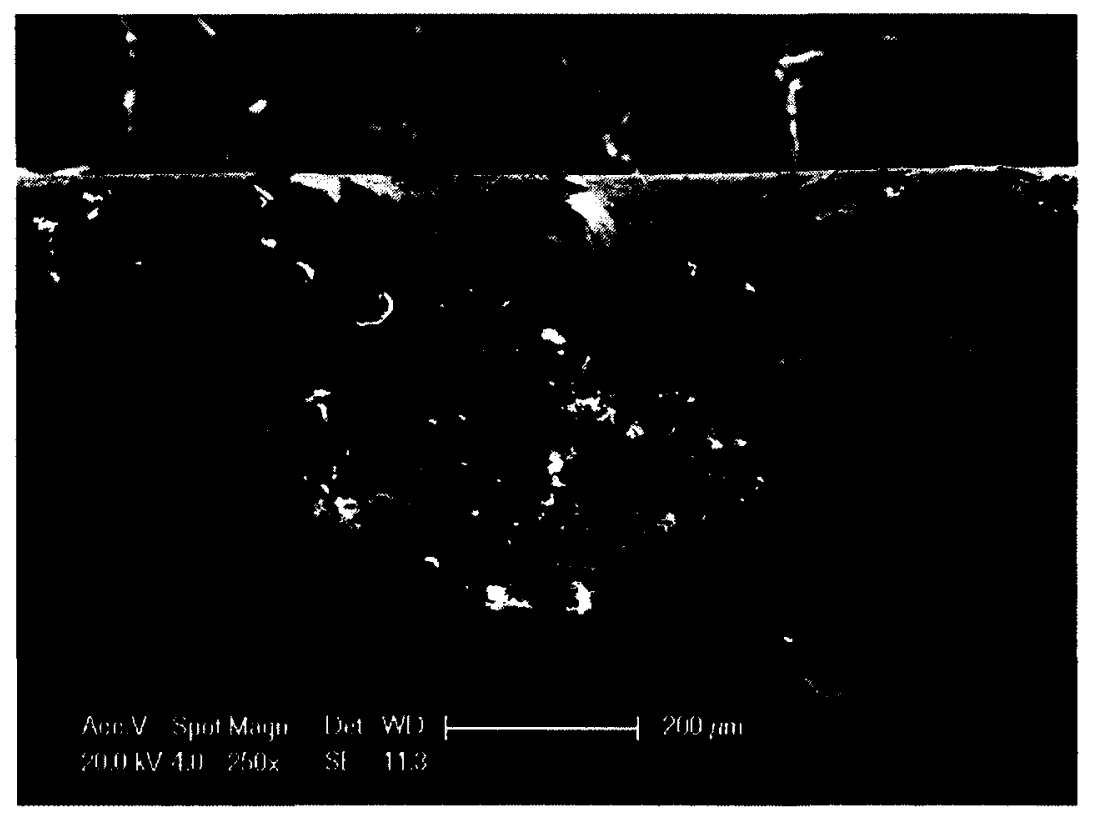

(b)

Figure 4-8: SEM images of a big pit in the Stellite $6 \mathrm{~K}$ specimen surface tested in

Grteen Death solution at $60^{\circ} \mathrm{C}$ for $24 \mathrm{~h}$ : (a) surface view and (b) section view. 


\subsubsection{Mass loss}

In general, immersion test can change the weight of the specimen with either gain or loss. If the substances in the chemical solution react with the tested material to generate the reaction products which integrate with original material, the specimen turns out weight gain. On the contrary, if the reaction products mainly dissolve into the ambience solution, the specimen shows weight loss. Based on the weight data of the specimens measured before and after the immersion test, the weight changes of each specimen were calculated and presented in Table 4-2 and Table 4-3. The measured data are in gram so that they are also mass data. From these tables, it is evident that mass change did occur on each specimen; all the specimens show mass loss.

Table 4-2: Weight data (gram) of Stellite 6B

\begin{tabular}{|c|c|c|c|c|c|c|}
\hline \multirow{2}{*}{ Sime(day) } & \multicolumn{2}{|c|}{2} & \multicolumn{2}{c|}{4} & \multicolumn{2}{c|}{6} \\
\cline { 2 - 7 } & Before & After & Before & After & Before & After \\
\hline 1 & 21.8961 & 21.8795 & 21.7333 & 21.6165 & 21.9552 & 21.6794 \\
\hline 2 & 22.0765 & 22.0530 & 21.9173 & 21.8473 & 21.9205 & 21.6349 \\
\hline Time(day) & \multicolumn{2}{|c|}{8} & \multicolumn{3}{|c|}{10} & \multicolumn{2}{|c|}{12} \\
\hline \multirow{2}{*}{ Specimen } & Before & After & Before & After & Before & After \\
\hline 1 & 22.0265 & 21.0935 & 21.8230 & 20.9922 & 21.6235 & 19.3959 \\
\hline 2 & 21.6560 & 20.7239 & 21.9809 & 20.2865 & 21.6749 & 20.7543 \\
\hline
\end{tabular}


Table 4-3: Weight data (gram) of Stellite 6K

\begin{tabular}{|c|c|c|c|c|c|c|}
\hline \multirow{2}{*}{ Time(day) } & \multicolumn{2}{|c|}{2} & \multicolumn{2}{c|}{4} & \multicolumn{2}{c|}{6} \\
\cline { 2 - 7 } Specimen & Before & After & Before & After & Before & After \\
\hline 1 & 32.0559 & 31.9642 & 32.1962 & 31.1352 & 32.1379 & 30.2142 \\
\hline 2 & 32.0943 & 31.8149 & 32.2230 & 31.3763 & 32.1696 & 30.7360 \\
\hline Time(day) & \multicolumn{2}{|c|}{$\mathbf{8}$} & \multicolumn{2}{|c|}{10} & \multicolumn{2}{|c|}{12} \\
\hline \multirow{2}{*}{ Specimen } & Before & After & Before & After & Before & After \\
\hline 1 & 32.0967 & 30.1116 & 32.2247 & 30.6236 & 32.2211 & 30.0032 \\
\hline 2 & 32.1581 & 30.5556 & 32.1134 & 29.9536 & 32.1671 & 30.2334 \\
\hline
\end{tabular}

As two specimens were tested in each condition for each alloy, the average of the mass losses of the two specimens was taken as the final mass loss of the alloy in a given test condition. The mass loss results for Stellite $6 \mathrm{~B}$ and Stellite $6 \mathrm{~K}$ are summarized in the histogram in Figure 4-9. It is shown that the mass losses of Stellite $6 \mathrm{~K}$ are apparently larger than those of Stellite $6 \mathrm{~B}$ in all the test conditions 


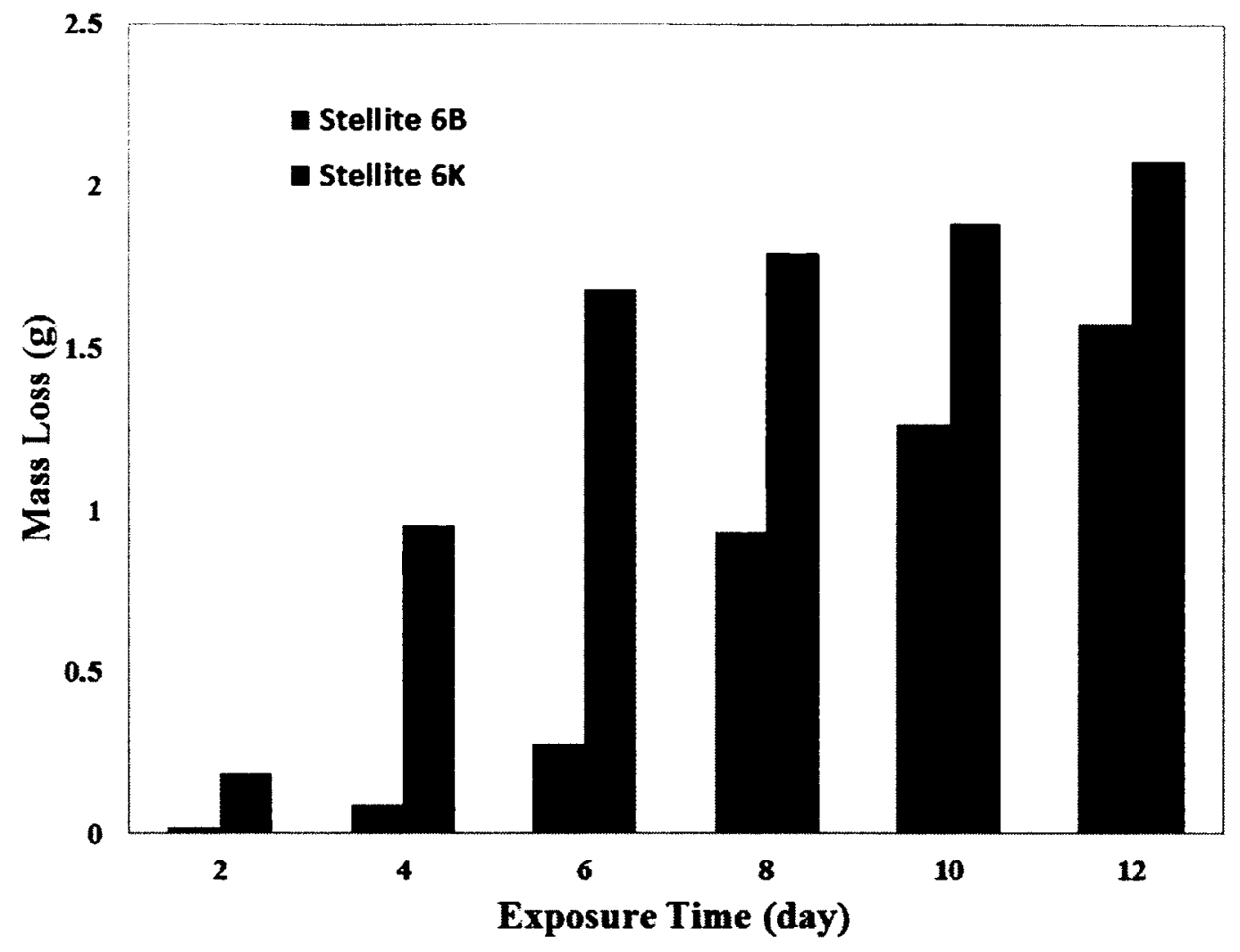

Figure 4-9: Comparison of mass loss between Stellite 6B and Stellite 6K in Green Death solution at $50^{\circ} \mathrm{C}$.

\subsubsection{Thickness change}

Similar to weight (mass) change, the thickness of each specimen was measured before and after the immersion test, and the data are recorded in Table 4-4 and Table 4-5. In general, the specimen thickness may increase or decrease after the test, however, from the data in the tables, both Stellite $6 \mathrm{~B}$ and Stellite $6 \mathrm{~K}$ show a reduction in thickness due to the corrosion. The average thickness loss of each alloy under each test condition was 
obtained from the thickness changes of the two specimens tested in the same condition; the values are illustrated in the histogram in Figure 4-10. Both Stellite $6 \mathrm{~B}$ and Stellite $6 \mathrm{~K}$ show an increasing trend of thickness loss with exposure time, although Stellite $6 \mathrm{~B}$ has a reverse behavior for 8 and 10 day tests.

Table 4-4: Measured thickness data $(\mathrm{mm})$ of Stellite $6 \mathrm{~B}$

\begin{tabular}{|c|c|c|c|c|c|c|}
\hline \multirow{2}{*}{ Time(day) } & \multicolumn{2}{|c|}{2} & \multicolumn{2}{c|}{4} & \multicolumn{2}{c|}{6} \\
\cline { 2 - 8 } & Before & After & Before & After & Before & After \\
\hline 1 & 2.98 & 2.92 & 2.99 & 2.92 & 2.99 & 2.91 \\
\hline 2 & 2.99 & 2.95 & 2.99 & 2.92 & 3.00 & 2.92 \\
\hline \multirow{2}{*}{ Time(day) } & \multicolumn{2}{|c|}{$\mathbf{8}$} & & $\mathbf{1 0}$ & \multicolumn{2}{|c|}{12} \\
\cline { 2 - 8 } & Before & After & Before & After & Before & After \\
\hline \multirow{2}{*}{$\mathbf{1}$} & 2.99 & 2.89 & 2.98 & 2.90 & 2.99 & 2.87 \\
\hline 2 & 2.97 & 2.93 & 2.97 & 2.89 & 3.01 & 2.88 \\
\hline
\end{tabular}


Table 4-5: Measured thickness data $(\mathrm{mm})$ of Stellite $6 \mathrm{~K}$

\begin{tabular}{|c|c|c|c|c|c|c|}
\hline Time(day) & \multicolumn{2}{|c|}{2} & \multicolumn{2}{|c|}{4} & \multicolumn{2}{|c|}{6} \\
\hline & Before & After & Before & After & Before & After \\
\hline 1 & 3.61 & 3.58 & 3.62 & 3.57 & 3.61 & 3.56 \\
\hline 2 & 3.62 & 3.56 & 3.63 & 3.58 & 3.61 & 3.55 \\
\hline Time(day) & \multicolumn{2}{|c|}{8} & \multicolumn{2}{|c|}{10} & \multicolumn{2}{|c|}{12} \\
\hline Specimen & Before & After & Before & After & Before & After \\
\hline 1 & 3.64 & 3.56 & 3.68 & 3.52 & 3.65 & 3.50 \\
\hline 2 & 3.65 & 3.55 & 3.67 & 3.52 & 3.70 & 3.51 \\
\hline
\end{tabular}




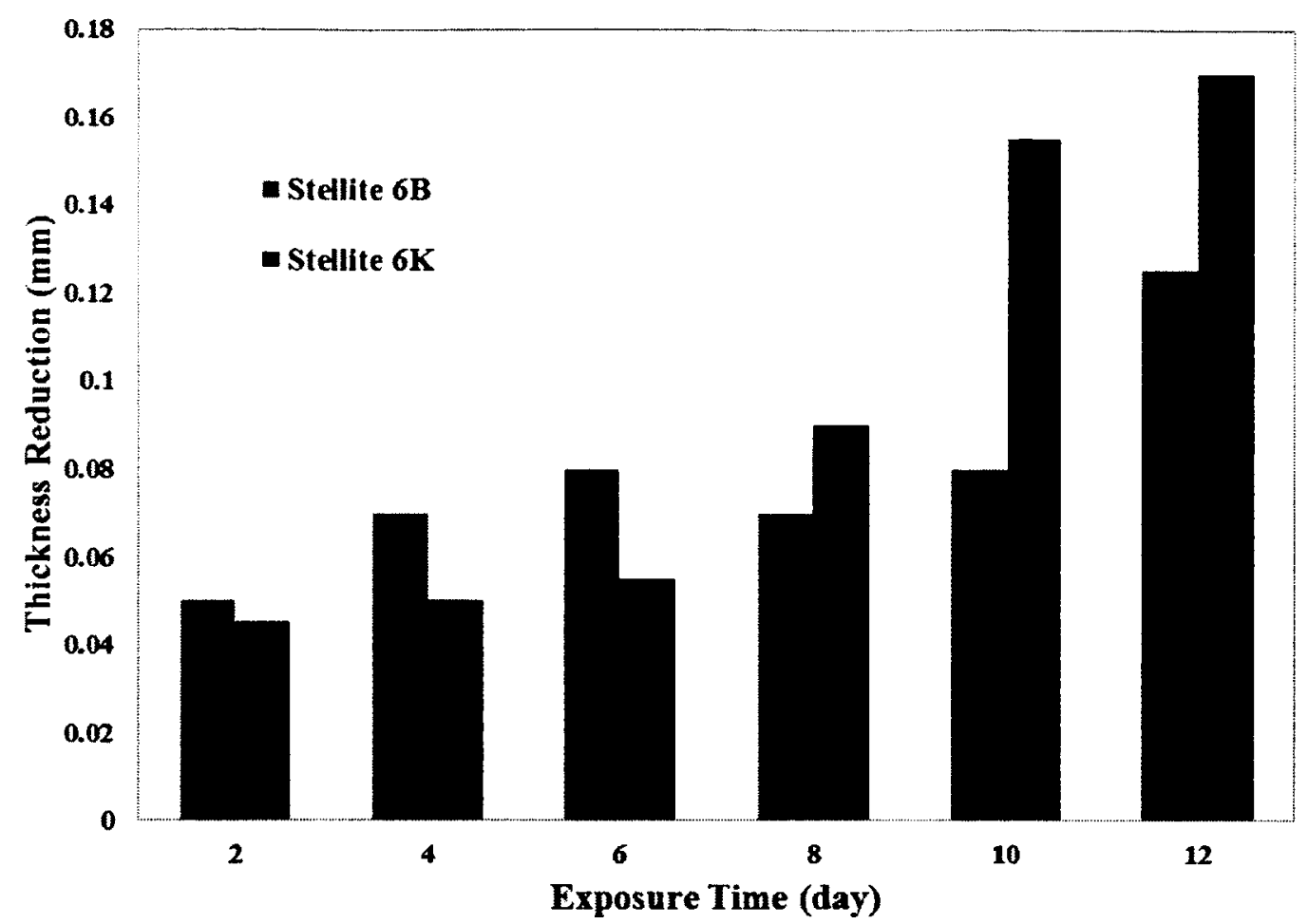

Figure 4-10: Comparison of thickness reduction between Stellite 6B and Stellite 6K in Green Death solution at $50^{\circ} \mathrm{C}$.

\subsubsection{EVA model}

\subsubsection{Pit depth measurement}

The EVA model is a statistics analysis method in pit depth study; therefore the input of the EVA model is maximum pit depths. In this method the data of top ten maximum pit depths are collected from each specimen. Thus, for each exposure period twenty maximum pit depth data were collected and ranked in an order from small to large value, because two specimens were tested for each condition. The pit depths were determined 
using a CONTOURECORD 1700SD surface texture and contour measuring instrument, shown in Figure 4-11, with the Tokyo Seimitisu Integrated Measuring System (TIMS) software (version 7.99B). The scale resolution of this facility is $0.0016 \mu \mathrm{m}$. The operation parameters are: $X$-axis measuring speed of $0.03 \mathrm{~mm} / \mathrm{s}$, stylus force of $30 \mathrm{mN}$, retract function. A DT45505 cemented carbide stylus, shown in Figure 4-12, was used with the measuring system, which is a standard accessory with $d=3 \mathrm{~mm}, L_{1}=60 \mathrm{~mm}$, $L_{2}=52 \mathrm{~mm}[49]$.

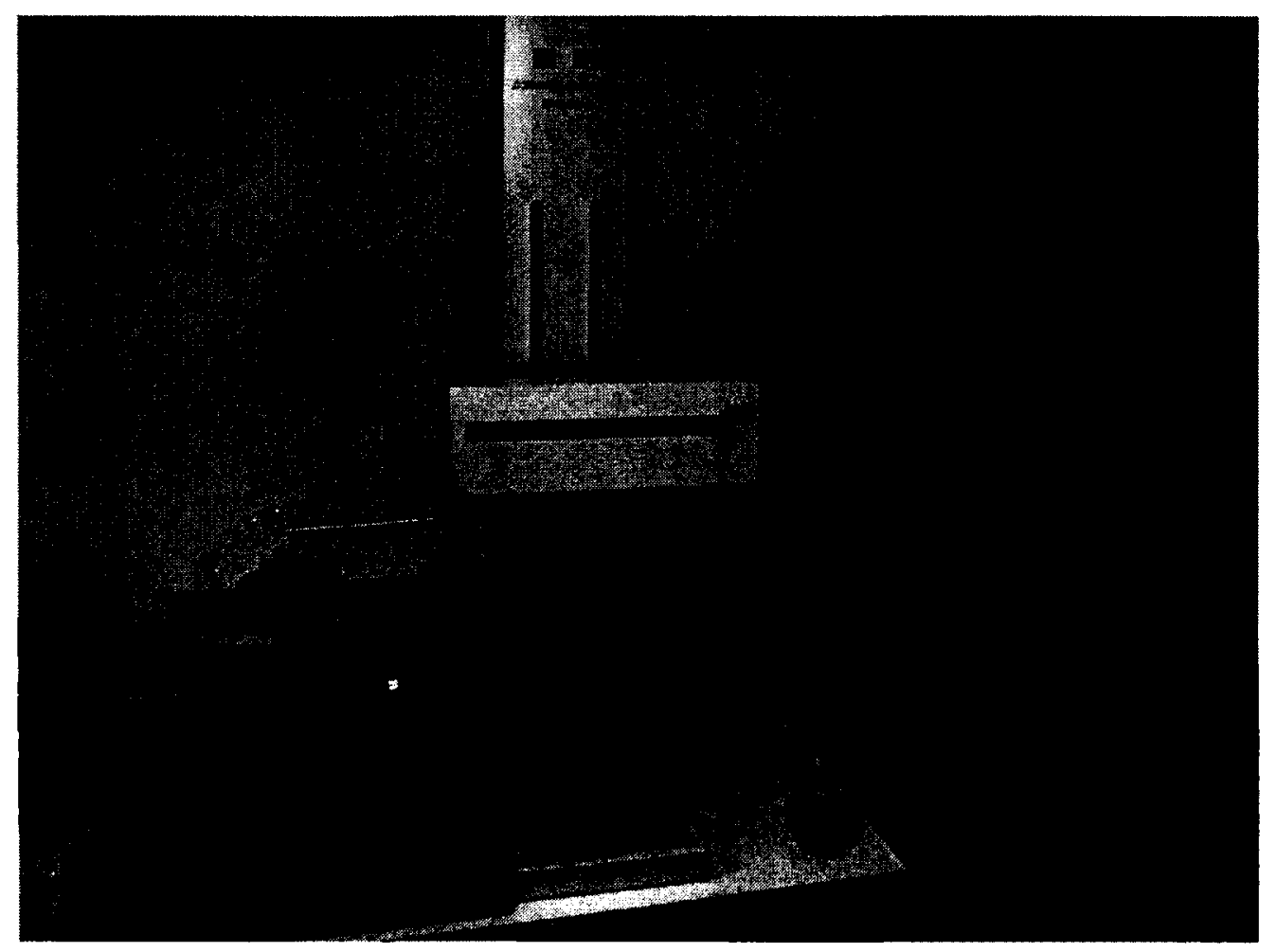

Figure 4-11: CONTOURECORD 1700SD surface texture and contour measuring instrument. 

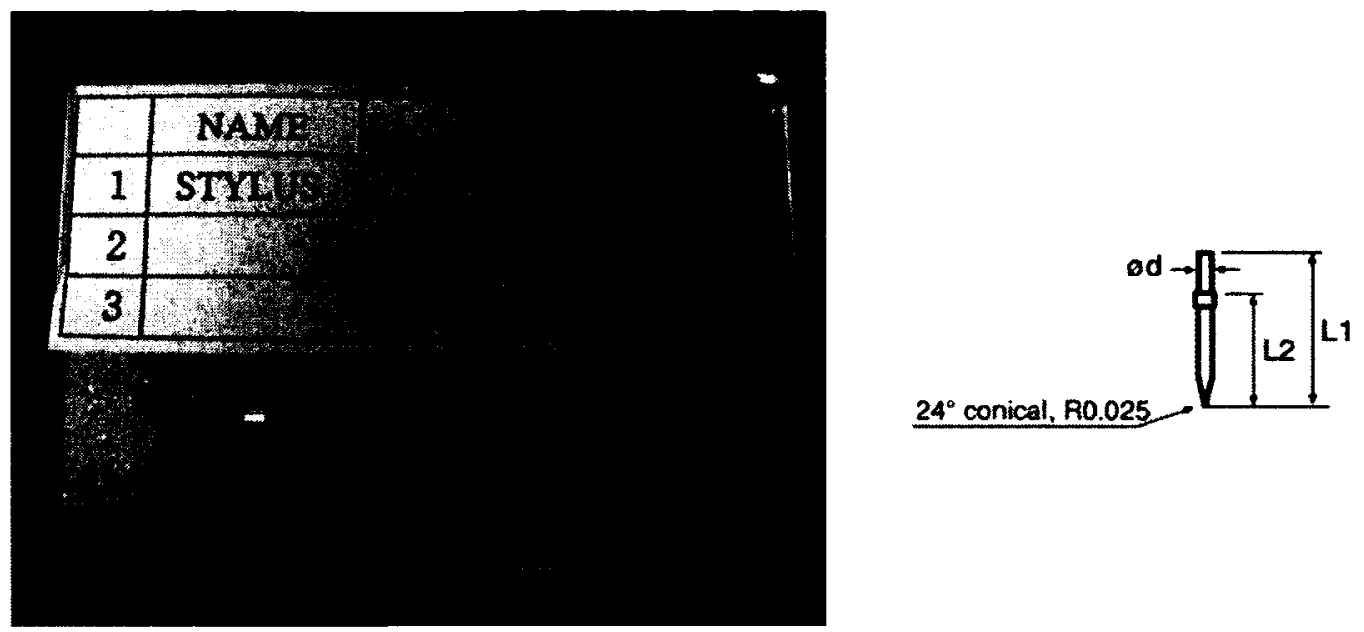

Figure 4-12: DT45505 stylus.

With this measuring system the cross section of a pit can be simulated and the corresponding 2D profile is obtained automatically. Some selected profiles of pits in Stellite $6 \mathrm{~B}$ and Stellite $6 \mathrm{~K}$ specimens tested for different exposure times are shown in Figure 4-13 and Figure 4-14. 

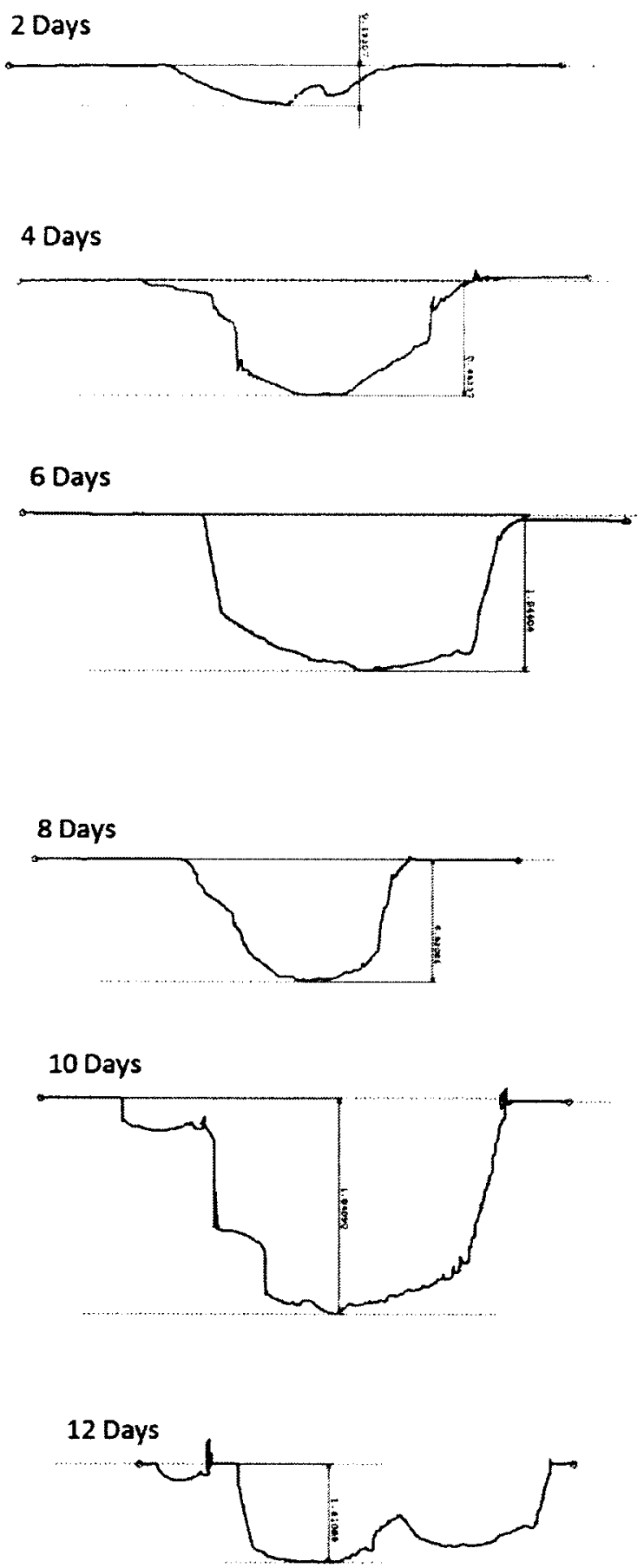

Figure 4-13: 2D profiles of cross section of pits in Stellite 6B specimen. 

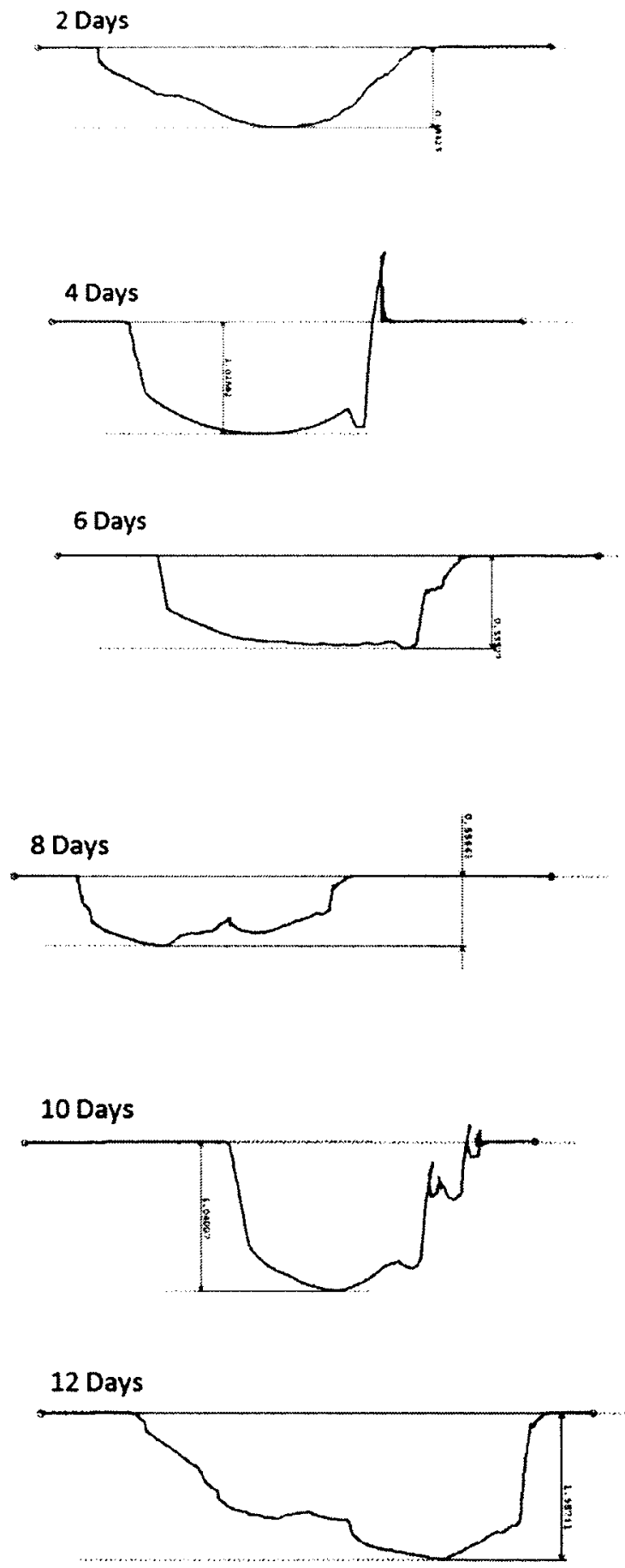

Figure 4-14: 2D profiles of cross section of pits in Stellite 6K specimen. 
In consideration of the thickness change, the maximum pit depth value should be modified by adding half of the thickness reduction, assuming that the thickness changes on both top and bottom surfaces of the specimen are uniform and the reductions are the same. Once adding single side thickness reduction on original data, the maximum pits depth data would become as shown in Table 4-6 and Table 4-7.

Table 4-6: Modified maximum pit depths $(\mathrm{mm})$ of Stellite 6B

\begin{tabular}{|c|c|c|c|c|c|c|}
\hline Time(day) & $\mathbf{2}$ & $\mathbf{4}$ & $\mathbf{6}$ & $\mathbf{8}$ & $\mathbf{1 0}$ & $\mathbf{1 2}$ \\
\hline $\mathbf{1}$ & & & & & & \\
\hline $\mathbf{2}$ & 0.17161 & 0.23271 & 0.34305 & 0.72436 & 0.37799 & 0.87643 \\
\hline $\mathbf{3}$ & 0.17322 & 0.23448 & 0.34800 & 0.74564 & 0.62474 & 0.98087 \\
\hline $\mathbf{4}$ & 0.17747 & 0.23996 & 0.38912 & 0.89046 & 0.73494 & 1.03264 \\
\hline $\mathbf{5}$ & 0.18112 & 0.24158 & 0.39252 & 0.90487 & 1.01463 & 1.08033 \\
\hline $\mathbf{6}$ & 0.18536 & 0.24362 & 0.39328 & 0.91662 & 1.11606 & 1.36888 \\
\hline $\mathbf{7}$ & 0.19275 & 0.28373 & 0.50290 & 0.92228 & 1.14805 & 1.40009 \\
\hline $\mathbf{8}$ & 0.20242 & 0.31485 & 0.51390 & 0.95712 & 1.15471 & 1.43751 \\
\hline $\mathbf{9}$ & 0.22696 & 0.32764 & 0.54277 & 0.96541 & 1.15832 & 1.51321 \\
\hline $\mathbf{1 0}$ & 0.23335 & 0.34140 & 0.55989 & 1.14693 & 1.29607 & 1.5819 \\
\hline $\mathbf{1 1}$ & 0.26646 & 0.36333 & 0.59794 & 1.16754 & 1.29725 & 1.58469 \\
\hline $\mathbf{1 2}$ & 0.26678 & 0.39921 & 0.67809 & 1.19987 & 1.36359 & 1.63726 \\
\hline $\mathbf{1 3}$ & 0.29029 & 0.40082 & 0.68573 & 1.26804 & 1.40876 & 1.63856 \\
\hline $\mathbf{1 4}$ & 0.30119 & 0.46895 & 0.74215 & 1.30929 & 1.56380 & 1.66833 \\
\hline $\mathbf{1 5}$ & 0.37412 & 0.47837 & 0.75980 & 1.33656 & 1.68291 & 1.67339 \\
\hline $\mathbf{1 6}$ & 0.40150 & 0.48397 & 0.86617 & 1.38086 & 1.68499 & 1.71195 \\
\hline $\mathbf{1 7}$ & 0.40632 & 0.50041 & 0.86977 & 1.42447 & 1.71345 & 1.90157 \\
\hline $\mathbf{1 8}$ & 0.40656 & 0.50508 & 1.07919 & 1.43578 & 1.75723 & 1.91140 \\
\hline $\mathbf{1 9}$ & 0.56544 & 0.58454 & 1.08604 & 1.45769 & 1.76583 & 1.94902 \\
\hline $\mathbf{2 0}$ & 0.60716 & 0.86946 & 1.09263 & 1.53755 & 1.87872 & 2.23516 \\
\hline & 0.65128 & 0.94720 & 1.25990 & 1.68231 & 1.88867 & 2.46407 \\
\hline
\end{tabular}


Table 4-7: Modified maximum pit depths $(\mathrm{mm})$ of Stellite $6 \mathrm{~K}$

\begin{tabular}{|c|c|c|c|c|c|c|}
\hline Time(day) & $\mathbf{2}$ & $\mathbf{4}$ & $\mathbf{6}$ & $\mathbf{8}$ & $\mathbf{1 0}$ & $\mathbf{1 2}$ \\
\hline $\mathbf{R a n k} \boldsymbol{r}$ & & & & & & \\
\hline $\mathbf{2}$ & 0.25293 & 0.39033 & 0.33182 & 0.39591 & 1.02918 & 0.69274 \\
\hline $\mathbf{3}$ & 0.30574 & 0.40470 & 0.34250 & 0.57486 & 1.05918 & 0.72573 \\
\hline $\mathbf{4}$ & 0.31217 & 0.42546 & 0.36808 & 0.60163 & 1.07450 & 0.76658 \\
\hline $\mathbf{5}$ & 0.32872 & 0.45482 & 0.40485 & 0.78181 & 1.16169 & 0.95405 \\
\hline $\mathbf{6}$ & 0.34412 & 0.49288 & 0.43683 & 0.78987 & 1.17378 & 0.96630 \\
\hline $\mathbf{7}$ & 0.38908 & 0.51120 & 0.46047 & 0.82939 & 1.19165 & 1.01956 \\
\hline $\mathbf{8}$ & 0.41911 & 0.52194 & 0.46497 & 0.92969 & 1.21873 & 1.12366 \\
\hline $\mathbf{9}$ & 0.42791 & 0.52536 & 0.54115 & 1.00036 & 1.26691 & 1.12507 \\
\hline $\mathbf{1 0}$ & 0.43187 & 0.53792 & 0.57546 & 1.00902 & 1.28970 & 1.29619 \\
\hline $\mathbf{1 1}$ & 0.46832 & 0.54196 & 0.61681 & 1.02456 & 1.29044 & 1.31867 \\
\hline $\mathbf{1 2}$ & 0.47899 & 0.54842 & 0.67128 & 1.05041 & 1.29954 & 1.40777 \\
\hline $\mathbf{1 3}$ & 0.48563 & 0.55078 & 0.68339 & 1.07672 & 1.35102 & 1.50289 \\
\hline $\mathbf{1 4}$ & 0.49273 & 0.59728 & 0.85359 & 1.10723 & 1.42073 & 1.50553 \\
\hline $\mathbf{1 5}$ & 0.49816 & 0.63452 & 1.01030 & 1.16395 & 1.43325 & 1.52650 \\
\hline $\mathbf{1 6}$ & 0.50789 & 0.64229 & 1.10973 & 1.19746 & 1.58012 & 1.73888 \\
\hline $\mathbf{1 7}$ & 0.52774 & 0.67165 & 1.11931 & 1.32420 & 1.60460 & 1.86958 \\
\hline $\mathbf{1 8}$ & 0.56567 & 0.79185 & 1.21361 & 1.48280 & 1.62120 & 1.91162 \\
\hline $\mathbf{1 9}$ & 0.58093 & 0.82940 & 1.49210 & 1.55715 & 1.63461 & 1.92423 \\
\hline $\mathbf{2 0}$ & 0.58745 & 1.05092 & 1.67686 & 1.86746 & 1.66245 & 2.05134 \\
\hline & 0.63244 & 1.30927 & 1.77080 & 1.93742 & 1.95778 & 2.11455 \\
\hline
\end{tabular}

\subsubsection{Calculation of EVA parameters}

As mentioned in Chapter 2, cumulative extreme value distribution is given by $F=\frac{r}{n+1}$, and then $-\ln (-\ln F)$ can be obtained, where $r$ is the rank, shown in Table 4-6 and Table 4-7; and $n$ is the segment size, $n=20$, in this research, because 10 maximum pit depths were selected for each specimen and two specimens were tested for each condition. The values of cumulative probability, calculated from the above equations summarized in Table 4-8. 
Table 4-8: Cumulative probability distribution parameters for EVA model

(Segment $n=20$ )

\begin{tabular}{|c|c|c|}
\hline Rank $r$ & $F=r / n+1$ & $-\ln (-\ln F)$ \\
\hline 1 & $1 / 21=0.047619$ & -1.11334 \\
\hline 2 & $2 / 21=0.095238$ & -0.855 \\
\hline 3 & $3 / 21=0.142857$ & -0.66573 \\
\hline 4 & $4 / 21=0.190476$ & -0.50575 \\
\hline 5 & $5 / 21=0.238095$ & -0.36122 \\
\hline 6 & $6 / 21=0.285714$ & -0.22535 \\
\hline 7 & $7 / 21=0.333333$ & -0.09405 \\
\hline 8 & $8 / 21=0.380952$ & 0.035543 \\
\hline 9 & $9 / 21=0.428571$ & 0.165703 \\
\hline 10 & $10 / 21=0.47619$ & 0.29849 \\
\hline 11 & $11 / 21=0.52381$ & 0.435985 \\
\hline 12 & $12 / 21=0.571429$ & 0.580505 \\
\hline 13 & $13 / 21=0.619048$ & 0.734859 \\
\hline 14 & $14 / 21=0.666667$ & 0.90272 \\
\hline 15 & $15 / 21=0.714286$ & 1.08924 \\
\hline 16 & $16 / 21=0.761905$ & 1.302197 \\
\hline 17 & $17 / 21=0.809524$ & 1.554433 \\
\hline 18 & $18 / 21=0.857143$ & 1.869825 \\
\hline 19 & $19 / 21=0.904762$ & 2.301751 \\
\hline 20 & $20 / 21=0.952381$ & 3.020227 \\
\hline
\end{tabular}

Fitting the data of Table 4-6 and Table 4-7 in terms of the Gumbel Distribution theory by plotting $-\ln (-\ln F)$ against maximum pit depth, gives the slope, $1 / \sigma$, and the $X$-axis intercept, $\mu$, at $-\ln (-\ln F)=0$, as shown in Figure 4-15 and Figure 4-16. Furthermore, plotting the two parameters, $\sigma$ and $\mu$, against time shows the time-dependent behavior of the parameters, as shown in Figure 4-17 and Figure 4-18. The maximum pit depth values of Stellite 6B are generally smaller than those of Stellite $6 \mathrm{~K}$ for shorter exposure time tests but larger for longer exposure time tests, which are demonstrated by the $\mu$ value. 
The deviation of the data is nearly the same for the two alloys, which is characterized by the $\sigma$ value. Both of the parameters increase with the exposure time.

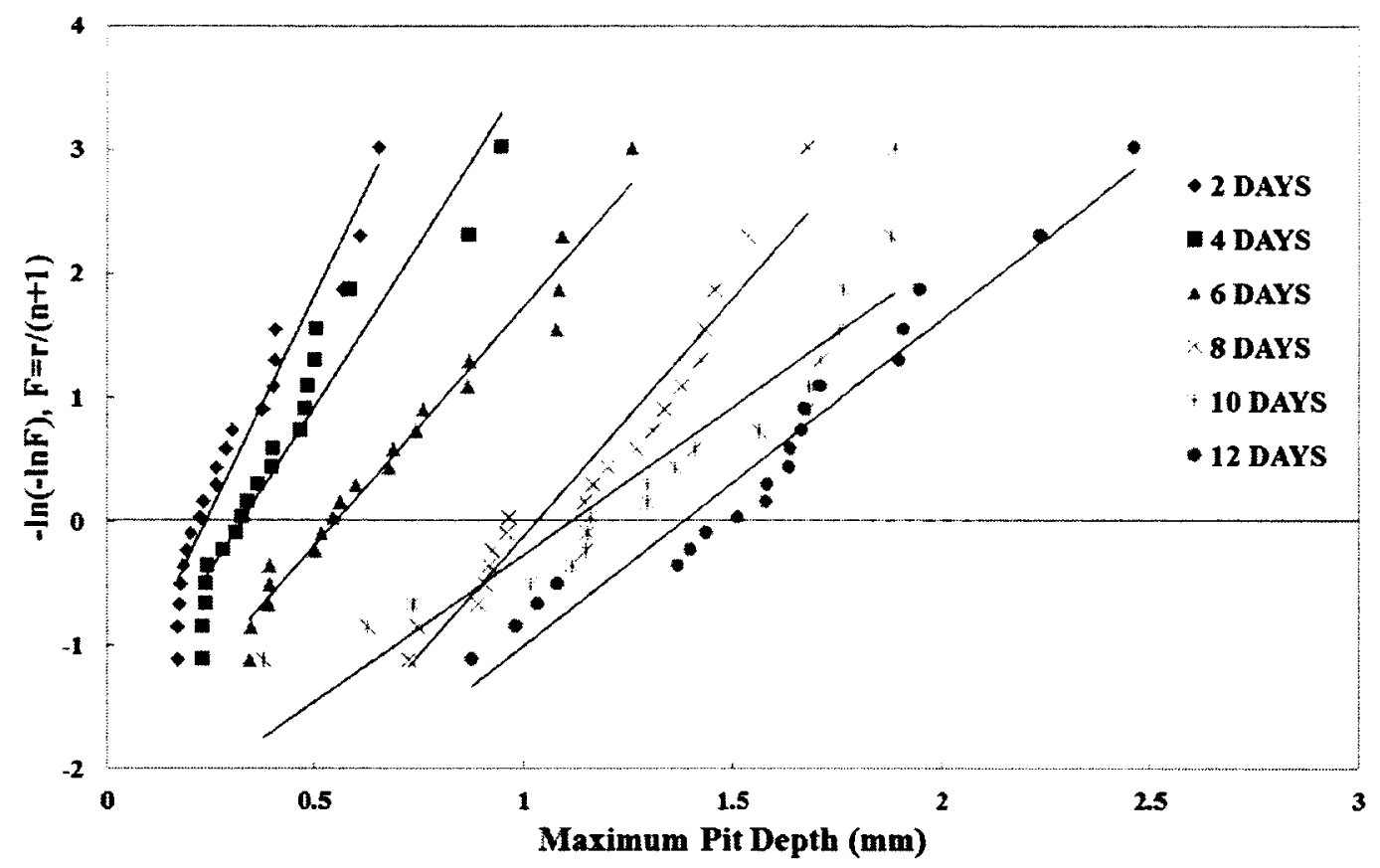

Figure 4-15: Extreme value fitting of Stellite 6B according to the Gumbel extreme value distribution. 


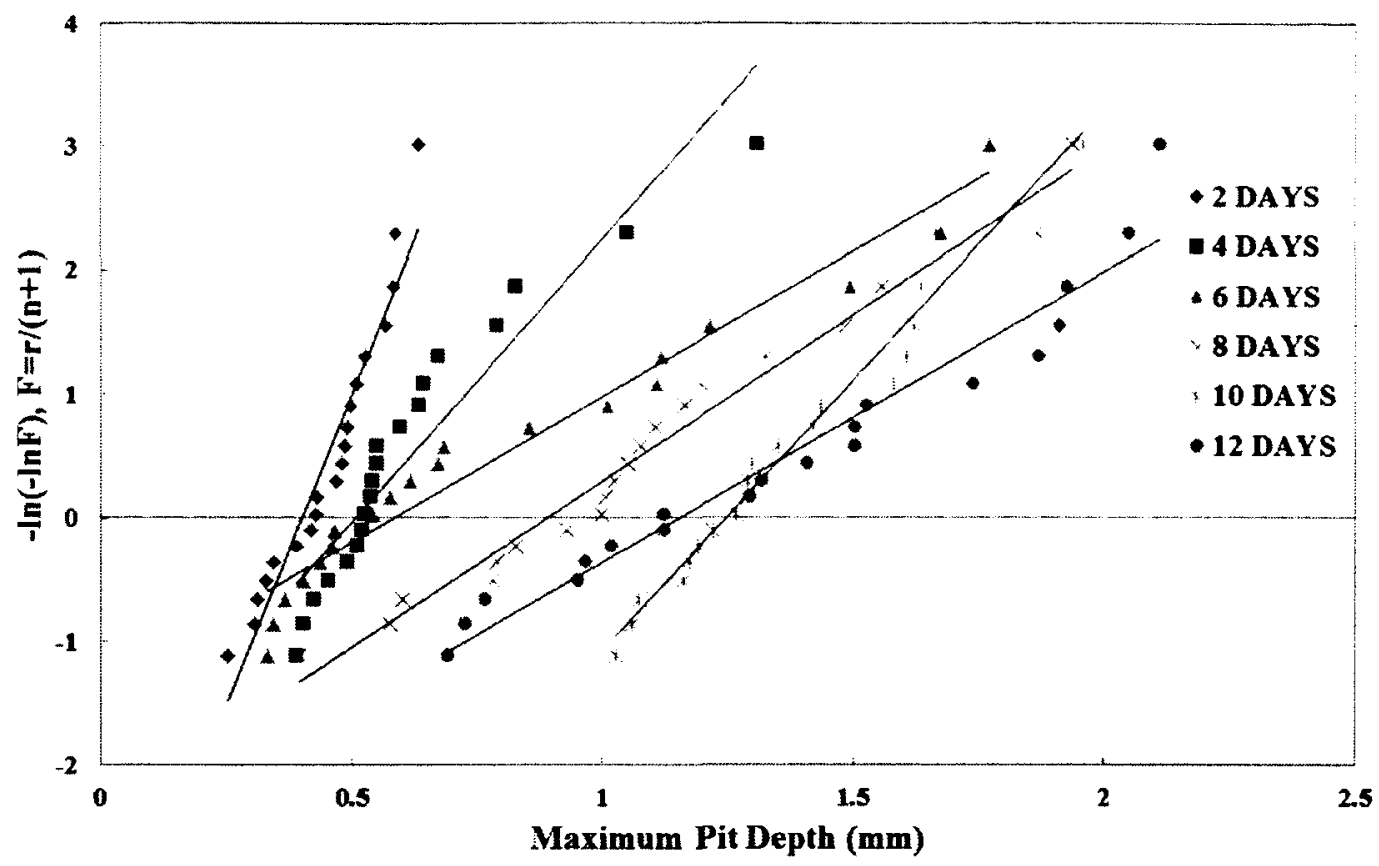

Figure 4-16: Extreme value fitting of Stellite $6 \mathrm{~K}$ according to the Gumbel extreme value distribution. 


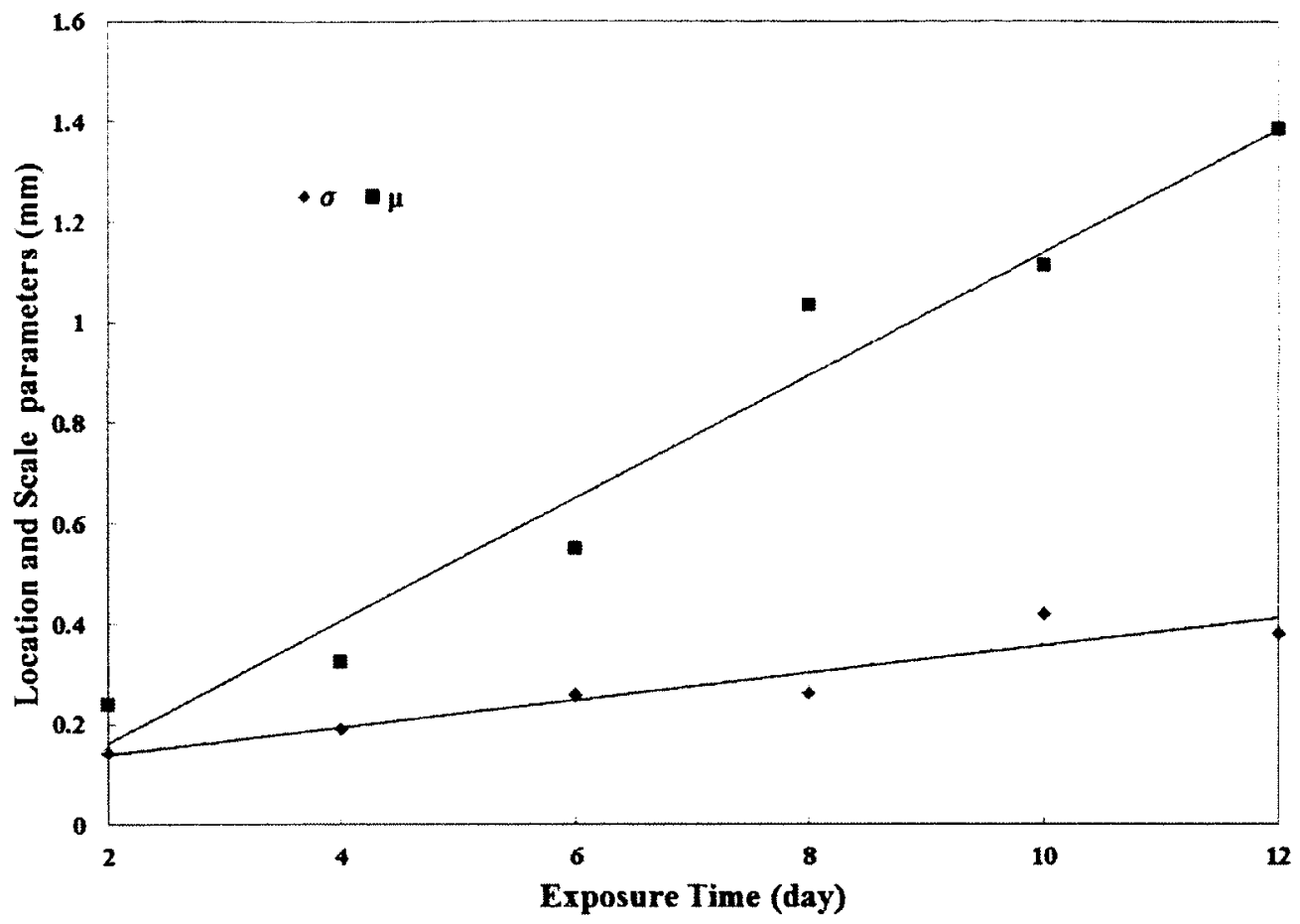

Figure 4-17: Time-dependence of the Gumbel Distribution parameters for

Stellite 6B. 


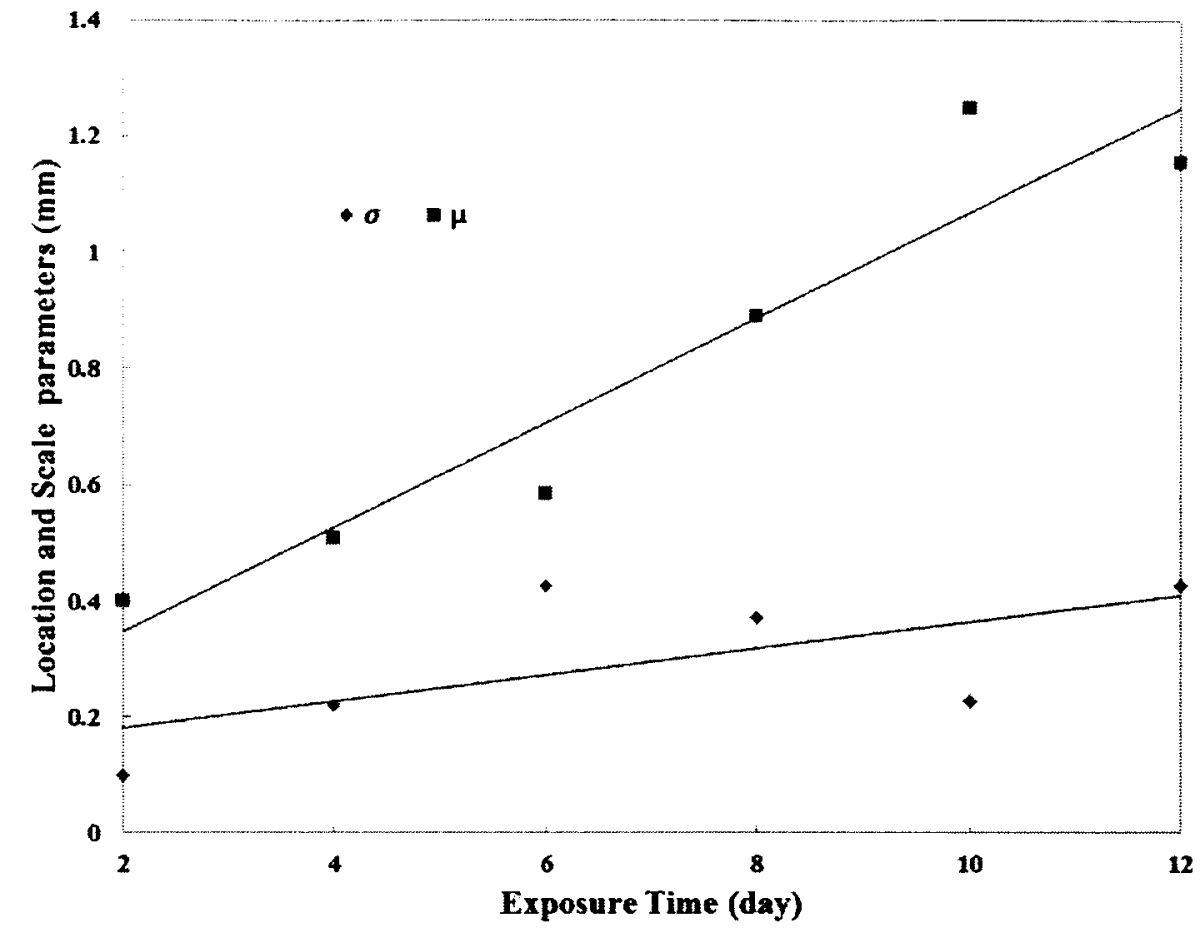

Figure 4-18: Time-dependence of the Gumbel Distribution parameters for Stellite 6K.

From Figure 4-17 and Figure 4-18, the slope of the $\mu$ line, $\gamma$, and the slope of the $\sigma$ line, $\beta$, can be obtained. As an example to demonstrate this model, assuming that the service lifetime of Stellite $6 \mathrm{~B}$ and Stellite $6 \mathrm{~K}$ is 10 years and that the material user will tolerate a risk $\alpha=0.5 \%$ chance of failure, from $R=-\ln [-\ln (1-\alpha)]$, the $R$ value is calculated to be 5.3. Finally, the minimum thickness, $D_{R}$, can be predicted according to $D_{R}=(\gamma+\beta R) t$, where $t=10 \mathrm{yr}, \gamma$ and $\beta$ are the slopes of the $\mu$ line and $\sigma$ line, respectively. The EVA model results for Stellite $6 \mathrm{~B}$ and Stellite $6 \mathrm{~K}$ are summarized in Table 4-9. The minimum thickness, $D_{R}$, values show that Stellite $6 \mathrm{~K}$ has better corrosion 
resistance in regard to pit depth as it requires less minimum thickness of the material for a given service life.

Table 4-9: EVA model results for Stellite 6B and Stellite 6K

\begin{tabular}{|c|c|c|c|}
\hline Parameter & $\gamma(\mathbf{m m} / \mathbf{d})$ & $\beta(\mathbf{m m} / \mathbf{d})$ & $D_{R}(\mathbf{m m})$ \\
\hline Alloy & & & \\
\hline Stellite 6B & 0.1195 & 0.0269 & 956.5555 \\
\hline Stellite 6K & 0.0859 & 0.0173 & 648.2053 \\
\hline
\end{tabular}

\subsubsection{Pitting area fraction}

In addition to pit depth, pitting area fraction is also an important parameter characterizing corrosion behavior of a material. Therefore, each tested specimen was analyzed in pitting area fraction using SEM. The procedure included two steps: (1) photograph both top and bottom surfaces of each specimen with a Tescan Vega II XUM VPSEM imaging system, shown in Figure 4-19; and (2) identify pitting areas of each surface and calculate the ratio of pitting area to total area of the surface, i.e., pitting area fraction, for each surface, using the Clemex vision lite 4.0 image analysis software. Two types of image techniques were utilized in one scan: Backscattered Electron (BSE) image and Secondary Electron (SE) image. BSE technique can provide better contrast for images and the SE technique can offer a 3D-like image. The SEM images of a pitting surface are shown in Figure 4-20 as an example. The pitting area fractions of each specimen, determined with the Clemex vision lite 4.0 image analysis software, are summarized in Table 4-10 and Table 4-11. 
Comparison of pitting area fraction between Stellite $6 \mathrm{~B}$ and Stellite $6 \mathrm{~K}$ is illustrated in Figure 4-21. It is shown that Stellite $6 \mathrm{~B}$ has better corrosion resistance as concerns pitting area fraction.

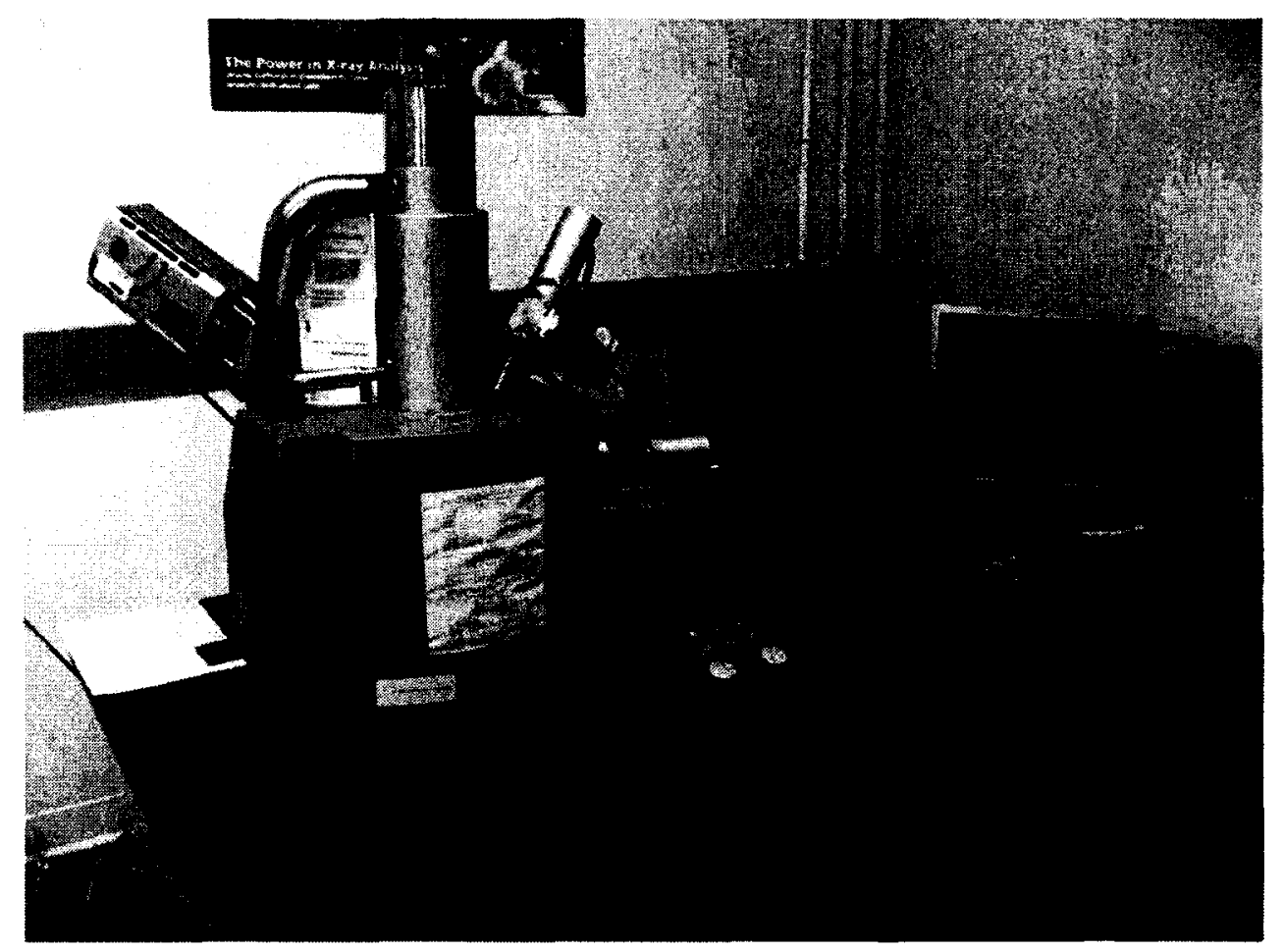

Figure 4-19: Tescan Vega II XUM VPSEM imaging system. 

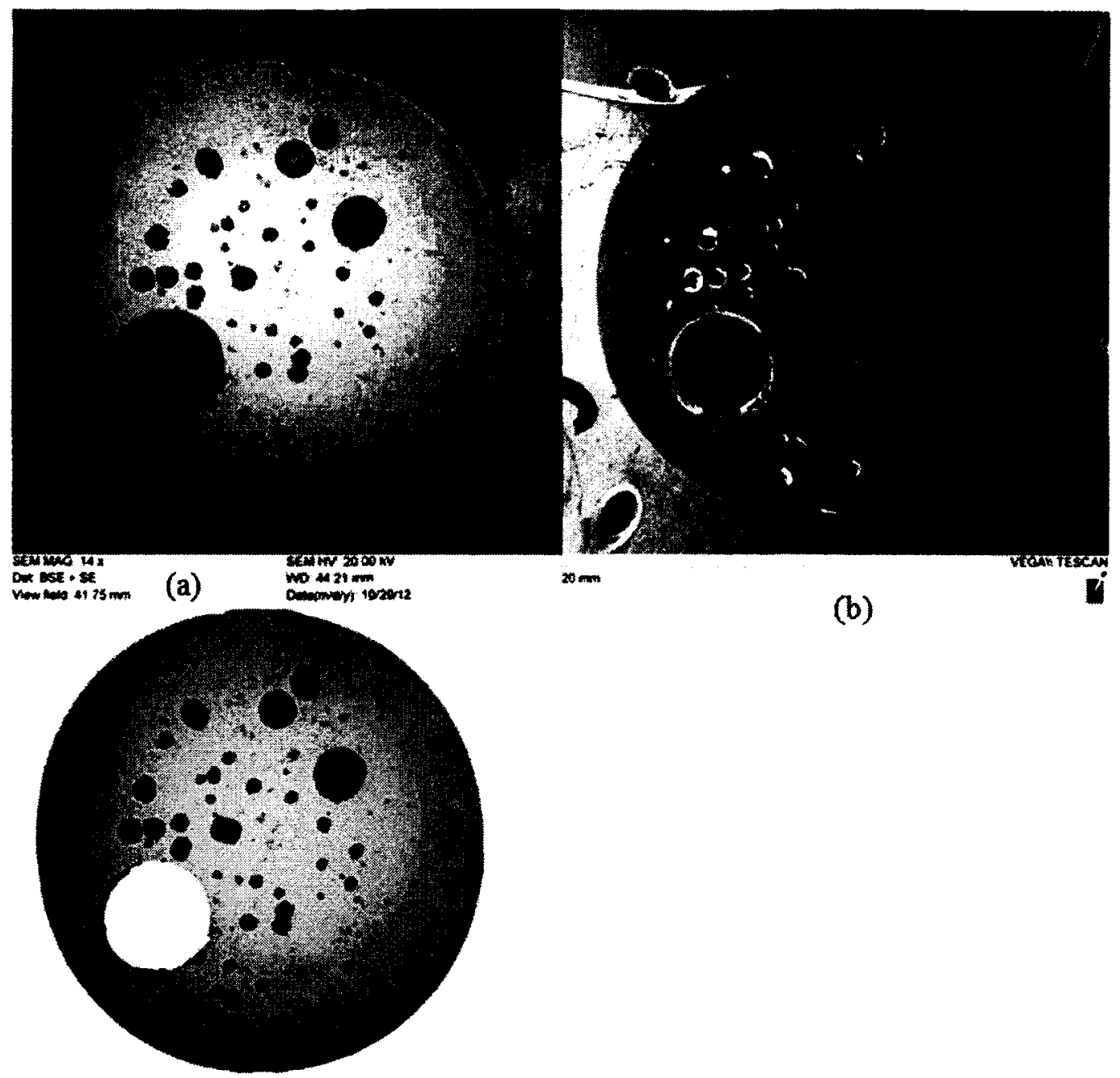

(b)

(c)

Figure 4-20: A pitting specimen surface: (a) BSE-SEM image, (b) SE-SEM image and (c) pits identified. 
Table 4-10: Pitting area fraction (\%) of Stellite 6B

\begin{tabular}{|c|c|c|c|c|c|c|}
\hline Time(day) & 2 & 4 & 6 & 8 & 10 & 12 \\
\hline \multirow{2}{*}{1} & & & & & & \\
\hline \multirow{2}{*}{2} & 0.651 & 0.781 & 4.161 & 6.371 & 8.451 & 8.971 \\
\cline { 2 - 7 } & 0.391 & 0.261 & 1.171 & 3.381 & 9.110 & 6.761 \\
\hline Average & 0.131 & 1.561 & 2.861 & 2.861 & 3.121 & 15.610 \\
\cline { 2 - 7 } & 0.781 & 0.521 & 0.911 & 8.321 & 6.111 & 9.621 \\
\hline
\end{tabular}

Table 4-11: Pitting area fraction (\%) of Stellite $6 \mathrm{~K}$

\begin{tabular}{|c|c|c|c|c|c|c|}
\hline Time(day) & $\mathbf{2}$ & $\mathbf{4}$ & $\mathbf{6}$ & $\mathbf{8}$ & $\mathbf{1 0}$ & $\mathbf{1 2}$ \\
\hline \multirow{2}{*}{1} & & & & & & \\
\hline \multirow{2}{*}{2} & 3.121 & 7.671 & 6.51 & 10.791 & 5.331 & 20.281 \\
\cline { 2 - 7 } & 1.691 & 6.111 & 9.491 & 12.221 & 7.151 & 13.911 \\
\hline Average & 1.691 & 8.321 & 7.671 & 9.621 & 7.931 & 11.571 \\
\cline { 2 - 7 } & 4.421 & 5.331 & 6.510 & 6.761 & 17.161 & 12.091 \\
\hline
\end{tabular}

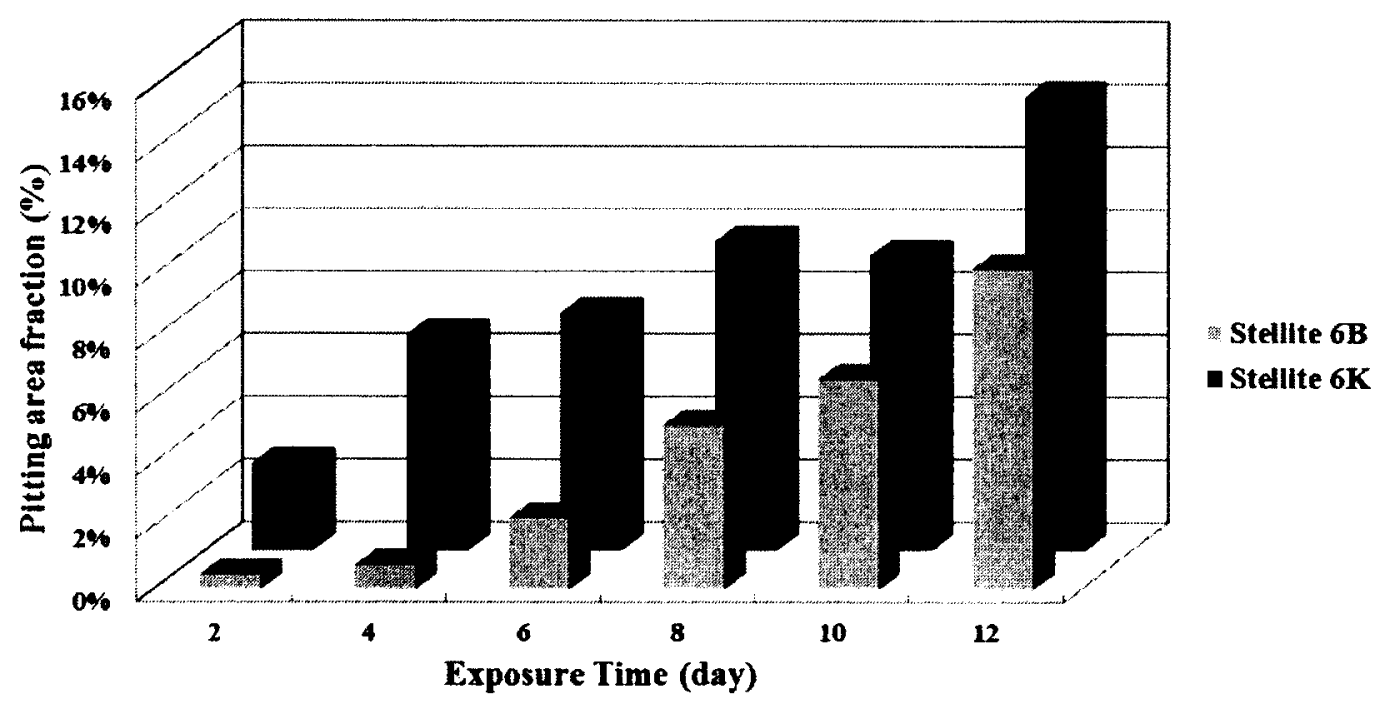

Figure 4-21: Comparison of pitting area fraction between Stellite 6B and Stellite 6K. 


\subsubsection{Chemical composition analysis of pits}

To further understand the corrosion mechanisms of Stellite $6 \mathrm{~B}$ and Stellite $6 \mathrm{~K}$ in Green Death solution, the chemical composition of pits was analyzed utilizing the EDX technique. The equipment used for this analysis is a Philips XL30S FEG Scanning Electron microscope (SEM) with an EDAX energy dispersive X-ray (EDX) spectroscopy system, shown in Figure 4-22. An un-corroded specimen of each alloy was analyzed first as the reference for element contents. Figure 4-23 and Figure 4-24 show the EDX results of the reference (not corrosion-tested) specimens of Stellite $6 \mathrm{~K}$ and Stellite $6 \mathrm{~B}$ respectively.

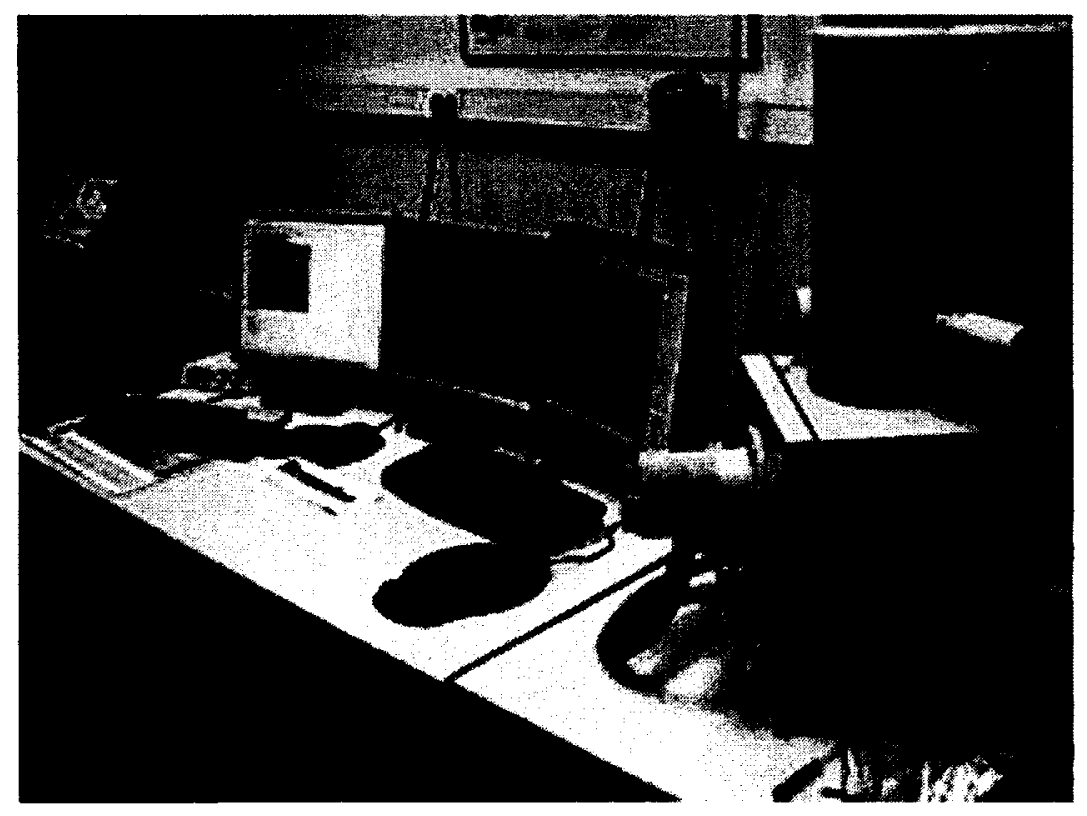

Figure 4-22: Philips XL30S FEG Scanning Electron microscope (SEM) with an EDAX energy dispersive X-ray (EDX) spectroscopy system. 

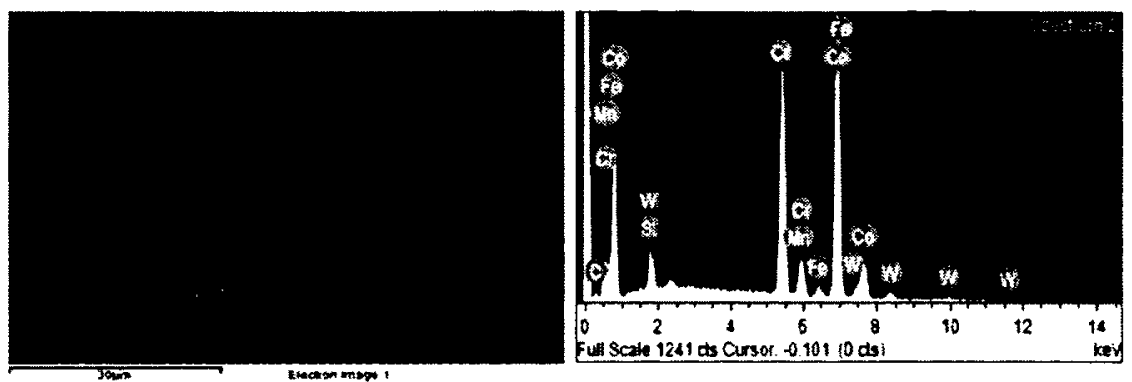

\begin{tabular}{|c|c|c|}
\hline Element & Weight\% & Atomic\% \\
\hline Si K & 0.78 & 1.86 \\
\hline Cr K & 26.60 & 29.652 \\
\hline Mn K & 2.00 & 2.1 \\
\hline Fe K & 1.61 & 1.68 \\
\hline Co K & 64.21 & 63.182 \\
\hline W M & 4.80 & 1.526 \\
\hline Totals & $\mathbf{1 0 0}$ & $\mathbf{1 0 0}$ \\
\hline
\end{tabular}

(a)
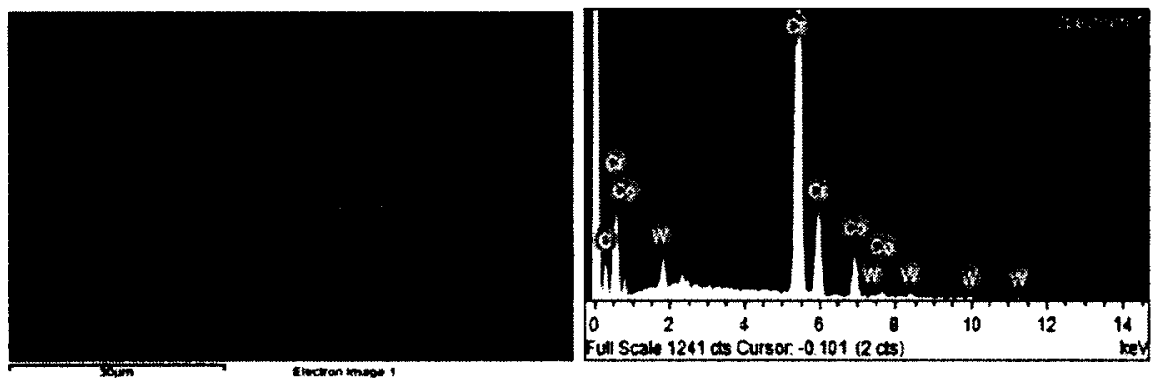

\begin{tabular}{|c|c|c|}
\hline Element & Weight \% & Atomic\% \\
\hline Cr K & 55.01 & 43.5 \\
\hline Mn K & 2.12 & 4.49 \\
\hline Fe K & 5.64 & 4.75 \\
\hline Co K & 19.63 & 33.42 \\
\hline Si K & 7.19 & 11.33 \\
\hline W M & 10.41 & 2.51 \\
\hline Totals & $\mathbf{1 0 0}$ & $\mathbf{1 0 0}$ \\
\hline
\end{tabular}

(b)

Figure 4-23: EDX results of reference specimen of Stellite 6B: (a) Co-rich solid solution and (b) Cr-rich carbides. 

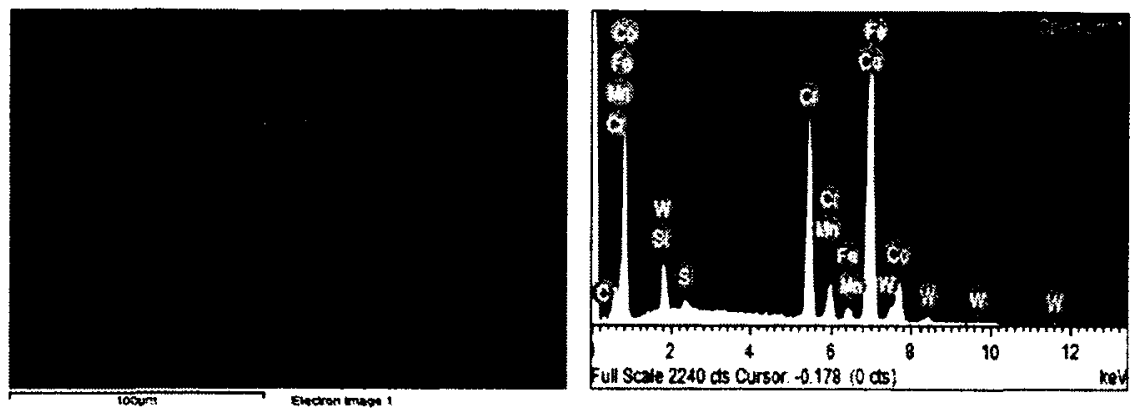

\begin{tabular}{|c|c|c|}
\hline Element & Weight $\%$ & Atomic\% \\
\hline Si K & 1.64 & 3.38 \\
\hline S K & 0.43 & 0.78 \\
\hline $\mathrm{Cr} \mathrm{K}$ & 23.10 & 25.65 \\
\hline $\mathrm{Mn} \mathrm{K}$ & 1.48 & 1.55 \\
\hline Fe K & 2.12 & 2.19 \\
\hline Co K & 66.21 & 64.87 \\
\hline Totals & $\mathbf{1 0 0}$ & $\mathbf{1 0 0}$ \\
\hline
\end{tabular}

(a)
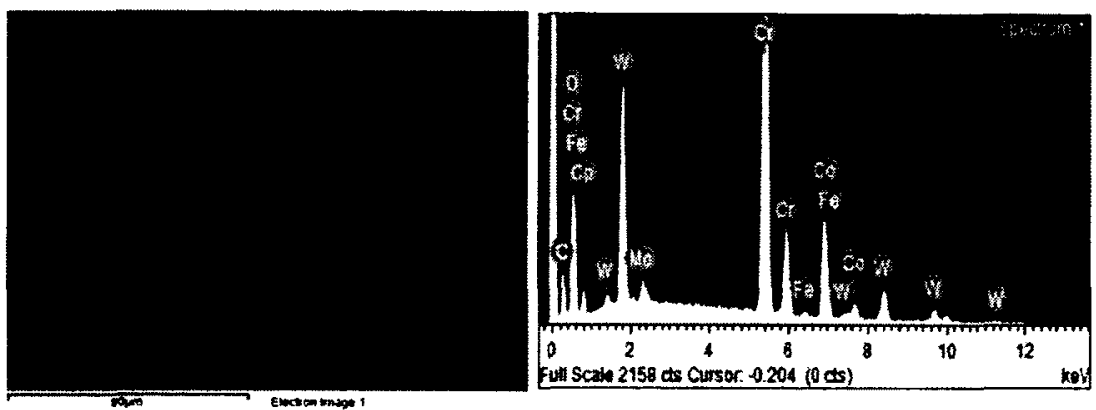

\begin{tabular}{|c|c|c|}
\hline Element & Weight\% & Atomic\% \\
\hline Cr K & 59.11 & 72.59 \\
\hline Fe K & 0.79 & 0.90 \\
\hline Co K & 16.22 & 17.57 \\
\hline Mo L & 2.04 & 1.36 \\
\hline W M & 21.83 & 7.58 \\
\hline Totals & $\mathbf{1 0 0}$ & $\mathbf{1 0 0}$ \\
\hline
\end{tabular}

(b)

Figure 4-24: EDX results of reference specimen of Stellite 6K: (a) Co-rich solid solution and (b) Cr-rich carbides. 
As seen in the EDX spectra, for both Stellite $6 \mathrm{~B}$ and Stellite $6 \mathrm{~K}$, the solid solution (light) contains high $\mathrm{Co}$ and $\mathrm{Cr}$ and the carbides (dark) contain very high $\mathrm{Cr}$ but low $\mathrm{Co}$. This is because Co mostly exists in the solid solution and the carbides are Cr-rich. Also, it is obvious that the $\mathrm{C}$ amount in the carbides is very high. However, the EDX system of the SEM cannot quantify non-metallic elements precisely. For the pitting specimens, in the pit region, as shown in Figure 4-25, there are also two distinct areas in light and dark, respectively. The chemical compositions of these two areas were analyzed; the EDX results are presented in Figure 4-26 to Figure 4-31.

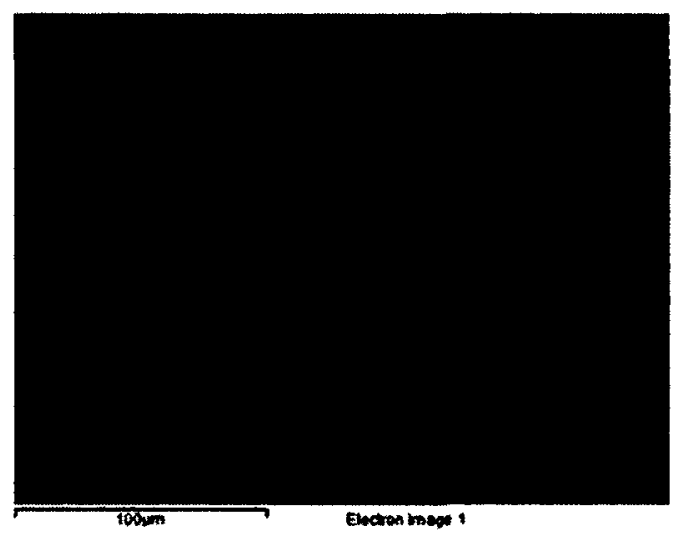

(a)

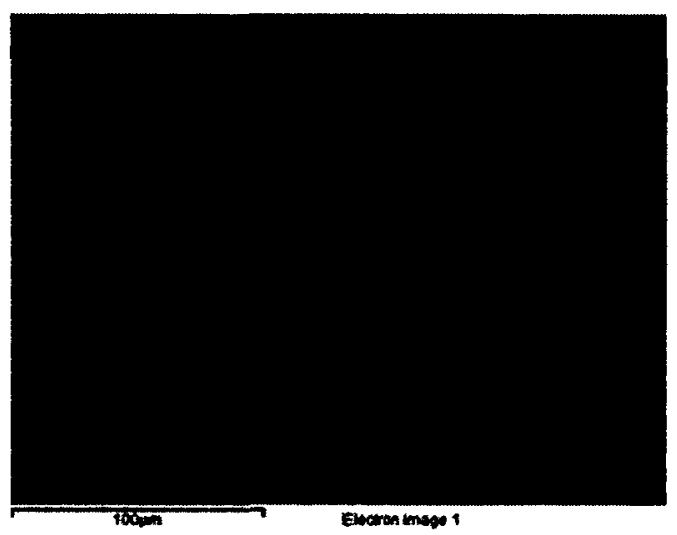

(b)

Figure 4-25: Pit region containing light and dark areas: (a) Stellite 6B and (b) Stellite 6K. 


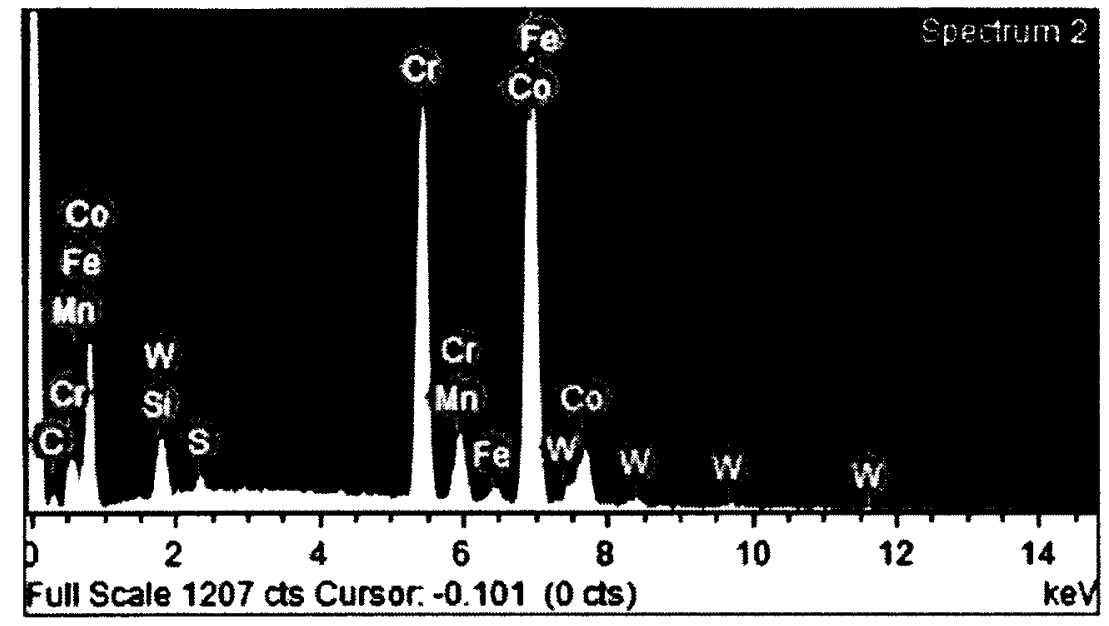

\begin{tabular}{|c|c|c|}
\hline Element & Weight \% & Atomic\% \\
\hline Si K & 0.79 & 1.61 \\
\hline $\mathrm{S} \mathrm{K}$ & 0.55 & 1.00 \\
\hline $\mathrm{Cr} \mathrm{K}$ & 27.45 & 30.39 \\
\hline $\mathrm{Mn} \mathrm{K}$ & 1.66 & 1.75 \\
\hline Fe K & 1.44 & 1.48 \\
\hline Co K & 63.99 & 62.48 \\
\hline W M & 4.12 & 1.29 \\
\hline Totals & $\mathbf{1 0 0}$ & $\mathbf{1 0 0}$ \\
\hline
\end{tabular}

(a) 


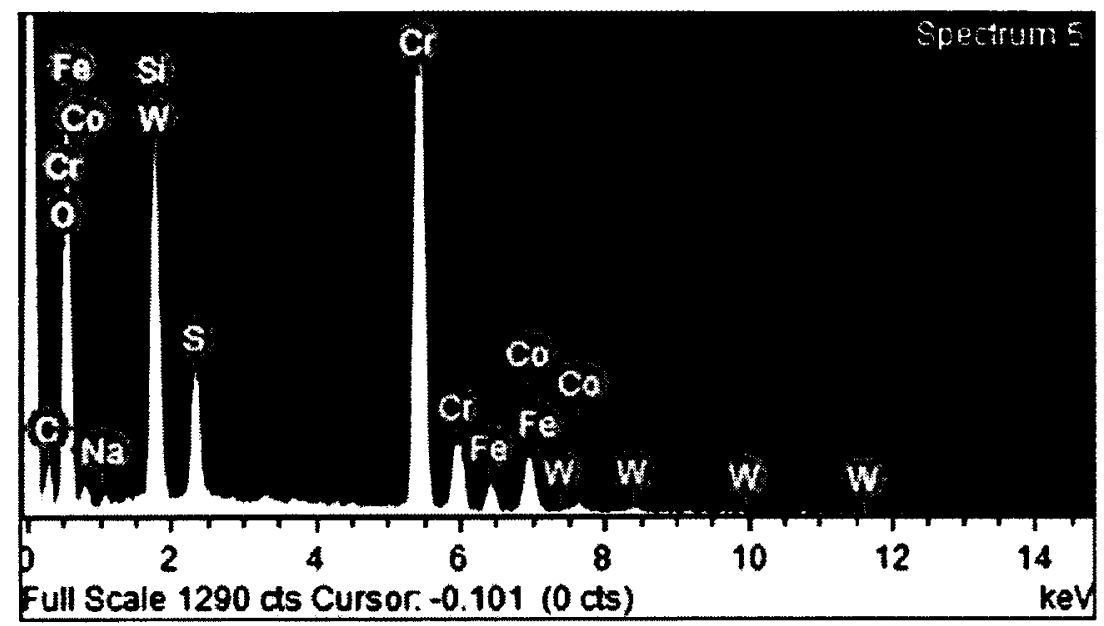

\begin{tabular}{|c|c|c|}
\hline Element & Weight\% & Atomic\% \\
\hline Na K & 0.94 & 1.93 \\
\hline Si K & 12.73 & 21.45 \\
\hline S K & 5.87 & 8.68 \\
\hline Cr K & 58.49 & 53.25 \\
\hline Fe K & 4.83 & 4.09 \\
\hline Co K & 11.34 & 9.12 \\
\hline W M & 5.81 & 1.49 \\
\hline Totals & $\mathbf{1 0 0}$ & $\mathbf{1 0 0}$ \\
\hline
\end{tabular}

(b)

Figure 4-26: EDX results of pits in the Stellite 6B specimen immersion-tested for 2 days: (a) light area and (b) dark area. 


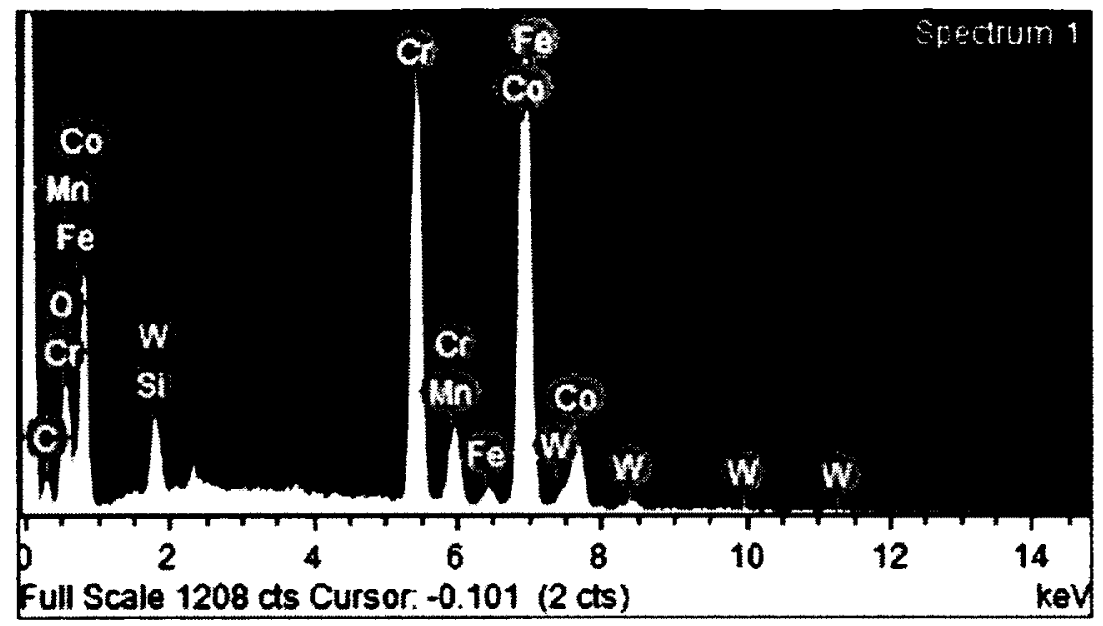

\begin{tabular}{|c|c|c|}
\hline Element & Weight \% & Atomic\% \\
\hline Si K & 0.71 & 1.46 \\
\hline $\mathrm{Cr} \mathrm{K}$ & 28.61 & 32.08 \\
\hline $\mathrm{Mn} \mathrm{K}$ & 1.75 & 1.86 \\
\hline Fe K & 1.80 & 1.88 \\
\hline Co K & 61.67 & 60.99 \\
\hline W M & 5.46 & 1.72 \\
\hline Totals & $\mathbf{1 0 0}$ & $\mathbf{1 0 0}$ \\
\hline
\end{tabular}

(a) 


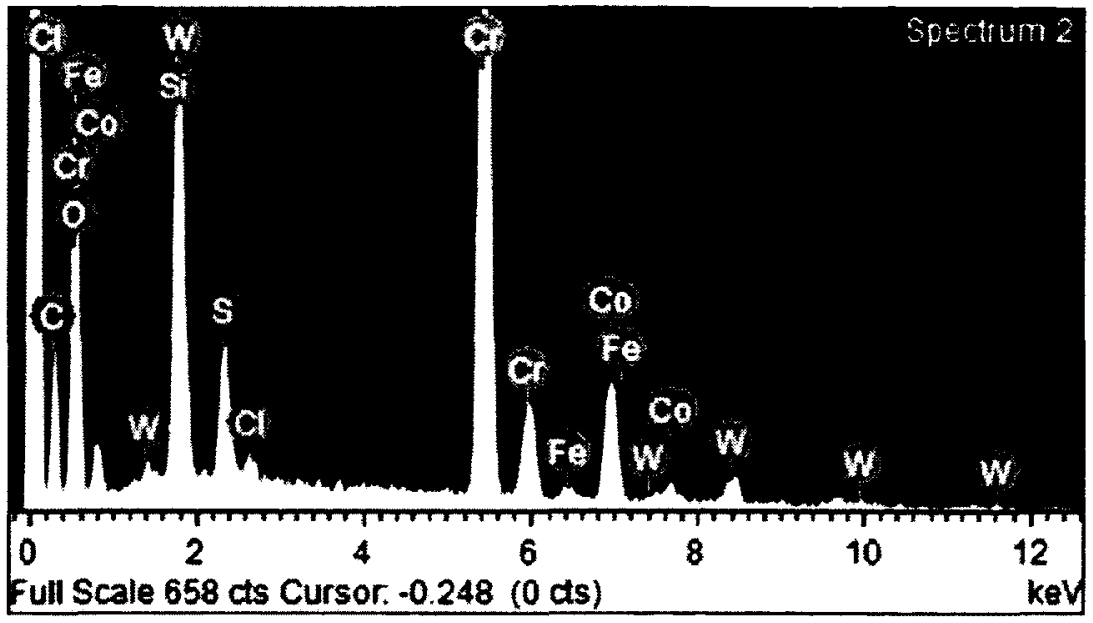

\begin{tabular}{|c|c|c|}
\hline Element & Weight $\%$ & Atomic\% \\
\hline Si K & 10.17 & 19.09 \\
\hline S K & 3.76 & 6.20 \\
\hline Cl K & 0.85 & 1.26 \\
\hline Cr K & 52.33 & 53.10 \\
\hline Fe K & 1.29 & 1.21 \\
\hline Co K & 16.52 & 14.81 \\
\hline W M & 15.08 & 4.33 \\
\hline Totals & $\mathbf{1 0 0}$ & 100 \\
\hline
\end{tabular}

(b)

Figure 4-27: EDX results of pits in the Stellite 6B specimen immersion-tested for 4 days: (a) light area and (b) dark area. 


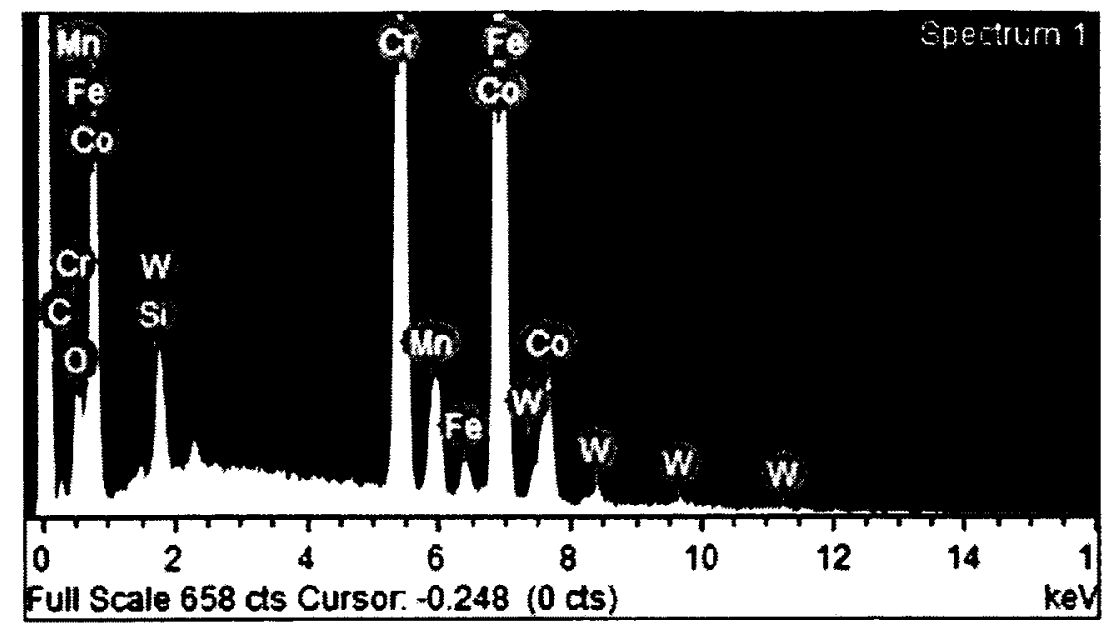

\begin{tabular}{|c|c|c|}
\hline Element & Weight\% & Atomic\% \\
\hline Si K & 0.80 & 1.65 \\
\hline $\mathrm{Cr} \mathrm{K}$ & 27.24 & 30.49 \\
\hline $\mathrm{Mn} \mathrm{K}$ & 1.45 & 1.53 \\
\hline $\mathrm{Fe} \mathrm{K}$ & 1.66 & 1.72 \\
\hline Co K & 63.76 & 62.99 \\
\hline W M & 5.10 & 1.62 \\
\hline Totals & $\mathbf{1 0 0}$ & $\mathbf{1 0 0}$ \\
\hline
\end{tabular}

(a) 


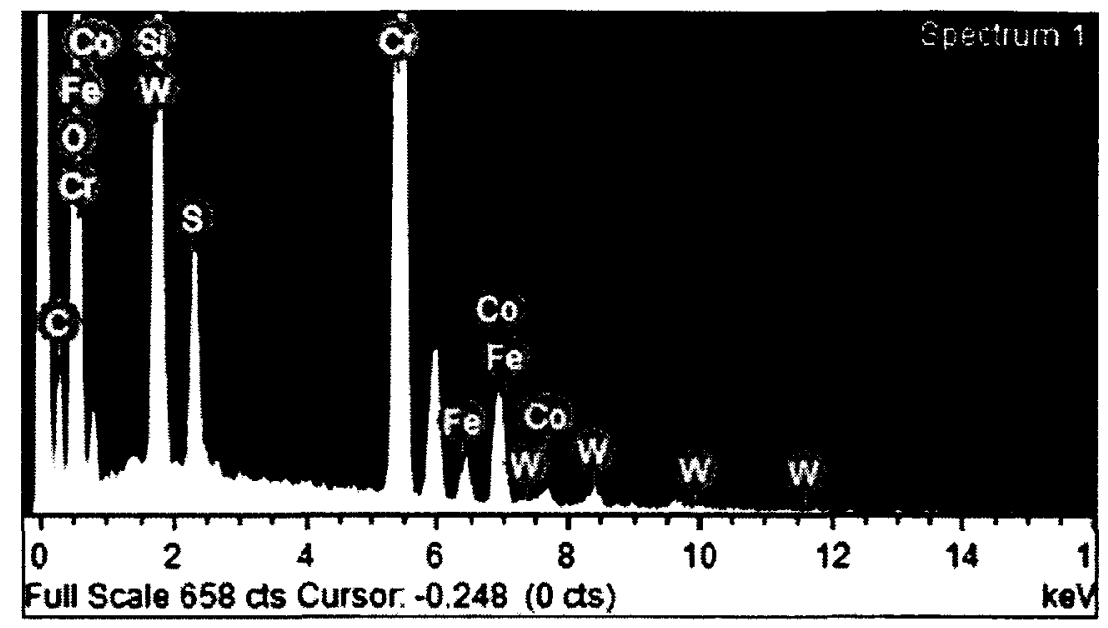

\begin{tabular}{|c|c|c|}
\hline Element & Weight \% & Atomic\% \\
\hline Si K & 10.62 & 18.87 \\
\hline S K & 4.71 & 7.32 \\
\hline Cr K & 61.25 & 58.89 \\
\hline Fe K & 3.20 & 2.86 \\
\hline Co K & 11.38 & 9.64 \\
\hline W M & 8.84 & 2.41 \\
\hline Totals & $\mathbf{1 0 0}$ & $\mathbf{1 0 0}$ \\
\hline
\end{tabular}

(b)

Figure 4-28: EDX results of pits in the Stellite 6B specimen immersion-tested for 12 days: (a) light area and (b) dark area. 
(e)

\begin{tabular}{|c|c|c|}
\hline 00I & $\overline{00 I}$ & S[E]0」L \\
\hline SS I & $S L D$ & W M \\
\hline$t I^{\circ} I$ & $\overline{\varepsilon \mathcal{E}} \mathcal{\varepsilon}$ & $79 x$ \\
\hline$Z Z^{\circ} I$ & $96^{\circ} I$ & T OW \\
\hline $0 \angle 8 S$ & 00.85 & X \\
\hline $68^{\circ} \varepsilon$ & $b 9^{\circ} \varepsilon$ & प्रे \\
\hline $69^{\circ} \mathrm{I}$ & $9 S^{\circ} \mathrm{I}$ & X पW \\
\hline$t \varepsilon 62$ & $6 S^{\circ} s 2$ & X्र」 \\
\hline $9 t z$ & $9 I^{\circ} I$ & X !S \\
\hline \%ग!umolv & $\% 148 !{ }^{8} M$ & ๆUวшว \\
\hline
\end{tabular}

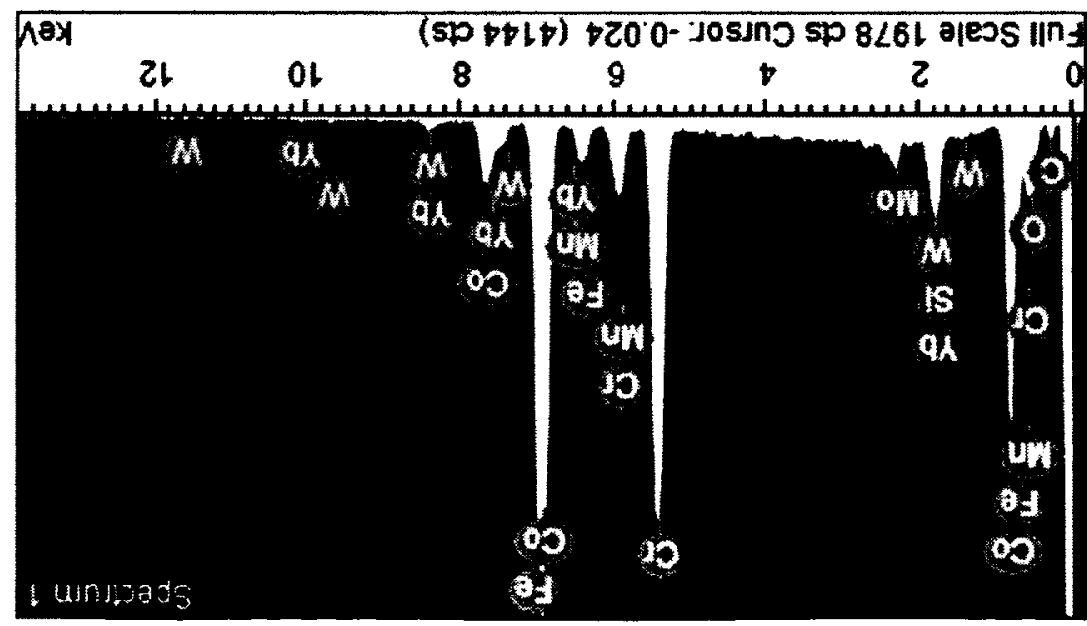




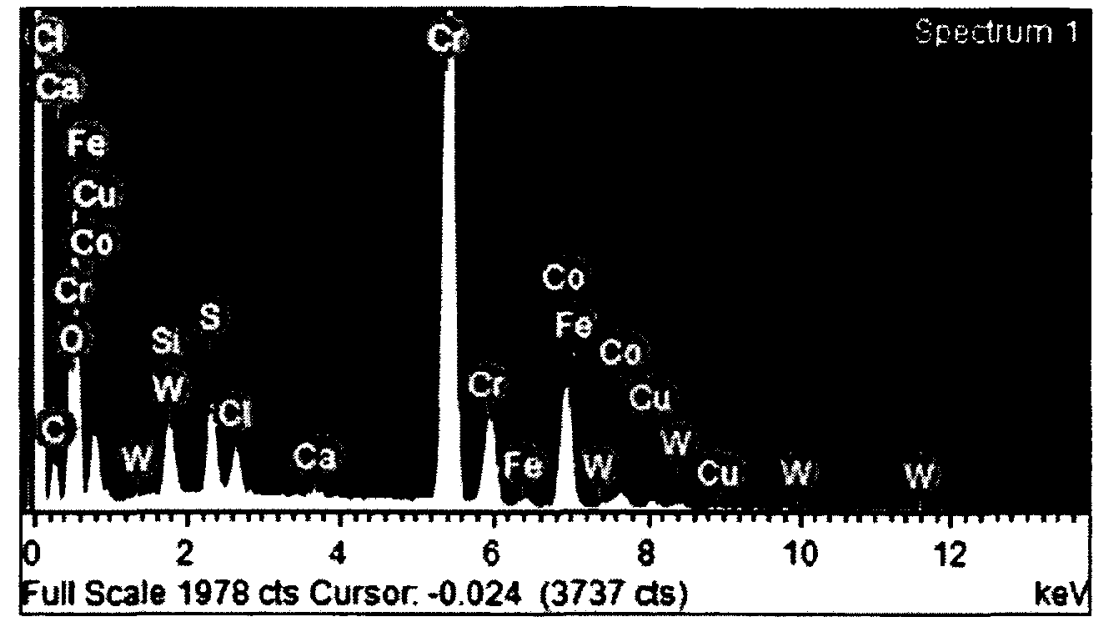

\begin{tabular}{|c|c|c|}
\hline Element & Weight\% & Atomic\% \\
\hline $\mathrm{Si} \mathrm{K}$ & 1.84 & 3.46 \\
\hline $\mathrm{S} \mathrm{K}$ & 3.63 & 5.91 \\
\hline $\mathrm{Cl} \mathrm{K}$ & 2.13 & 3.16 \\
\hline $\mathrm{Ca} \mathrm{K}$ & 0.36 & 0.47 \\
\hline $\mathrm{Cr} \mathrm{K}$ & 63.39 & 63.87 \\
\hline $\mathrm{Fe} \mathrm{K}$ & 1.28 & 1.20 \\
\hline $\mathrm{Co} \mathrm{K}$ & 22.01 & 19.57 \\
\hline $\mathrm{Cu} \mathrm{K}$ & 1.52 & 1.26 \\
\hline W M & 3.82 & 1.11 \\
\hline Totals & 100 & 100 \\
\hline \multicolumn{3}{|r}{} \\
\end{tabular}

Figure 4-29: EDX results of pits in the Stellite 6K specimen immersion-tested for 2 days: (a) light area and (b) dark area. 


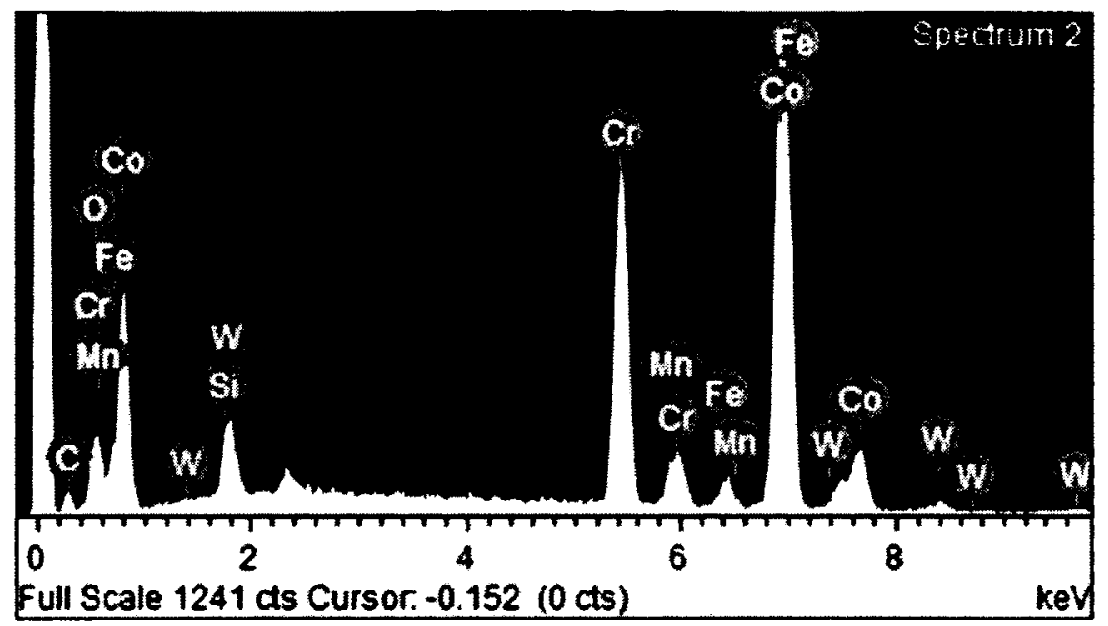

\begin{tabular}{|c|c|c|}
\hline Element & Weight $\%$ & Atomic\% \\
\hline Si K & 1.50 & 3.11 \\
\hline Cr K & 24.13 & 26.84 \\
\hline Mn K & 1.47 & 1.55 \\
\hline Fe K & 2.92 & 3.02 \\
\hline Co K & 65.25 & 64.00 \\
\hline W M & 4.72 & 1.48 \\
\hline Totals & $\mathbf{1 0 0}$ & $\mathbf{1 0 0}$ \\
\hline
\end{tabular}

(a) 


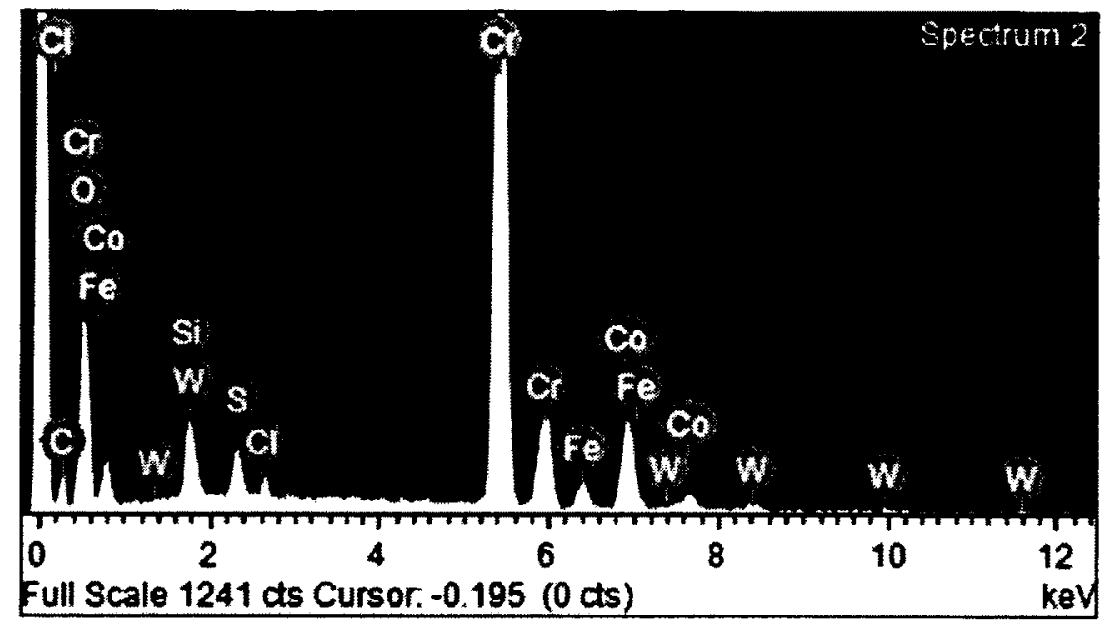

\begin{tabular}{|c|c|c|}
\hline Element & Weight\% & Atomic\% \\
\hline Si K & 2.26 & 4.28 \\
\hline S K & 1.94 & 3.19 \\
\hline Cl K & 0.87 & 1.30 \\
\hline Cr K & 70.19 & 71.39 \\
\hline Fe K & 4.00 & 3.77 \\
\hline Co K & 16.59 & 14.88 \\
\hline W M & 4.15 & 1.18 \\
\hline Totals & $\mathbf{1 0 0}$ & $\mathbf{1 0 0}$ \\
\hline
\end{tabular}

(b)

Figure 4-30: EDX results of pits in the Stellite 6K specimen immersion-tested for 4 days: (a) light area and (b) dark area. 


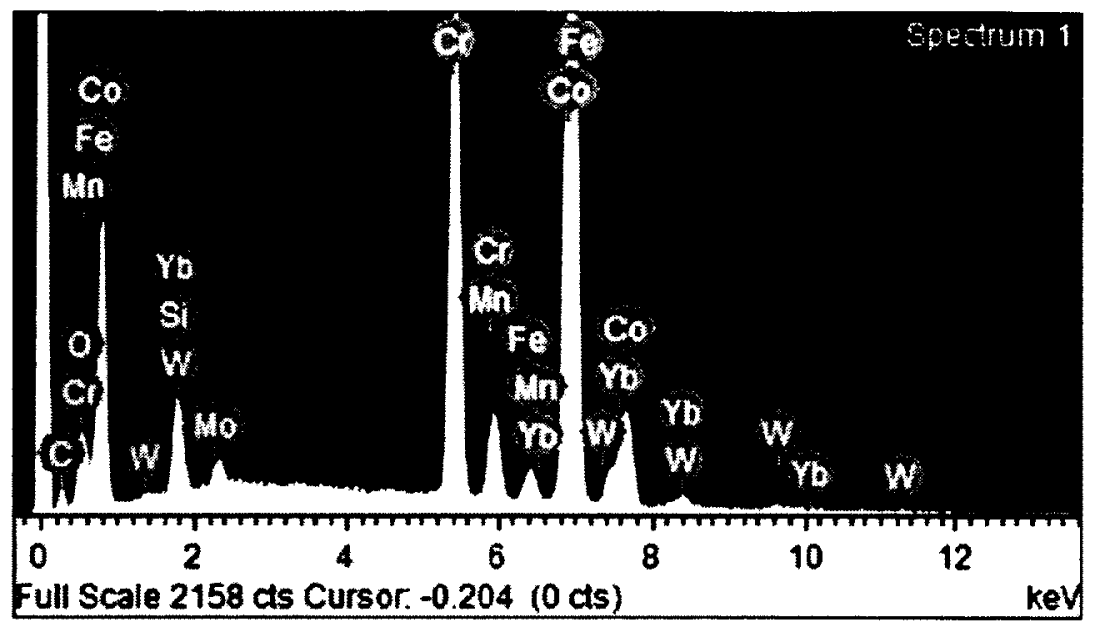

\begin{tabular}{|c|c|c|}
\hline Element & Weight \% & Atomic\% \\
\hline $\mathrm{Si} \mathrm{K}$ & 1.26 & 2.66 \\
\hline $\mathrm{Cr} \mathrm{K}$ & 23.14 & 26.34 \\
\hline $\mathrm{Mn} \mathrm{K}$ & 1.55 & 1.67 \\
\hline $\mathrm{Fe} \mathrm{K}$ & 2.17 & 2.30 \\
\hline $\mathrm{Co} \mathrm{K}$ & 63.54 & 63.82 \\
\hline $\mathrm{Mo} \mathrm{L}$ & 1.56 & 0.95 \\
\hline Yb L & 3.06 & 1.04 \\
\hline W M & 3.74 & 1.20 \\
\hline Totals & $\mathbf{1 0 0}$ & $\mathbf{1 0 0}$ \\
\hline
\end{tabular}

(a) 


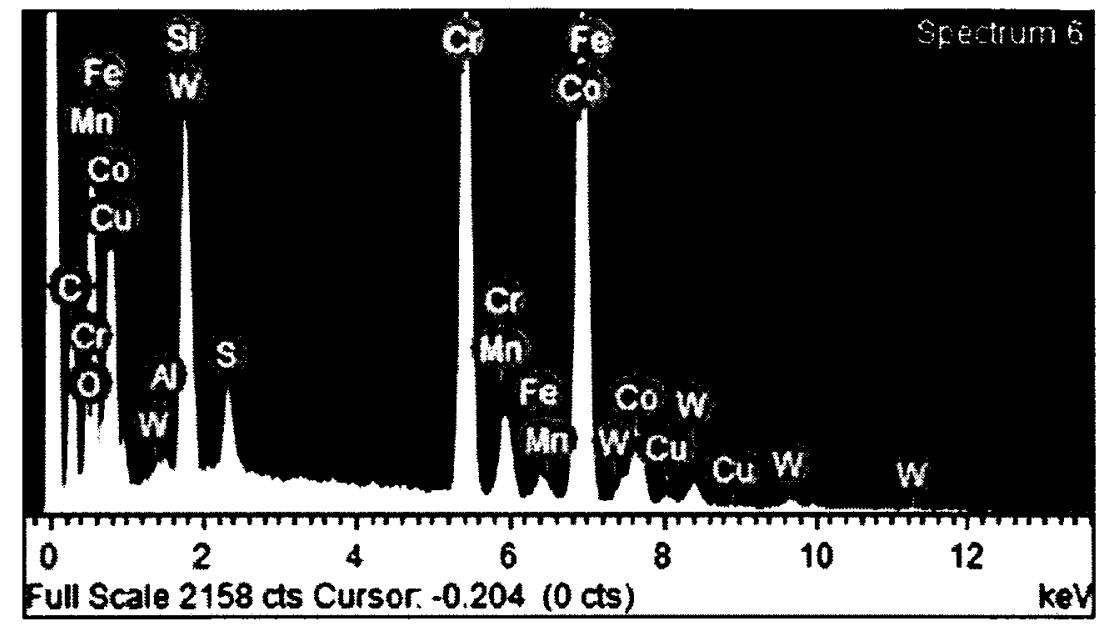

\begin{tabular}{|c|c|c|}
\hline Element & Weight\% & Atomic\% \\
\hline Si K & 1.05 & 0.79 \\
\hline S K & 1.68 & 1.11 \\
\hline Cl K & 0.89 & 0.53 \\
\hline Cr K & 64.37 & 26.13 \\
\hline Fe K & 0.87 & 0.33 \\
\hline Co K & 16.61 & 5.95 \\
\hline W M & 4.66 & 0.53 \\
\hline Totals & $\mathbf{1 0 0}$ & $\mathbf{1 0 0}$ \\
\hline
\end{tabular}

(b)

Figure 4-31: EDX results of pits in the Stellite 6K specimen immersion-tested for 12 days: (a) light area and (b) dark area.

Comparing the EDX spectra in Figure 4-23 and Figure 4-26, for Stellite 6B, the chemical composition of the light area of pits in the specimen tested for 2 days is similar to that of the solid solution of the reference specimen, but the dark area of pits contains oxygen $(O)$ and the other element concentrations in this area are similar to those of the carbides of the 
reference specimen. For Stellite $6 \mathrm{~K}$, both the light and dark areas of pits in the specimen tested for 2 day contain $O$. The presence of $O$ indicates that oxides formed in the pits during the corrosion test. In the solid solution region the oxide should be $\mathrm{Cr}$-rich, as the free $\mathrm{Cr}$ was prone to form $\mathrm{Cr}$-oxide with $\mathrm{O}$, while in the carbide region, the reaction of the carbides with $\mathrm{O}$ formed $\mathrm{Cr}$-rich carbonate. $\mathrm{Cr}$-oxide is hard and tough, can prevent the surface from further corrosion when formed as a thin surface layer. However, $\mathrm{Cr}$-rich carbonate is brittle and loose, can be easily spalled from the surface, and has no any protective effects for the surface corrosion. Furthermore, although the EDX system cannot provide accurate $\mathrm{O}$ content, based on the ratio of $\mathrm{O}$ to $\mathrm{Cr}$ in the spectra, it is clear that the $\mathrm{O}$ amount in the pits remains at a high level with the exposure time for both the alloys, i.e., during the pit development, the oxides formed continuously in the specimen in the corrosive environment. 


\section{Discussion on results}

\subsection{Polarization test}

Polarization test is a popular approach to investigating electrochemical corrosion behavior of metals. In this research, two types of electrolyte, $3.5 \mathrm{wt} \% \mathrm{NaCl}$ and Green Death solution, were selected to study the electrochemical corrosion behavior of Stellite $6 \mathrm{~B}$ and Stellite $6 \mathrm{~K}$. The former is a general and common electrolyte that has been widely used to test and rank various metals; the latter is a mixed-oxidizing solution and a strong corrosive medium that has been found to cause failure of metals in many applications of industry. Metals may exhibit very different corrosion behavior in different corrosive circumstances; therefore, the selection of corrosive medium for test should be based on the application environment of the material.

\subsubsection{Electrochemical corrosion behavior in $\mathrm{NaCl}$ electrolyte}

According to Figure 3-11 and Table 3-2, in $3.5 \mathrm{wt} \% \mathrm{NaCl}$ electrolyte, Stellite $6 \mathrm{~B}$ has a larger $I_{c o r}$ value than Stellite $6 \mathrm{~K}$, which means that the former has higher potential to be corroded in this electrolyte at the initial stage of corrosion (anodic region). However, on the other hand, once the alloys started becoming corroded in anodic region, Stellite 6B exhibited a larger passive region than Stellite $6 \mathrm{~K}$. This passive region implies that an oxide film had formed on the surfaces of the specimens that prevented the surfaces from further corrosion. Stellite $6 \mathrm{~B}$ and Stellite $6 \mathrm{~K}$ contain a same high level of $\mathrm{Cr}$, and in the 
corrosive solution Cr-oxide films formed on the surfaces of the alloys, which resulted in the passive region on the polarization curves. However, with increasing the potential, the oxide films could break because they were thin films, which caused corrosion to occur on a fresh surface of the specimens. As shown on the polarization curve of Stellite $6 \mathrm{~K}$ in Figure $3-11$, there is an inflexion point around $0.01 \mu \mathrm{A} / \mathrm{cm}^{2}$, at which pitting generation commenced. In general, pitting occurs when the electric potentials of individual phases in a metal are largely different; the phase with higher electric potential is corroded easier and consumed in the chemical reaction. For Stellite $6 \mathrm{~B}$ and Stellite $6 \mathrm{~K}$, when the electric potentials of $\mathrm{Cr}$-rich carbides and Co-rich solid solution in these alloys differed largely, electrochemical corrosion occurred at their interfaces. Since the carbides of Stellite $6 \mathrm{~B}$ and Stellite $6 \mathrm{~K}$ are $\mathrm{Cr}$-rich, in the local region of the carbides/solid solution interface, $\mathrm{Cr}$ was depleted in the solid solution due to the large amount $\mathrm{Cr}$ in the carbides, causing corrosion occurrence there. Compared with Stellite $6 \mathrm{~K}$, Stellite $6 \mathrm{~B}$ seemed to form larger Cr-oxide films which are protective for the alloy to be further corrosion-attacked, because there are no inflexion points found on its polarization curve in the tested range of potential, see Figure 3-11. An inflexion point may occur when the potential reaches a certain high level.; Stellite $6 \mathrm{~B}$ contains lower $\mathrm{C}$ than Stellite $6 \mathrm{~K}$ but they contain the same amount of $\mathrm{Cr}$, thus more $\mathrm{Cr}$ remained in the solid solution of Stellite $6 \mathrm{~B}$ than in that of Stellite $6 \mathrm{~K}$, which provided the former with better corrosion resistance. 


\subsubsection{Electrochemical corrosion behavior in Green Death electrolyte}

In Green Death solution, as shown in Figure 3-14 and Table 3-3, Stellite 6B and Stellite $6 \mathrm{~K}$ behaved similarly, in both cathodic region and anodic region. They have nearly the same $E_{\text {cor }}$ around $300 \mathrm{mV}$, a similar passive region ending at almost a same potential level and a secondary passive region after a rapid increase in current density $\left(I_{\text {corr }}\right)$, but the Stellite 6B curve is a little offset to the left of the Stellite $6 \mathrm{~K}$ curve. Stellite $6 \mathrm{~B}$ and Stellite $6 \mathrm{~K}$ have a similar pitting potential $\left(E_{p}\right)$ that is the potential value $(\sim 900 \mathrm{mV})$ at the end of the first passive region. Therefore, at the corrosion (pitting) potential ( $\left.E_{p}\right)$, the current density $\left(I_{c o r}\right)$ of Stellite $6 \mathrm{~B}$ is slightly lower than that of Stellite $6 \mathrm{~K}$, which indicates that the former is more corrosion-resistant than the latter in Green Death solution. Furthermore, as shown in Figure 3-15 and Figure 3-16, in the cyclic polarization tests both Stellite $6 \mathrm{~B}$ and Stellite $6 \mathrm{~K}$ have an electropositive hysteresis effect, characterized by the electropositive hysteresis reverse curve (curve II), which indicate that these alloys possess good localized corrosion resistance. Comparing the localized corrosion resistance between Stellite $6 \mathrm{~B}$ and Stellite $6 \mathrm{~K}$, the hysteresis loop of the former exhibits more electropositive hysteresis, because the difference in the potential between curve I (forward polarization cycle) and curve II (reverse polarization cycle) of Stellite $6 \mathrm{~B}$ at a same current density is larger than that of Stellite $6 \mathrm{~K}$. All these evidences demonstrate that Stellite 6B is more corrosion-resistant in the Green Death environment. As discussed above, the carbides/solid solution interfaces formed primary batteries that initiated the electrochemical-reaction corrosion of the alloys. As Stellite $6 \mathrm{~B}$ contains 
lower $\mathrm{C}$ thus less volume fraction of carbides, the corrosion batteries in this alloy would be less. In the meanwhile, a less amount of carbides took less $\mathrm{Cr}$. As a result, more $\mathrm{Cr}$ remained in the solid solution of this alloy, forming larger protective Cr-oxide films for corrosion resistance.

\subsection{Immersion test}

\subsubsection{Carbide volume fraction effects}

Stellite $6 \mathrm{~B}$ and Stellite $6 \mathrm{~K}$ were investigated under immersion test and their corrosion behavior was compared in several different parameters, such as CPT, mass loss, thickness change, and the Extreme Value. Firstly, for CPT, there is no difference between Stellite $6 \mathrm{~B}$ and Stellite $6 \mathrm{~K}$; they all exhibited pitting at $60^{\circ} \mathrm{C}$. Secondly, in mass loss analysis, there is remarkable distinction between Stellite 6B and Stellite 6K. As shown in Figure 49 , for all the test periods, the mass loss of Stellite $6 \mathrm{~K}$ is much more than that of Stellite $6 \mathrm{~B}$, but the general trend of the histograms shows that the difference in mass loss between the two alloys decreases with the test time. Thirdly, the thickness reduction of Stellite $6 \mathrm{~B}$ is more than that of Stellite $6 \mathrm{~K}$ for short test periods but is less for long test periods, as illustrated in Figure 4-10. Finally, based on the results of pit depth analysis and EVA models, shown in Table 4-6, Table 4-7 and Table 4-9, the required thickness $\left(D_{R}\right)$ for Stellite $6 \mathrm{~K}$ is about one-third less than that for Stellite 6B. 
The chemical composition and microstructure of a material have significant effects on its corrosion behavior. Comparing the chemical composition and microstructure between Stellite $6 \mathrm{~B}$ and Stellite $6 \mathrm{~K}$, the main differences are the carbide content and the carbide size. Stellite $6 \mathrm{~K}$ contains more $\mathrm{C}$ and thus a larger volume fraction of carbides. The estimation of carbide volume fraction of the Stellite $6 \mathrm{~B}$ and Stellite $6 \mathrm{~K}$ specimens was performed using SEM in this research. Two specimens of each alloy were examined, and three interested areas were randomly chosen for each specimen. Firstly, an image of microstructure was obtained, as shown in Figure 5-1(a) and Figure 5-2(a). Secondly, the carbide phase was identified and colored in blue, as shown in Figure 5-1(b) and Figure 5-2(b). Thirdly, the system software calculated the percentage of carbide phase in the imaged area automatically. In this process, the noises, such as scratches, debris, impurities, could be detected and removed from the calculation, which provided more accurate results.

The carbide volume fractions of each specimen calculated from the process are presented in Table 5-1; the average carbide volume fractions of Stellite $6 \mathrm{~B}$ and Stellite $6 \mathrm{~K}$ are $15.7 \%$ and $40.5 \%$ respectively. In the pitting area fraction analysis of Chapter 4 , it is shown that Stellite $6 \mathrm{~K}$ has larger pitting area fraction, see Table 4-10 and Table 4-11. The results of polarization test and those of immersion test agree well, which all show that Stellite 6B containing lower $\mathrm{C}$ has better corrosion resistance with respect to pitting area fraction. Stellite $6 \mathrm{~K}$ has a larger amount of carbides so that more pits were formed on its surface. 


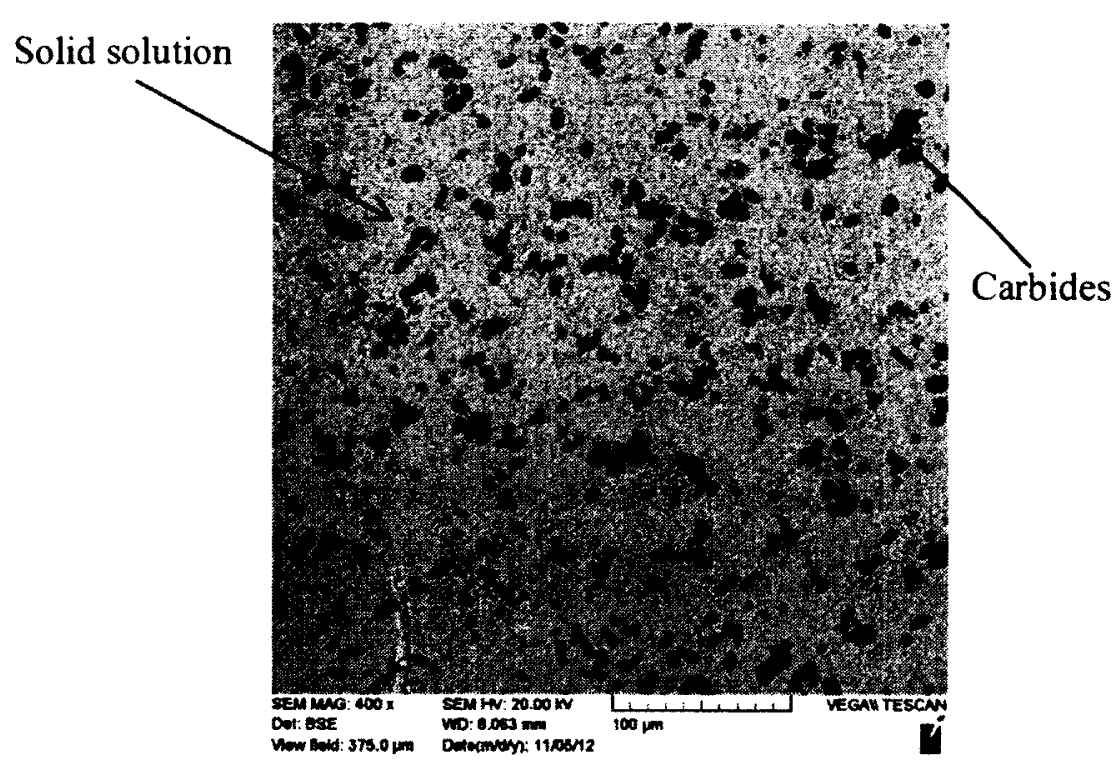

(a)

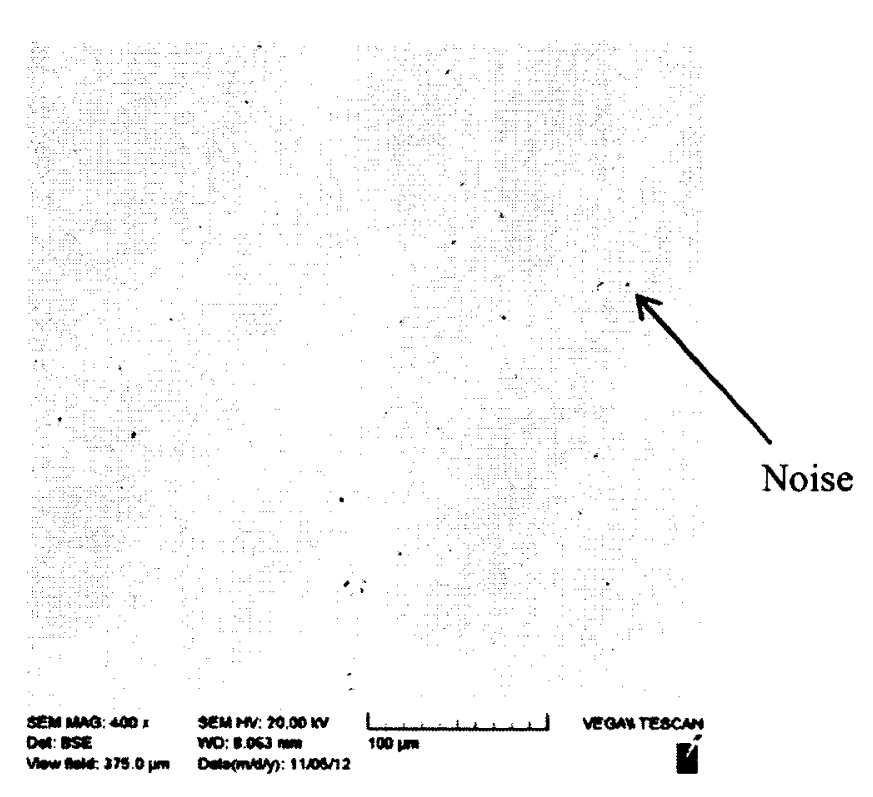

(b)

Figure 5-1: SEM images for carbide fraction calculation of Stellite 6B: (a) microstructure and (b) identified carbide region. 


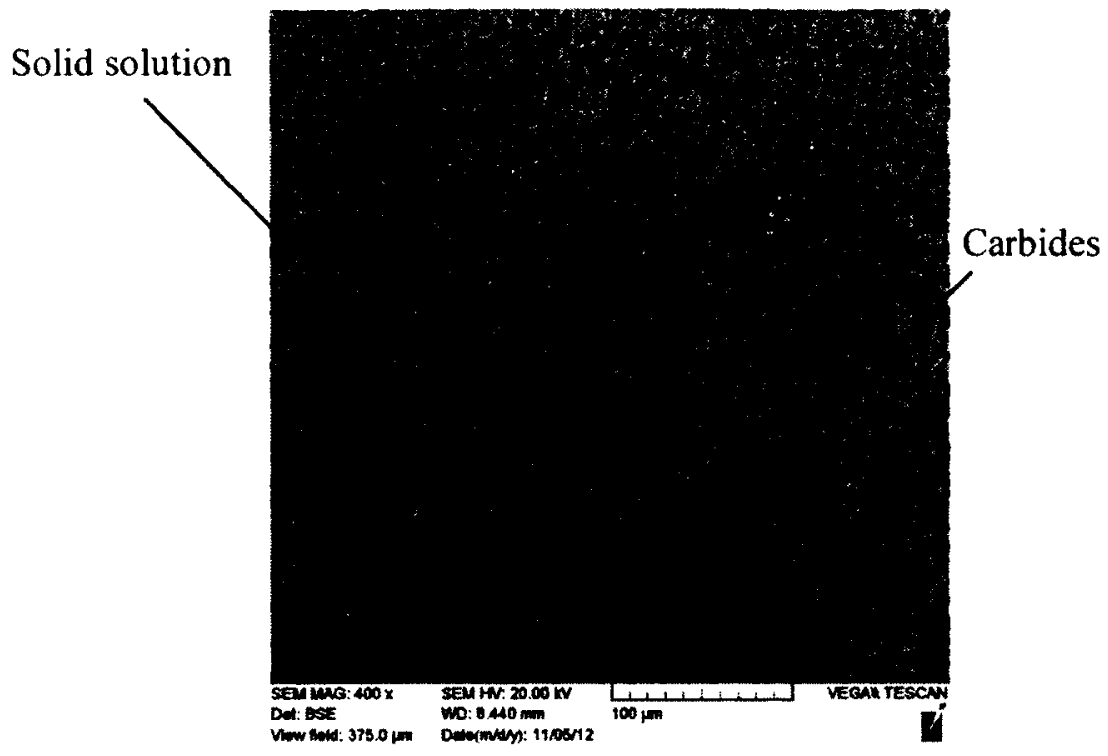

(a)

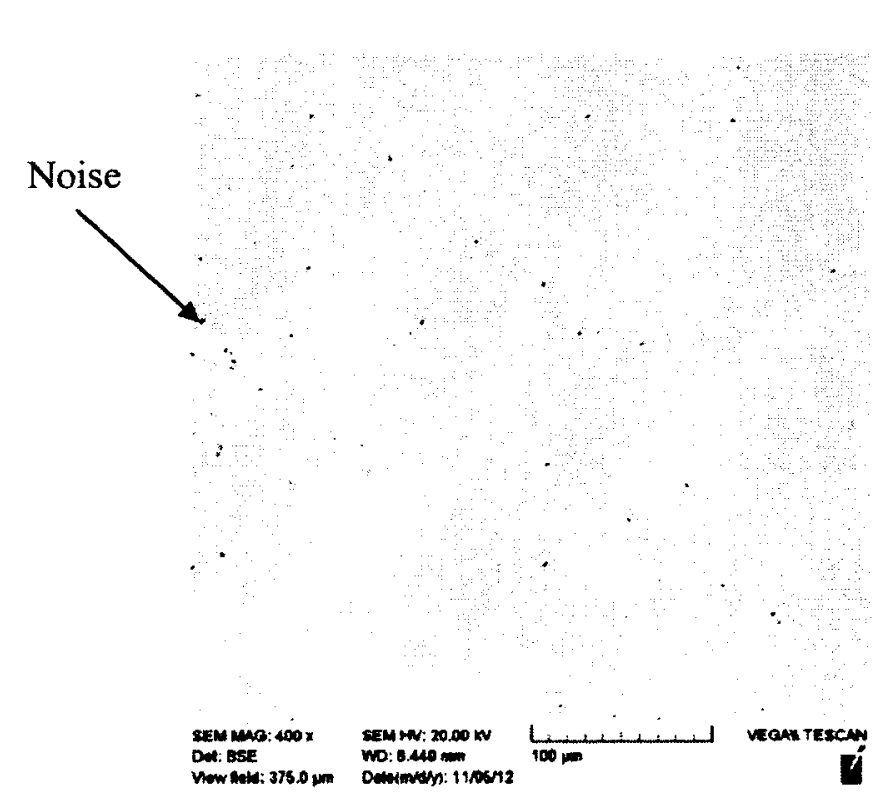

(b)

Figure 5-2: SEM images for carbide fraction calculation of Stellite 6K: (a) microstructure and (b) identified carbide region. 
Table 5-1: Carbide volume fractions (\%) of Stellite 6B and Stellite 6K specimens

\begin{tabular}{|c|c|c|c|}
\hline \multicolumn{2}{|c|}{ Alloy } & Stellite 6B & Stellite 6K \\
\hline \multirow{2}{*}{1} & & \\
\hline \multirow{3}{*}{2} & Area 1 & 13.5 & 42.0 \\
\cline { 2 - 4 } & Area 2 & 15.4 & 42.1 \\
\cline { 2 - 4 } & Area 3 & 17.7 & 37.4 \\
\hline \multirow{2}{*}{2} & Area 1 & 16.3 & 42.3 \\
\cline { 2 - 4 } & Area 2 & 16.1 & 38.8 \\
\cline { 2 - 4 } & Area 3 & 15.0 & 40.0 \\
\hline \multicolumn{2}{|c|}{ Mean } & 15.7 & 40.5 \\
\hline
\end{tabular}

\subsubsection{Carbide size effects}

In addition to carbide volume fraction, carbide size may also play an important role in the corrosion performance of Stellite 6B and Stellite 6K. As shown in Figure 3-2 and Figure $3-3$, the carbides of Stellite 6B are apparently bigger than those of Stellite $6 \mathrm{~K}$. From the EDX analyses of the pitting surfaces in Chapter 4, the carbide region contains a high level of $\mathrm{O}$, which implies that there is a large amount of $\mathrm{Cr}$-rich carbonate there. These oxide products are brittle and loose, can be easily spalled off from the alloys. On the other hand, corrosion occurred initially in the local region of solid solution at the carbides/solid solution interface due to $\mathrm{Cr}$ depletion; the consumption of solid solution would result in spallation of carbides from the solution matrix. Since the carbide size of Stellite $6 \mathrm{~B}$ is larger than that of Stellite $6 \mathrm{~K}$, when the carbides spalled from the alloy, the pits left in the surface of the former would be deeper and bigger than those left in the latter. This can explain the results of maximum pit depth analysis, shown in Table 4-6 and Table 4-7, that Stellite 6B has larger maximum pit depths. 


\subsubsection{Oxidization effects}

To further investigate the corrosion mechanisms of Stellite $6 \mathrm{~B}$ and Stellite $6 \mathrm{~K}$, the oxygen amounts in each pitted specimen were evaluated with the EDX technique; the results are presented in Table 5-2 and Table 5-3. It is shown that the oxygen amount in the carbides is much larger than in the solid solution for both the alloys, which confirms that a large amount of $\mathrm{Cr}$-rich carbonate formed in the carbide phase. Furthermore, comparing the oxygen amount in the carbides and solid solution between Stellite $6 \mathrm{~B}$ and Stellite $6 \mathrm{~K}$, it is clear that the former has a larger amount than the latter in both of the phases. This can be explained as follows. Stellite $6 \mathrm{~B}$ and Stellite $6 \mathrm{~K}$ have a same $\mathrm{Cr}$ content (30 wt\%), but the latter has a higher content of $\mathrm{C}$ and took more $\mathrm{Cr}$ to form Cr-rich carbides, thus the $\mathrm{Cr}$ amount left in the solid solution of the latter would be definitely less than that left in the solid solution of the former. The more $\mathrm{Cr}$ in the solid solution of the former would form more Cr-oxides in the phase, which resulted in more $\mathrm{O}$ in it. For the carbides, since the carbide size of Stellite $6 \mathrm{~B}$ is much larger than that of Stellite $6 \mathrm{~K}$, more $\mathrm{Cr}$-rich carbonates would form in the carbides of the former due to the larger exposure area, leading to a higher $O$ concentration in the carbide phase. This behavior has been verified by the cyclic polarization test results in Figure 3-15 and Figure 3-16. The potential difference between the forward polarization curve and reverse polarization curve at a same current density for Stellite $6 \mathrm{~B}$ is much larger than that for Stellite $6 \mathrm{~K}$. In other words, at a same potential level, the current density difference between the forward cycle and reverse cycle is much larger for Stellite 6B than for Stellite 6K. This indicates that Stellite $6 \mathrm{~B}$ has a larger passive range in the reverse 
polarization thus higher localized corrosion resistance, which may be attributed to the larger protective $\mathrm{Cr}$-oxide films that formed in the solid solution phase.

Table 5-2: Oxygen percentages (wt\%) in pitted Stellite 6B specimens

\begin{tabular}{|c|c|c|}
\hline Region & Solid solution & Carbides \\
\hline Time(day) & & \\
\hline $\mathbf{2}$ & 0 & 35.32 \\
\hline $\mathbf{4}$ & 6.53 & 31.43 \\
\hline $\mathbf{8}$ & 5.25 & 36.71 \\
\hline $\mathbf{1 0}$ & 3.43 & 39.17 \\
\hline $\mathbf{1 2}$ & 4.09 & 46.28 \\
\hline Mean & 3.63 & 38.63 \\
\hline
\end{tabular}

Table 5-3: Oxygen percentages $(\mathrm{wt} \%)$ in pitted Stellite $6 \mathrm{~K}$ specimens

\begin{tabular}{|c|c|c|}
\hline Region & Solid solution & Carbides \\
Time(day) & & \\
\hline $\mathbf{2}$ & 2.07 & 25.68 \\
\hline 4 & 4.32 & 15.12 \\
\hline $\mathbf{6}$ & 2.07 & 18.96 \\
\hline $\mathbf{8}$ & 4.45 & 19.84 \\
\hline $\mathbf{1 0}$ & 1.92 & 18.15 \\
\hline $\mathbf{1 2}$ & 1.68 & 19.19 \\
\hline Mean & $\mathbf{2 . 7 5}$ & $\mathbf{1 7 . 8 2}$ \\
\hline
\end{tabular}




\section{Conclusions and future work}

\subsection{Summary of research}

Stellite $6 \mathrm{~B}$ and Stellite $6 \mathrm{~K}$ are wrought products and are tough wear resistant materials. They are commonly used in an environment where the synergetic attack of wear and corrosion occurs. The mechanical and tribological properties of these alloys have been extensively studied and reported, but their corrosion resistance was rarely investigated. In this research, the corrosion behavior of Stellite $6 \mathrm{~B}$ and Stellite $6 \mathrm{~K}$ was studied through polarization test and immersion test in a typical industry corrosive environment — Green Death solution; the experimental data and pitted specimens were analyzed using various tools including statistics analysis, SEM/EDX, and the Value Analysis (EVA) model.

\subsubsection{Conclusions}

The following conclusions can be drawn from the experimental results and associated analyses and discussion:

1. The corrosion behaviour of Stellite $6 \mathrm{~B}$ and Stellite $6 \mathrm{~K}$ is strongly dependent on their chemical compositions such as $\mathrm{Cr}$ and $\mathrm{C}$ contents and microstructures including carbide volume fraction and carbide size.

2. Stellite 6B and Stellite $6 \mathrm{~K}$ are generally corrosion-resistant because of their high $\mathrm{Cr}$ contents. In the polarization tests in Green Death solution, Stellite 6B and Stellite $6 \mathrm{~K}$ 
all demonstrated a passive feature due to formation of $\mathrm{Cr}$-oxide films. However, these films would break down with further increasing potential, which caused corrosion of fresh surfaces.

3. Stellite $6 \mathrm{~B}$ and Stellite $6 \mathrm{~K}$ have a same Critical Pitting Temperature (CPT), $60^{\circ} \mathrm{C}$, in Green Death solution.

4. Several parameters were used to measure the corrosion resistance of Stellite $6 \mathrm{~B}$ and Stellite $6 \mathrm{~K}$ in immersion test, including mass lost, thickness change, the Extreme Value (minimum thickness) from the Extreme Value Analysis (EVA) model. Stellite 6B and Stellite $6 \mathrm{~K}$ behaved differently in Green Death solution with respect to these parameters.

5. According to the experimental results of mass loss and thickness change, Stellite $6 \mathrm{~B}$ is superior to Stellite $6 \mathrm{~K}$ in corrosion resistance. These parameters are affected by the carbide volume fraction of the alloys. Stellite $6 \mathrm{~K}$ contains a higher level of $\mathrm{C}$ thus a larger volume fraction of carbides than Stellite 6B. In the oxidizing acid solution-Green Death solution the carbides/solid solution interfaces initiated primary batteries in the electrochemical reaction. The solid solution in the interface region was corroded and consumed due to $\mathrm{Cr}$ depletion. In the meanwhile, the carbides reacted with oxygen forming $\mathrm{Cr}$-rich carbonates which are brittle, loose and broken easily. The larger the carbide volume fraction of an alloy, the more severe the corrosion of the alloy is. 
6. However, according to the results of the EVA model, Stellite $6 \mathrm{~K}$ is superior to Stellite $6 \mathrm{~B}$ in corrosion resistance, because the former requires less minimum thickness for a given service time. The prediction of minimum thickness is based on maximum pit depths that are affected by the carbide size. Since corrosion occurred around the carbides and the spallation of carbides due to corrosion of surrounding solid solution resulted in formation of pits, the larger the carbide size, the deeper and bigger the pits are. Stellite $6 \mathrm{~B}$ has larger carbide size so that the pits that formed on its surface are larger and deeper, compared with Stellite $6 \mathrm{~K}$.

7. The cyclic polarization test results show that both Stellite $6 \mathrm{~B}$ and Stellite $6 \mathrm{~K}$ have localized corrosion resistance, because at a same potential the current density of reverse polarization is less than that of forward polarization, i.e., the probability of corrosion occurrence is reduced in reverse polarization. Stellite $6 \mathrm{~B}$ has better localized corrosion resistance than Stellite $6 \mathrm{~K}$, because at a same potential the difference in current density between forward polarization and reverse polarization of the former is larger. The better localized corrosion resistance of Stellite $6 \mathrm{~B}$ may be attributed to the larger protective $\mathrm{Cr}$-oxide films. Stellite $6 \mathrm{~B}$ and Stellite $6 \mathrm{~K}$ have the same $\mathrm{Cr}$ content, but since the former contains lower $\mathrm{C}$ than the latter, the $\mathrm{Cr}$ amount in the solid solution of the former would be larger than that in the solid solution of the latter. The more $\mathrm{Cr}$ in the solid solution would form larger $\mathrm{Cr}$-oxide films which protected further corrosion of the alloy. 
8. For corrosion resistance application the Stellite alloys with low carbon content are good candidates and with same carbon content the Stellite alloys having small-size carbides are preferable.

\subsubsection{Significant contributions}

Stellite $6 \mathrm{~B}$ and Stellite $6 \mathrm{~K}$, as the most popular Stellite alloys, are employed for various wear and corrosion resistance applications. However, according to the literature review and the information from the material industry, Kennametal Stellite Inc., the corrosion properties of these alloys have been rarely studied, which has caused many problems in practical applications, for example, in some corrosive environments, these alloys perform well but in others, especially when temperature is also involved, they behaved poorly. The outcomes of this research provide the material industry with direct experimental results of corrosion properties of Stellite $6 \mathrm{~B}$ and Stellite $6 \mathrm{~K}$ in a typical industry corrosive environment - Green Death solution. The main corrosion mechanisms of these alloys in Green Death solution were explored; one was the electrochemical reaction at the carbides/solid solution interfaces which caused consumption of the solid solution, the other was the formation of brittle and loose $\mathrm{Cr}$-rich carbonates that consumed the carbides. This research also demonstrated that the carbide volume fraction and carbide size play a key role in oxidizing-corrosion resistance of Stellite alloys. These outcomes can guide the design and manufacturing of new Stellite alloys. Another important contribution of this research is the application of the Extreme Value Analysis (EVA) 
model, which was derived from the Gumbel Distribution, to corrosion studies of materials.

\subsection{Future work}

This research is a part of the project "Investigation of Corrosion Behavior of Stellite Alloys"; therefore the following tasks have been planned toward the completion of the entire project:

1. Since the microstructure of Stellite alloys affects their corrosion behavior significantly, the Stellite alloy specimens manufactured with different processes will be studied. For example, the Stellite $6 \mathrm{~B}$ and Stellite $6 \mathrm{~K}$ specimens used in this research are wrought bar products, but sheet products may have a different microstructure, for example, a change in carbide size.

2. Other Stellite alloys will also be studied for corrosion resistance, such as Stellite 28, Stellite 22, Stellite 3, Stellite 12, Stellite 80 , Stellite 300, etc. These alloys have different $\mathrm{C}$ and $\mathrm{Cr}$ contents, and also contain different $\mathrm{W}$ and Mo contents. Thus the corrosion mechanisms and conclusions derived from this research for Stellite alloys can be verified. In the meanwhile, in addition to $\mathrm{C}$ and $\mathrm{Cr}$, the effects of other alloying elements, such as $\mathrm{W}$ and Mo, on the corrosion behavior of Stellite alloys will also be investigated. 
3. Stellite alloys will be tested in other corrosive media, for example, artificial sea water having a pH of $8.2,1 \mathrm{~mol} \mathrm{H}_{2} \mathrm{SO}_{4}, 5 \% \mathrm{HCL}, 65 \% \mathrm{HNO}_{3}$, which are the environments in which Stellite alloys usually serve.

4. The influence of heat treatment on the corrosion behavior of Stellite alloys will be investigated, because heat treatments may change the microstructure of Stellite alloys significantly, thus affecting their corrosion behavior. 


\section{Reference}

[1] ASM Handbook Committee, "Nickel, Cobalt, and Their Alloys", ASM International, Cleveland, USA, 2000.

[2] M. X. Yao, J. Wu, and Y. Xie, "Wear, corrosion and cracking resistance of some W- or Mo-containing stellite hardfacing alloys", Materials Science and Engineering A, Vol. 407, pp. 234-244, 2005.

[3] J. R. Davis, Cobalt-base alloys, in nickel, cobalt, and their alloys, ASM International, Materials Park, 2000.

[4] M. Nessin, Estimating the risk of pipeline failure due to corrosion, in: W. Revie (Ed.), Uhlig's Corrosion Handbook, second ed., John Wiley \& Sons, Inc., p.85, 2000.

[5] E. Bardal, "Corrosion and Protection", Springer, London, 2004.

[6] D. L. Klarstrom, "In Metal Handbook", ASM International, Metals Park, OH 1987.

[7] N. Perez, "Electrochemistry and corrosion science", Kluwer Academic Publishers, 2004 .

[8] S. C. Dexter, "Localized corrosion", in Corrosion, Vol. 13, ASM International, pp. $104,1987$.

[9] I. Inman, S. Rose and P. Datta, "Development of a simple 'temperature versus sliding speed' wear map for the sliding wear behaviou of dissimilar metallic interfaces," Wear, no. 260, pp. 919-932, 2006.

[10] J. R. Nicholls and D. J. Stephenson, "A life prediction model for coatings based on the statistical analysis of hot salt corrosion performance", Corrosion Science, Vol. 
33, No. 8, pp. 1313-1325, Printed in Great Britain, 1992.

[11] D. Rivas, F. Caleyo, A. Valor, J. M. Hallen, "Extreme value analusis applied to pitting corrosion experiments in low carbon steel: Comparison of block maxima and peak over threshold approaches", Corrosion Science Vol. 50, pp. 3193-3204, Elsevier Ltd. 2008.

[12] C. J. Heathcock and A. Ball, "Cavitation Erosion of Cobalt-based Stellite Alloys, Cemented Carbides and Surface-treated Low Alloy Steels," Wear. 74, pp. 11-26, 1981-1982.

[13] R. Jeshvaghani, M. Shamanian and M. Jaberzadeh, "Enhancement of wear resistance of ductile iron surface alloyed by stellite 6", Materials and Design, vol. 32, pp. 2028-2033, 2011.

[ 14 ] Geddes, Blaine; Leon, Hugo; Huang, Xiao, "Superalloys-Alloying and Performance", ASM International, c2010.

[15] R. Jeshvaghani, M. Shamanian and M. Jaberzadeh, "Enhancement of wear resistance of ductile iron surface alloyed by stellite 6," Materials and Design, vol. 32, pp. 2028-2033, 2011.

[16] R. Liu, M. X. Yao, and X. Wu, "Influence of carbon content in cobalt-based superalloys on mechanical and wear properties", Journal of Engineering Materials and Technology, Vol. 126(2), pp. 204-12, 2004.

[17] F.C. Campbell, "Manufacturing Technology for Aerospace Structural Materials", Elsevier Science and Technology Books, St. Louis, USA, 2006.

[18] A. Beltran, E. Brown, W. Chambers, and D. Chang, "Superalloys II ", Wiley Inc., 
New York, USA, 1987.

[19] A. Khoddamzadeh, "Development of Lead-Free PTFE Based Sliding Bearing Materials", M.A.Sc Materials, Department of Mechanical and Aerospace Engineering of Carleton University, Ottawa, Canada, 2005.

[20] A. Raman, "Materials Selection and Applications in Mechanical Engineering", Industrial Press, New York, USA, 2007.

[21] W. Jiang, X. Yao, and Z. Hu, "Secondary M6C precipitation in a cobalt-base superalloy", Journal of Materials Science Letters, Vol. 18, pp.303-5, 1999.

[22] Y. Q. Wang and B.L. Zhou, "Behavior of coating on reinforcements in some metal matrix composites", Composites Part A, 27A, pp. 1139-45, 1996.

[23] Y. Ning, "Effects of Sintering Process and the Coating of the Reinforcements on the Microstructure and Performance of Co-based Superalloy Composites", M.A.Sc, Department of Mechanical and Aerospace Engineering of Carleton University, Ottawa, Canada, 2004.

[24] P. Waldner, E. Knigsberger, and H. Gamsjfiger, "Computer-assisted optimization of cobalt-base alloy compositions", Journal of Alloys and Compounds, Vol. 220, pp. 148-51, 1995.

[25] I. Radu, D. Li and R. Llewellyn, "Tribological behavior of Stellite 21 modified with Yttrium", Wear, no. 257, pp. 1154-1166, 2004.

[26] M. Amateau and G.W.A., "Survey of Materials for High-Temperature Bearing and Sliding Applications", Wear, no. 7, pp. 385-418, 1964.

[27] A. Davin and D. Coutsouradis, "Development of abrasion-andcorrosions-resistant 
alloys for use in aqueous media", Cobalt, Vol. 52, pp. 160-161 1971.

[28] I.M. Hutchings, "Tribology: friction and wear of engineer materials", Boston: Butterworth-Heinemann, 2003.

[29] R. Davis, "Cobalt-base alloys, in Nickel, Cobalt, and Their Alloys", ASM International, Materials Park, 2000.

[ 30 ] V. K. W. Grips, H.C. Barshilia, V. Ezhil Selvi, Kalavati, K.S. Rajam, "Electrochemical behaviour of single layer $\mathrm{CrN}$, TiN, TiAIN coatings and nanolayered $\mathrm{TiN} N \mathrm{~N} / \mathrm{CrN}$ multilayer coatings prepared by reactive direct current magnetron sputtering“, Thin Solid Films, 514 pp. 204, 2006.

[31] J.E. Strutt, J.R. Nicholls and B. Barbier, The Prediction of Corrosion by Statistical Analysis of Corrosion Profiles, Corrosion Science, Vol. 25, No. 5, pp. 305-315, printed in Great Britain 1985.

[32] J. J. Vajo, R. Wei, Application of extreme value analysis to crevice corrosion, Corrosion Science 45, pp. 497-509, 2003.

[33] ASTM G46-94 (reapproved 2005), Standard Guide for Examination and Evaluation of Pitting Corrosion, American Society for Testing and Materials, West Conshohocken, Pennsylvania, 2005.

[34] J. R. Nicholls and P. Hancock, High temperature corrosion, NACE-6, pp. 198-210, San Diego 1983.

[35] E. J. Gumbel, Statistics of Extremes. Columbia University Press, New York, 1966.

[36] ASTM G28-02 (reapproved 2008), Standard Test Methods for Detecting Susceptibility to Intergranular Corrosion in Wrought, Nickel-Rich, 
Chromium-Bearing Alloys, American Society for Testing and Materials, West Conshohocken, Pennsylvania, 2008.

[37] A. W. Bott, Practical Problems in Voltammetry 3: Reference Electrodes for Voltammetry, Current Separations 14, pp. 64, 1995.

[38] ASTM G59-97 (reapproved 2003), Standard Test Method for Conducting Potentiodynamic Polarization Resistance Measurements, American Society for Testing and Materials, West Conshohocken, Pennsylvania, 2003.

[39] ASTM G102-89 (reapproved 1999), Standard Practice for Calculation of Corrosion Rates and Related Information from Electrochemical Measurements, American Society for Testing and Materials, West Conshohocken, Pennsylvania, 1999.

[40] ASTM G5-94, Standard Reference Test Method for Making Potentiostatic and Potentiodynamic Anodic Polarization Measurements, American Society for Testing and Materials, West Conshohocken, Pennsylvania, 2002.

[41] V. K. W. Grips, H.C. Barshilia, V. Ezhil Selvi, Kalavati, K.S. Rajam, Electrochemical behaviour of single layer $\mathrm{CrN}, \mathrm{TiN}, \mathrm{TiAlN}$ coating and nanolayered $\mathrm{TiAlN} / \mathrm{CrN}$ multilayer coatings prepared by reactive direct current magnetron sputtering, Thin Solid Films 514, pp. 204, 2006.

[42] ASTM G61-86 (reapproved 2009), Steandard Test Method for Conducting Cyclic Potentiodynamic Polarization Measurements for Localized Corrosion Susceptibility of Iron-, Nickel-, or Cobalt-Based Alloys, American Society for Testing and Materials, West Conshohocken, Pennsylvania, 2009.

[43] ASTM G3-89 (reapproved 2010), Standard Practice for Conventions Applicable to 
Electrochemical Measurements in Corrosion Testing, American Society for Testing and Materials, West Conshohocken, Pennsylvania, 2010.

[44] ASTM G102-89 (reapproved 2010), Standard Practice for Calculation of Corrosion Rates and Related information from Electrochemical Measurements, American Society for Testing and Materials, West Conshohocken, Pennsylvania, 2010.

[45] D. A. Jones, Principles and Prevention of Corrosion, Macmillan Publishing Company, New York, 1992.

[46] N. Perez, Electrochemistry and Corrosion Science, Kluwer Academic Publishers, 2004.

[47] ASTM G31-99 (reapproved 1999), Standard Practice for Laboratory Immersion Corrosion Testing of Metals, American Society for Testing and Materials, West Conshohocken, Pennsylvania, 1999.

[48] ASTM G150-99 (reapproved 2010), Standard Test Method for Electrochemical Critical Pitting Temperature Testing of Stainless Steels, American Society for Testing and Materials, West Conshohocken, Pennsylvania, 2010.

[49] Contour Styluses, Tokyo Seimitsu Co., LTD. http://gagesgalore.com/Zeiss/Images/Contour\%20Styli.pdf 